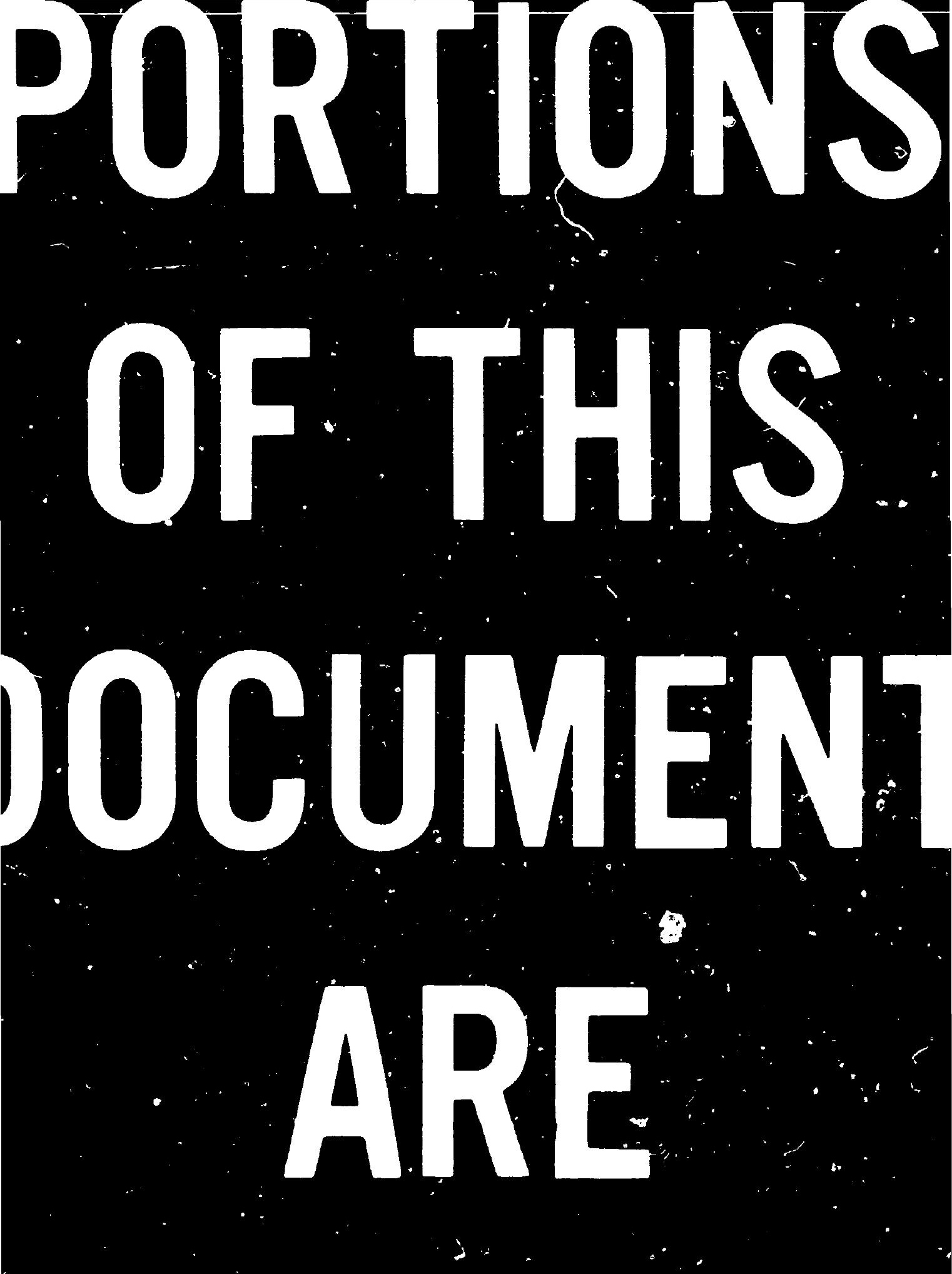




\section{EBT Time-Dependent Point ilodel Code: Description and User's Guide}
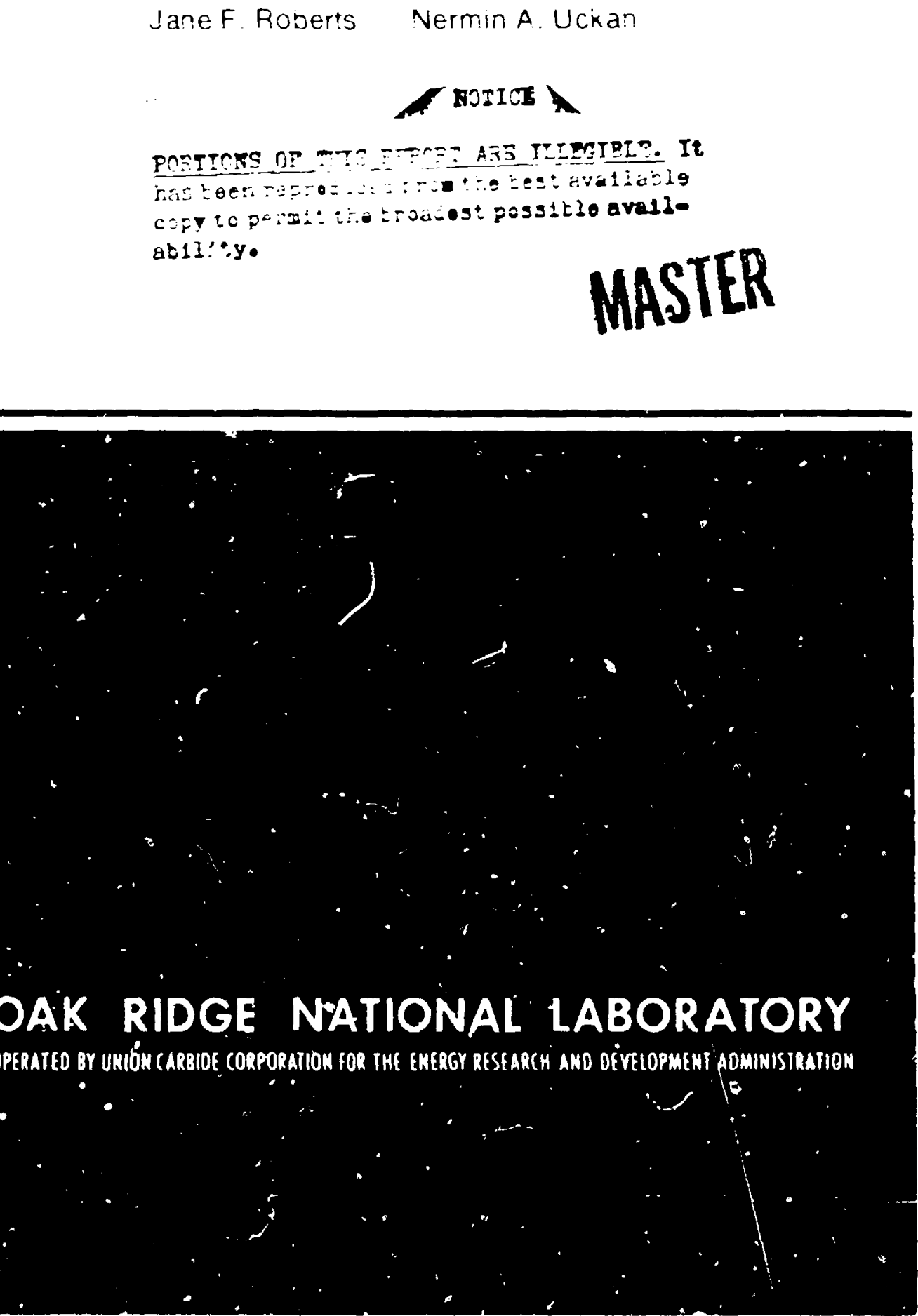
Printed in the United States of America Aviliable from Nationa! Tecrinical Information Senice

U.S. Dep-riment of Commerce 5285 Port Royal Road. Springfield. Virgin:a 2216!

Price: Printed Copy $\$ 5.50$. Nicrofiche $\$ 3.00$

Ths reccrt was prepared ts an accoune ot werk sernsoned 0 , he Unted siates Governtrert Neitre the Urited States ro in. Energ, Fesearch and Dewe opment

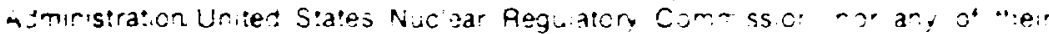
tr sloyees. nor zny ot ine compractors. subcortractors or the emgives trakes any warranty expresz oritg ied or assumes any iega ab ry or respons buty ti, the

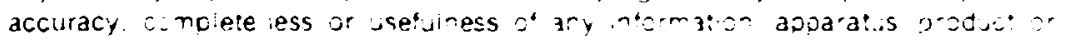

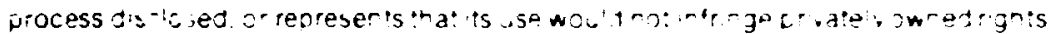


ORNL/CSD $/ T M-27$

Contract No. W-7705-eng-26

COMPUTER SCIENCES DIVISION

EBT TIME-DEPENDENT POINT MODEL CODE: OESCRIPTION AND USER'S GUIDE

Jane F. Roberts

Computer Sciences Division

and

Nermin A. Uckan

Fusion Energy Division

Date Published: July 1977

NOTICE

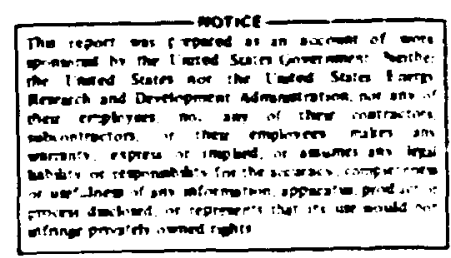

This document contains information of a preliminary nature. It is subject to revision or correction and therefore does not represent a final report.

UNION CARBIDE CCRPORATION, NUCLEAR DIVISION operating the

Oak Ridge Gaseous Diffusion Plant - Oak Ridge National Laboratory Oak Ridge $Y-12$ Plant for the - Paducah Gaseous Diffusion Plant ENERGY RESEARCH AND DEVELOPMENT ADMINISTRATION 
TABLE GF CONTENTS

ACKNOHLEDGMENTS $\ldots \ldots \ldots \ldots \ldots$

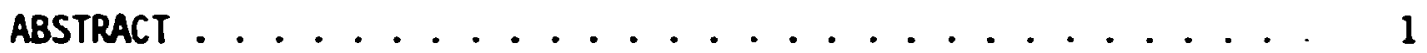

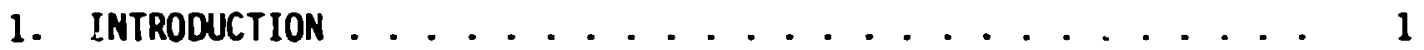

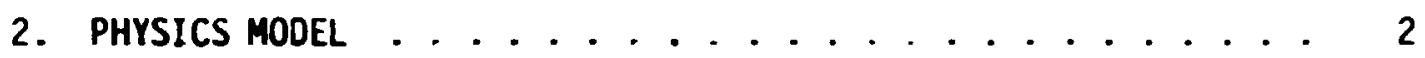

3. PROGRAM LOGIC AND ORGANIZATION ............... 4

3.1. Description of Routines ........... 4

3.2. Integration ................. 10

3.3. Input ....................... 11

3.4. Execution .................... 13

3.5. Output: Printed ............... 14

3.6. Output: Plotting ............... 15

REFERENCES ......................... 17

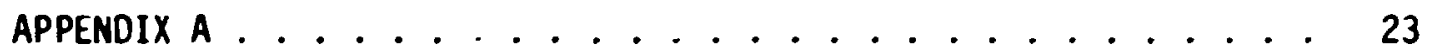

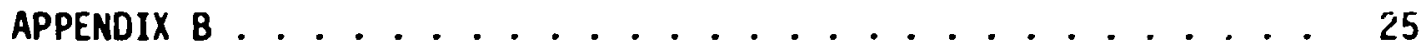

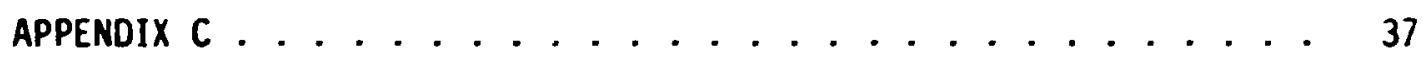

APPENDIX $0 \ldots \ldots \ldots \ldots \ldots$ 
ACXNOWL EDGMENTS

This work was supported by the Fusion Energy jivision at Oak Ridge National Laboratorj.

We would like to specifically acknowledge and thank C. L. Hedrick of the Fusion Energy Division and S. E. Attenberger of the Computer Sciences Division for the: $r$ help in distinguishing, interpreting, and resolving physical and numerical difficulties encouncered during code de vel odment. 
EBT TIME-OC̈PENDËNT .OINT MODEL CODE: DFSCRIPTION AND USER'S GUIDE

\author{
Jane F. Roberts \\ Coriputer Sciences Civision \\ and \\ Nermin A. Uckan \\ Fusion Energy Division
}

\begin{abstract}
A D-T time-dependent point model has been developed to asses, the energy balance in an EBT reactor plasma. Flexibility is retained in the model to permit more recent data to be incorporated as they become available from the theoretical and experimenta! studies. This report includes the physics models involved, the program logic, and a description of the variables and routines used. Ail the files necessary for execution are listed, and the code, including a post-execution plotting routine, is discussed.
\end{abstract}

\title{
1. INTROCUCTION
}

As a first step in assessing the energy balance in an EBT reactor plasma,' a simulation model (point model) has been developed in which the bulk plasma is characterized by simple energy and particle containmerit times, with appropriate density and temperature scaling. In view of uncertainties in the theoretical coefficients and the present lack of experimental evidence in this area f fexioility is retaineci in the simulation model to permit more recent data to be incorporated as they become available.

The full time-dependent point mode! for D-T fusion in EBT consists of nine coupled nonlinear ordinary differential equations (discussed in Sect. 2). The program logic and organization is outlined in Sect. 3. A description of the variab?es, a listing of the files, and the execurion routine are jiven in appendixes. 


\section{PHYSICS MODEL}

The particle and energy balance equations used in the code are

$$
\begin{aligned}
& \frac{d n_{D}}{d t}=S_{D C O L D}+S_{D B E A M}\left(1-f_{D}\right)-n_{D} n_{T}\langle\delta V\rangle D T \\
& +n_{e} n_{00}^{<\sigma v>} \text { ioniz }_{T_{p, D}}-\frac{n_{D}}{\tau_{p,}} \text {. } \\
& \frac{d n_{T}}{d t}=S_{T C O L D}-S_{D B E A M} f_{D}-n_{D} n_{T}\langle\sigma V\rangle_{D T}+n_{e} n_{O T}\langle\sigma V\rangle_{\text {ioniz }}-\frac{{ }^{n_{T}}}{T_{P, D}}, \\
& \frac{d n_{\alpha}}{d t}=S_{D B E A M} f_{D}+n_{D} n_{T}\langle\sigma V\rangle_{D T}-\frac{n_{\alpha}}{\tau_{p, \alpha}}, \\
& \frac{d n_{I}}{d t}=\left(n_{D} n_{T}\langle\sigma v\rangle{ }_{D T}+S_{D B E A M} f_{D}\right) I_{N}+\frac{n_{D}}{\tau_{p, D}} I_{D}+\frac{r_{1}}{\tau_{p, T}} I_{T}+\frac{n_{\alpha}}{\tau_{p, \alpha}} I_{\alpha} \\
& +\frac{n_{I}}{\tau_{p, I}}\left(I_{I}-1\right)
\end{aligned}
$$

$$
\begin{aligned}
\frac{d n_{H I}}{d t}= & \left(n_{J} n_{T}<\sigma V>_{D T}+S_{D B E A M} f_{D}\right) I_{N}+\frac{n_{D}}{\tau_{p, D}} I_{D}+\frac{n_{T}}{\tau_{p, T}} I_{T}+\frac{n_{Q}}{\tau_{p, x}} I_{\alpha} \\
& +\frac{n_{H I}}{\tau_{F, H I}}\left(I_{H I}-1\right),
\end{aligned}
$$

$\frac{d n_{O D}}{d t}=\frac{n_{D}}{\tau_{D, D}} f_{R D}-n_{e^{n}} n_{O D}\left\langle\sigma v{ }_{\text {ion } i z}\right.$,

$\frac{d n_{O T}}{d t}=\frac{n_{T}}{{ }^{n_{P, T}}} f_{R T}-n_{e}{ }^{n_{O T}}{ }^{\langle\sigma V\rangle_{i o n i z}}$, 


$$
\begin{aligned}
\frac{d}{d t}\left(p_{e}\right)= & F_{\nu}+S_{D B E A M}\left(f_{D B, e}+f_{D} U_{\alpha} f_{d e} i+n_{D} n_{T}\left\langle\sigma V V_{D T}\left(U_{\alpha} f_{\alpha e}-3 T_{e}\right)\right.\right. \\
& -\frac{p_{e}}{{ }^{T} E, e}-{ }_{e i}-P_{R A D}, \\
\frac{d}{d t}\left(p_{i}\right)= & n_{D} n_{T}<\sigma V V_{D T}\left(U_{\alpha} f_{\alpha i}-3 T_{i}\right)+S_{D B E A M}\left(U_{B E A M} f_{D B, i}+f_{D} U_{\alpha} f_{\alpha i}\right) \\
& +P_{e i}-\frac{p_{i}}{\tau_{E, i}},
\end{aligned}
$$

where

$$
\begin{aligned}
& n_{e}=n_{D}+n_{T}+2 n_{\alpha}+i_{I} n_{I}+Z_{H I} n_{H I}, \\
& n_{i}=n_{0}+n_{T}, \\
& P_{e}=\frac{3}{2} n_{e} T_{e}, \\
& P_{i}=\frac{3}{2} n_{i} T_{i} .
\end{aligned}
$$

As a first step. a simple model has been analyzed. The equations implemented in the current version of the EBT point mode) code (see Appendix A) are a subset of Eqs. 1-9. The parameters used in Eqs. 1-9 are listed in Appendix B.

The code was developed using the full set of equations. The modifications were accomplished by changing expressions in various subroutines (maintaining the full expressions in comment statements) and by specific choices of input parameters. This will be discussed in detail later in this report.

The units of both the model and the code are mks ("temperatures," representing energy, are in keV:. The only numerical problem this has raused so far is in expressions $1 i k e n_{D} n_{T}\langle\sigma V\rangle D T$. Since densities are $\sim 10^{20}$ and cross-sections $\sim 10^{-20}$, it is necessary in coding to force the 
order of multiplication with parentheses to avoid overflows on the PDP-10: DEND(DENT-SIGVDT) .

\section{PROGKAM LOGIC AND ORGANIZATION}

Figure 1 shows how control flows from one routine to ancther. Specifically, MAIA controls the run. INIT and PRINTI are called at the very beginning for initialization of variables and parameters and initiai printout; the rest of the subroutines are called repeatedly as integration progresses in time.

A simplified flow chart appears in fig. 2. There are only two main loops: the larger loop represents integration of the equations in time until some final, specified time (controlled in MAIN), and the smaller loop represents repeated integration over a specific time-step until the convergence critorion is met for all equations (controlled by EXTINT).

Excedt for EXTINT, ERROR, F, PRINT2, and GETVAR, the subroutines have no arguments - all variables, parameters, and combinational terms are passed to routines through common blccks. Table 1 shows which common blocks are currently used in which routines. All commons appear to their full extent in MAIN (for initial allocation of core) and nearly -11 comons appear in PKINT2, to facilitate output (for debugging, for example).

\subsection{Jescription of Routines}

A listing of the EBT time-dependent point model code is in Appendix $C$. A descriptive iisting of all the variables used in the code appears in Appendix $B$. The routines operate as follows: 
MAIN

MA controls the integration of the equations, calculates globa: variables for output, controls the frequency of output (in integration time) and shecks feedbacks on cold fueling rates. The cold fueling rates are decreased or increased in order to keep $n_{D}$ and $n_{T}$ near the operating value $n_{\text {OTf }}$, after the neutrals reach steady state. The feedbaci of $S_{\text {DCOLC }}$, $S_{\text {TCOLD }}$, if $x>$ IISTAR (the time for $n_{0 i}$ to reach steady state), is as follows for $i=0, T$ :

$$
\begin{aligned}
& \text { if } n_{i}>r_{\text {OTf }} \text { and } \frac{d n_{i}}{d t}>0, S_{i \text { COLD }}=x S_{i \text { COLU }}, i<1 \text {; } \\
& \text { if } n_{i}<n_{\text {DTf }} \text { and } \frac{d n_{i}}{d t}<0, s_{i \operatorname{COLO}}=2 i \text { ilOSS } i, \hat{s}>1 \text {. }
\end{aligned}
$$

MAIN also controls the turriing off of microwave power after ignition.

INIT

INIT does all the initialization necessary for the run: makes iritial assignments, reads input data from EBT7EQ. IN. sets up a Y-array of oependent variables for EXTINT, and opens the output files specified by PRTFIL and PLTFIL.

PRINT1

PRINTI does the initial printout into the files PRTFIL and PLIFIL. FRINT2 $(X, H Q)$

PRINT2 does the printout at time $x$ during integration of the equations. 


\section{GETVAR(Y)}

GETVAR takes the dependent variables out of the arraj $Y$ (used by EXTINT) and gives them mnemonic names in the common block VARBLE.

$F(X, Y, D Y)$

$F$ calculates the right-hand sides of the differential equations for EXTINT (see the list of equations in Appendix $A$ and the descriptive list of variabies in Appendix B).

FCOUNT counts how many times $F$ has been called by EXTINT; it normally takes on values like $7,13,21,53$, etc. FCOUNT $>200$ indicates problems with the equations converging smoothly.

\section{SIGDT}

SIGDT reads COV'DT as a function of $T_{i}$ from SIGVDT.DAT (the first time it is called). Then <OV > is calculated through linear interpolation of the values corresponding to the temperatures that bracket $T_{i}$ ifound by a binary search of the array TEMP).

\section{SIGION}

SIGION calculates $\langle 0 v\rangle_{\text {ioniz }}$ as a func, 'n of $T_{e}$, and $\langle\sigma v\rangle_{c x}$ as a function of $T_{i}$.

$$
\begin{aligned}
& \langle\sigma v\rangle_{\text {ioniz }}=10^{-6} \exp \left\{\sum_{i=0}^{6} a_{j}\left[\ln \left(10^{3} T_{e}\right)\right]^{i}\right\}, \\
& \langle\sigma v\rangle_{c x}=10^{-6} \exp \left\{\sum_{i=0}^{8} b_{j}\left[\ln \left(10^{3} T_{i}\right)\right]^{i}\right\}
\end{aligned}
$$


COLMB

CCLMB calculates $F_{e, i}$, the power transferred to the electrons from the ions during Coulomb collisions:

$$
p_{e, i}=1.5 \times 10^{-19} \frac{n_{E}}{T_{e}^{3 / 2}} \sum_{j=D, T} \frac{Z_{j}^{2} n_{j}}{A_{j}}\left(T_{e}-T_{i}\right)(\ln \Lambda) .
$$

where

$$
\ln \Lambda=39.4-\ln \left(\frac{\sqrt{n_{e}}}{T_{e}}\right) \text {, in the full model; }
$$

in $\Lambda=17.0$, currently.

\section{TAUS}

Taus calculates all the particle and energy confinement times, using Kourizhnykh's results. 2

$$
\begin{aligned}
& \tau_{p, j}=c_{j} \frac{1}{v_{j}}\left(1+\frac{v_{j}^{2}}{\Omega_{j}^{2}}\right), j=0, T, \alpha, I, H I, \\
& v_{j}=2.218 \times 10^{-28} \text { en } \Lambda \frac{n_{j} Z_{j}^{2}}{\sqrt{A_{j}} T_{j}^{3 / 2}} \text {, } \\
& c_{j}=\frac{3}{4}\left[{ }_{R_{T}}^{R_{c}}\left(1+10^{-3} \frac{Z_{j} E_{r} R_{c}}{T_{i}}\right)\right]^{2}, \\
& \Omega_{j}=10^{3} \frac{T_{j}}{Z_{j} B R_{c} \mathrm{a}}\left(1+10^{-3} \frac{Z_{j} E_{r} R_{c}}{T_{j}}\right), \\
& \frac{1}{\tau_{p, i}}=\frac{n_{D}}{n_{i}} \frac{1}{\tau_{p, D}}+\frac{n_{T}}{n_{i}} \frac{1}{\tau_{p, T}} \text {, }
\end{aligned}
$$


8

$$
\begin{aligned}
& \frac{1}{\tau_{C X}}=\langle\sigma v\rangle_{C x} \frac{n_{D} n_{0 D}+n_{T} n_{0 T}}{n_{i}} \\
& \tau_{E, \text { CCD }}=\frac{3}{7} \tau_{p, i} \text { (currently, } \tau_{E, \text { CONs }}=0 \text { ) , } \\
& \tau_{S}=0.24 \times 10^{15} \frac{T_{e}^{3 / 2}}{n_{e}} \quad \text { (currently, } \tau_{S}=0 \text { ), } \\
& \frac{1}{\tau_{E, i}}=\frac{1}{\tau_{p, i}}+\frac{1}{\tau_{c X}}+\frac{1}{\tau_{E, \text { COlD }}} \quad \text { (currently, } \frac{1}{\tau_{E, i}}=\frac{1}{\tau_{p, i}}+\frac{1}{\tau_{c X}} \text { ), } \\
& \tau_{E, e}=\tau_{p, i}
\end{aligned}
$$

FRAT

FRACT Calculates the fractions of energy transferred by various mechanisms. (See ref. 1.)

$$
\begin{aligned}
f_{\alpha i} & =\frac{T_{e}}{50}-0.37\left(\frac{T_{e}}{50}\right)^{7 / 4}, \\
f_{\alpha e} & =1-f_{\alpha i}, \\
f_{D B, i} & =0.5 \exp \left[-0.0916 \frac{U_{D B E A M}}{U_{C R}}\left(1+0.5 \frac{\tau_{s}}{\tau_{c X}}\right)\right] \\
& +0.5 \exp \left[-0.635 \frac{U_{D B E A M}}{U_{C R}}\left(1+0.5 \frac{\tau_{s}}{\tau_{C X}}\right)\right], \\
f_{D B, e} & =1-f_{D B, i}\left(c u r r e n t i y, f_{D B, i}=f_{D B, e}=0 ;\right. \\
f_{R D} & \left.=f_{R T}=0 ; f_{H}=0 .\right)
\end{aligned}
$$


POWRAD

POARAD calculates the power losses due to various types of radiation: Brensstrahlung, line radiation, and synchrotron radiation.

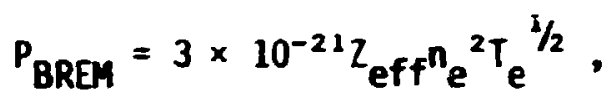

$$
\begin{aligned}
& Z_{\text {eff }}=\frac{\sum_{j} Z_{j}{ }^{2} n_{j}}{\sum_{j} Z_{j} n_{j}}=\frac{\sum_{j} Z_{j}{ }^{2} n_{j}}{n_{e}} \text {, for } j=D, T, \alpha, I, H I \text {, } \\
& \left.P_{\text {LINE }}=2 \times 10^{-17} n_{\text {HI }} n_{e} \text { (currently, } P_{\text {LINE }}=0\right) \text {, } \\
& P_{\text {SYNC }}=1.5 \times 10^{5} \sqrt{\frac{n_{e} b^{5}}{a}} T_{e}^{11 / 4}\left(1-R_{e}\right)\left(1 \div \frac{T_{e}}{204}\right) \\
& \text { (currently, } P_{\text {HSYNCH, }} \text { HSYNC }=0 \text { ), } \\
& P_{\text {RAD }}=P_{\text {BREM }}+P_{\text {SYNC }}-F_{\text {HSY }}{ }_{\text {NC }}^{0}+P_{\text {LINE }} .
\end{aligned}
$$

\section{SPUTR}

SPUTR will calculate the sputtering rates of impurities off the walls. Currently, this routine is not even called (no impurities are implemented in the code).

FUFRAC

FUFRAC will calculate $f_{D}$, the fraction of the deuterium beam which undergoes suprathermal fusion.

$$
f_{D}=\frac{U_{\text {DBEAM }}{ }^{n} T\left(U_{\text {DBEAM }}, T_{e}\right)}{1.76 \times 10^{4} n_{e}}
$$

Currently FUFRAC is not even called, as there is no deuterium beam. 
As the physics is understood better and as more things are implemented in the code, the form of the subroutines will change, particularly TAUS, FRACT, PJWRAD, SPUTR, FUFRAC, and of course F. And as the expressions becone more complicated, the calling sequence of some of the subroutines by $F$ may need to be changed to keep everything consistent in time.

\subsection{Integration}

Integration of the differential equations is done by EXTINT, a deferred-limit integrator written by J. P. Boris and N. K. Hindsor, using the extrapolation method developed by R. Bulerisch and J. Stoer. ${ }^{3}$

The arguments are described in the initial coments in the listing of EXTINT in Aopendix $C$.

EXTINT cal ls a subroutine, ERROR (also contained in the file EXTINT.F4), which determines whether or not all the equations have met the convergence criterion (EPS) for integration over the time-step (HD). If not, after FAX extrapolation attempts, $H D$ is halved. The original ERROR did a relative error check,

$$
\left|\frac{d y_{i} / d x}{y_{i \max }}\right|<\text { EPS }
$$

for convergence of the $i^{\text {th }}$ equation, $S(I)=Y_{\text {imax }}=$ the maximum value yet reached by $Y_{i}$. But this has been changed to give a strict relative error check,

$$
\left|\frac{d y_{i} / d X}{Y_{i}}\right|<\text { EPS , }
$$

for convergence of the $i^{\text {th }}$ equation. 


\subsection{Input}

The input file, EBT7EQ.IN, is listed in Appendix $C$. The input formats in INIT (except for the first record) are such that the first eight spaces are skipped. Thus the v.riable name is typed in tnose first eight spaces, next to each input value, simplifying modification of the input file for the user.

The input variables are as foliows:

LABEL (1st record) An 80-character descriptive title of the run, to appear on both printer output and DISSPLA plots.

PRTFIL

A 10-character file name for the printer output.

PLTFIL

A 10-character file name for the (intermediate) plot file.

EPS

$\operatorname{miax}$

The convergence criteria for EXTINT and ERROR (EPS $<10^{-6}$ would require double precision).

The maximum number of extrapolation attempts EXTINT makes before decreasing the time-step.

XSTART

The starting time in seconds (usually 0.0).

$H D$

The initial time-step for EXTINT in seconds.

XFIMAL

The fina? time in seconds.

PRTFRQ

EPSO

The frequency in seconds with which printer and plotting output is required, for example, every $0.5 \mathrm{sec}$.

"Error condition" for neutral equations. Neutrals reach steady state when $d n_{0 D} / d t$ and $\mathrm{dn}_{0 T} / \mathrm{dt}$ are less than EPSO.

CIGNIT

Ignition criterion. When CPALP = CPLOSS + CIGNIT, ignition has occurred.

ZI

Nuclear charge of the low- $Z$ imsurity ions.

Mass number of the low- $Z$ impurity ions. 
ZHI

AHI

PMICRO

UDBEAM

UALPHA

PBEAN

RCURVA

PMANOR

RMINOR

ERATIO

BFIELD

DENDTF

DEN9DF

DENDTF

TEF

TIF

DEND

DENT

DENA

DENIM

DENHIM
Nuclear charge of the high- $Z$ impurity ions.

Mass number of the high- 2 impurity ions.

Microwave power, input as $\mathrm{MW} / \mathrm{m}^{3}$ (converted

to $\mathrm{keV} / \mathrm{m}^{3} / \mathrm{sec}$ for computation).

Deuterium beam energy.

The energy of the alpha particles $=3.5 \mathrm{MeV}$

for D-T fusion (in keV).

Total beam power ( 0.0 for no bears).

$\frac{V B}{B}=$ the radius of curvature of the $B$-field.

Major radius of the EBT, in meters.

Minor radius of the EBT, in meters.

$\frac{10^{-3} E_{r} R_{c}}{T_{i}}$, the ratio of the radial electric

Magnitude of the $\vec{B}-f i e l d$ at the center of the midplane, in tesla.

Final deuterium density desired = final tritium density desired, in $m^{3}$.

Final neutral deuteron density desired, in $\mathrm{m}^{-3}$.

Final neutral triton density desired, in $m^{-3}$.

The final electron temperature desired, in keV.

The final ion temperature desired, in keV.

The initial deuteron density, in $\mathrm{m}^{-3}$.

The initial triton density, in $\mathrm{m}^{-3}$.

The initial alpha particle density, in $\mathrm{m}^{-3}$.

The initial low- $Z$ impurity density, in The initial high- $Z$ density, in $\mathrm{m}^{-3}$. 
DENDD

DENPT

TE

TI
The initial neutral deuterium density, in $\mathrm{m}^{-3}$.

The initial neutral tritiun density, in $\mathrm{m}^{-3}$.

The initial electron temperature, in keV.

The initial ion temprature, in kei.

\subsection{Execution}

The point model code has been developed for the DECsystem-10 (POP-10). Execution can be either in time-sharing mode or batch mode.

Figure 3 shows the execution flow. The files necessary are as follows (listings are in Appendix $\mathrm{C}$ ).
EBTTEQ.IN
Input data
EBT7EQ.F4
Source file for point model code, containing routines MAIN, INIT, PRINT1, GETVAR, PRINT2, F, SIGDT, SIGION, COLMB, TAUS, FUFRAC, SPUTR, FRACT, and PONRAD.
EXTINT.F4
Source file containing EXTINT and ERROR.
SIGVDT.GAT
Resident disk file containing <OV> $O$ as a
DISTEQ.F4
function of $T_{i}$ (used by SIGDT).
DISVEC.CMD
OISTEK.CMD
Source file of DISSPLA plotting program.
Command files of all DISSPLA modules to be linked in to execute DISSPLA program.
The output consists of two files:
PRINT.?EQ
Printer output of variables and parameters in time (see example in Appendix 0 ).
P'LOT.7EQ
Intermediate plot file - contains data wich is input to plotting program, DISTEQ.F4
(example in Appendix D).

The names of these two output files are character input values of the variables PRTFIL and PLTFIL read in from EBT7EQ. IN, so that successive 
runs can be done without overwriting the output files, merely by changing the output file names.

To run under Batch, one needs an additional file, a Batch comand file such as 7EQ.CND, listed in Appendix C. With error-checking at every other step, this file shuuld enable the user to trace aborted runs through the messages printed in the user's Batch log.

The monitor command SSUBMIT 7EQ.CMD/TIME: 10:00/CORE:50K/AFTER:18:00\

will submit the Batch job to run after 6 p.m. with 50K core (necessary for the plots), for a maximum time of 10 minutes. It will create a BATCH log file named 7EQ.LOG in the user's disk space. A /RESTART switch will force the Batch job to completely restart after a system crash (normaily the Batc! jobs continue from the point of interruption, unless the crash is severe).

\subsection{Output: Printed}

The printed output will be in the user's disk area in a file with the name the user chose to be the value of the input variable PRTFIL, which, in our example, is PRiNT.7EQ.

To have this output printed, the user needs to give the monitor print command:

.PRINT PRINT.7EQL

The /DISPOSE:RENAME switch, if used, will remove the file from the user's disk area for temporary storage in a system area until it is printed, after which the file disappears. 


\subsection{Output: Plotting}

The DISSPLA plotting routine, DISTEQ.F4, makes five semi-log plots

(listing in Appendix $\mathrm{C}$ ):

1. electron, ion, and alpha densities vs time,

2. electron and ion temperatures vs time,

3. total alpha power and total power losses vs time,

4. deuterium and tritium cold fueling rates vs time,

5. time-step (HQ) vs time.

Sinple execution of this program may require two char.ges by the user:

1. The input to the plotting routine is the outfile designated by the input variable PLTFIL, in our example PLOTZEQ. If a different file name is used, the OPEN and CLOSE statements in the plotting program rust be changed to the new value of FLTFIL.

2. A device-initialization routine must be the first DISSPLA subro'tine called. So depending on whether a Tektronix CRT termina $i$ is being used or Versatek printer plots are desired, either the CALL TKTRN (ICPS, IMODE) or the CALL VRSTEC instructicn twust be imolemented, and the other one commented out (see listing in Appendix C). Also, the value of ICPS should be 30 or 120 depending on the line-speed of the Tektronix terminal.

Depending on which plotting device is being used, the user must link

in the routines listed either in DISVEC.CMD or DISTEK.CMD (listed in Appendix $\mathrm{C}_{j}$, for example,

EXX DIS7EQ. F4, BDISVEC.CMD .

If the Tektronix terminal is being used (handy for time-sharing), OISSPLA rings the bell upon completion of a plot and waits for a carriage return from the user before generating the next plot.

If the Versatek printer is being used to produce plots, the user needs to run the post-processor utility program VECVER:

.R VECVERL

FILE: 1

FILE: esC 
and the plots will automatically be queued to the Versatek printer (with the /OISPOSE:REMME switch). An example of the Versatek plots is in Appendix $\mathrm{D}$. 


\section{References}

1. D. G. McAlees et al., The EIAO Bumy Sorus Rextor (EBTi?) Reference Desi.gn, ORNL/TM-5669 (1976).

2. L. M. Kovrizhnykh, "Transport Phenomena in Toroidal Magnetic Systems," 2h. Eksp. Teor. Fiz. 56:877 (1969) [Sov. Phis. JETP, 29:475 (1969)].

3. Roland Bulerisch and Joseph Stoer, "Numerical Treatment of Ordinary Differential Equations by Extröpolation Methods," . .merische Nathematik, 8:1-13 (1966). 
OANL OWCI $1 /$ /3FW

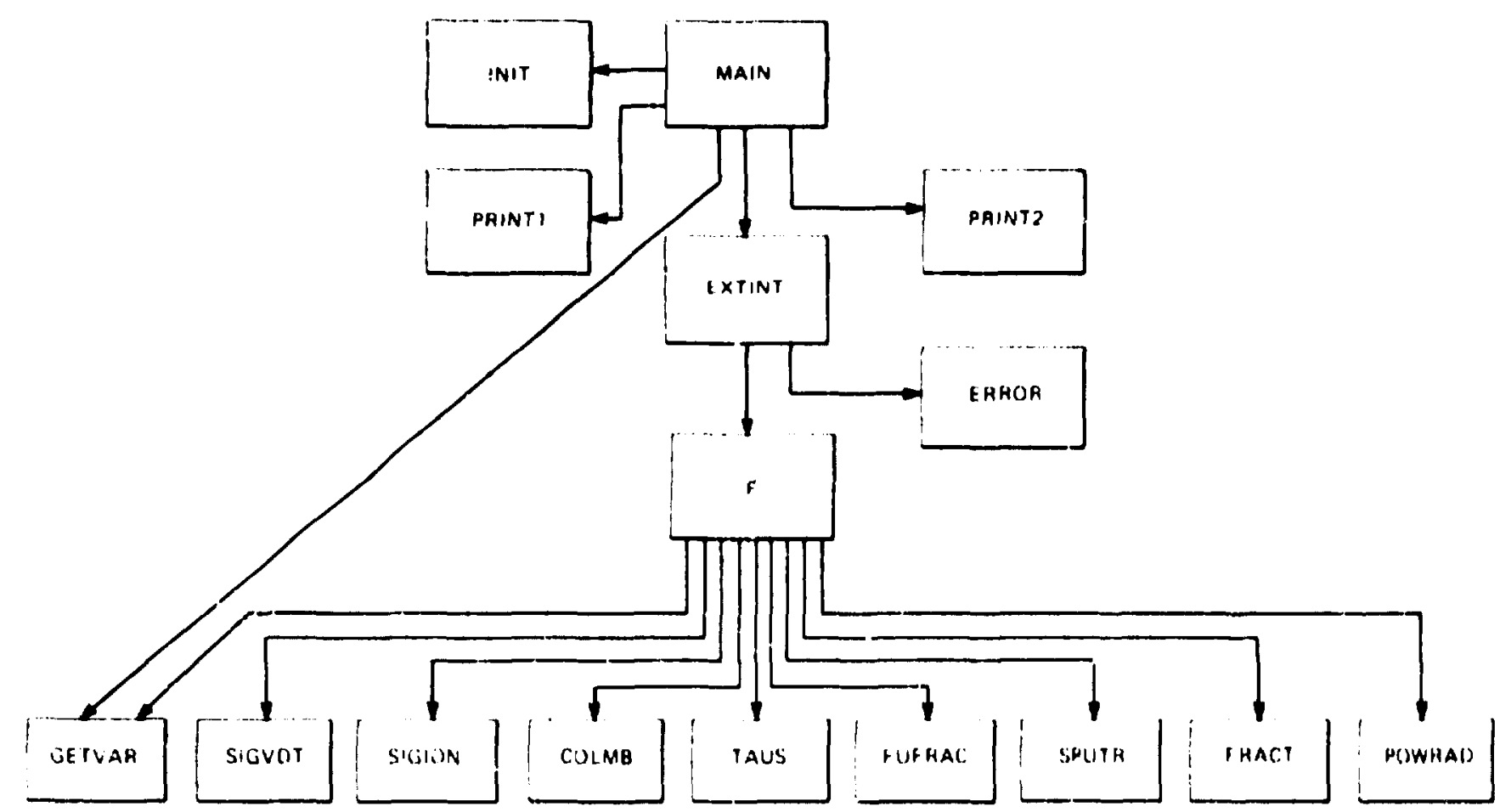

Fig. 1. Subroutine hierarchy. 
$30 \cdot . .2 m \cdot 3 i=$

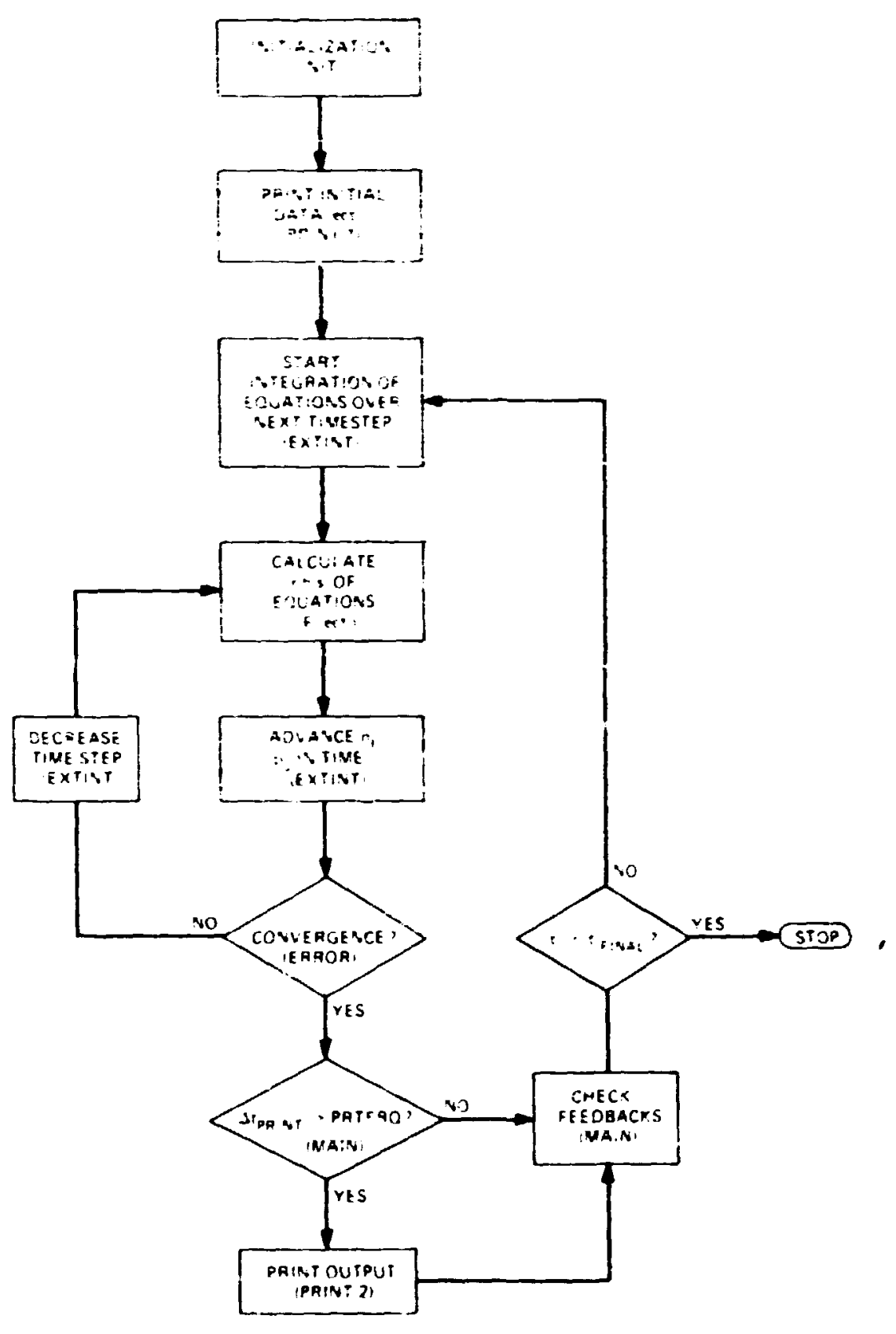

Fig. 2. Simplified flow chart. 
UANL OMG:" TJS

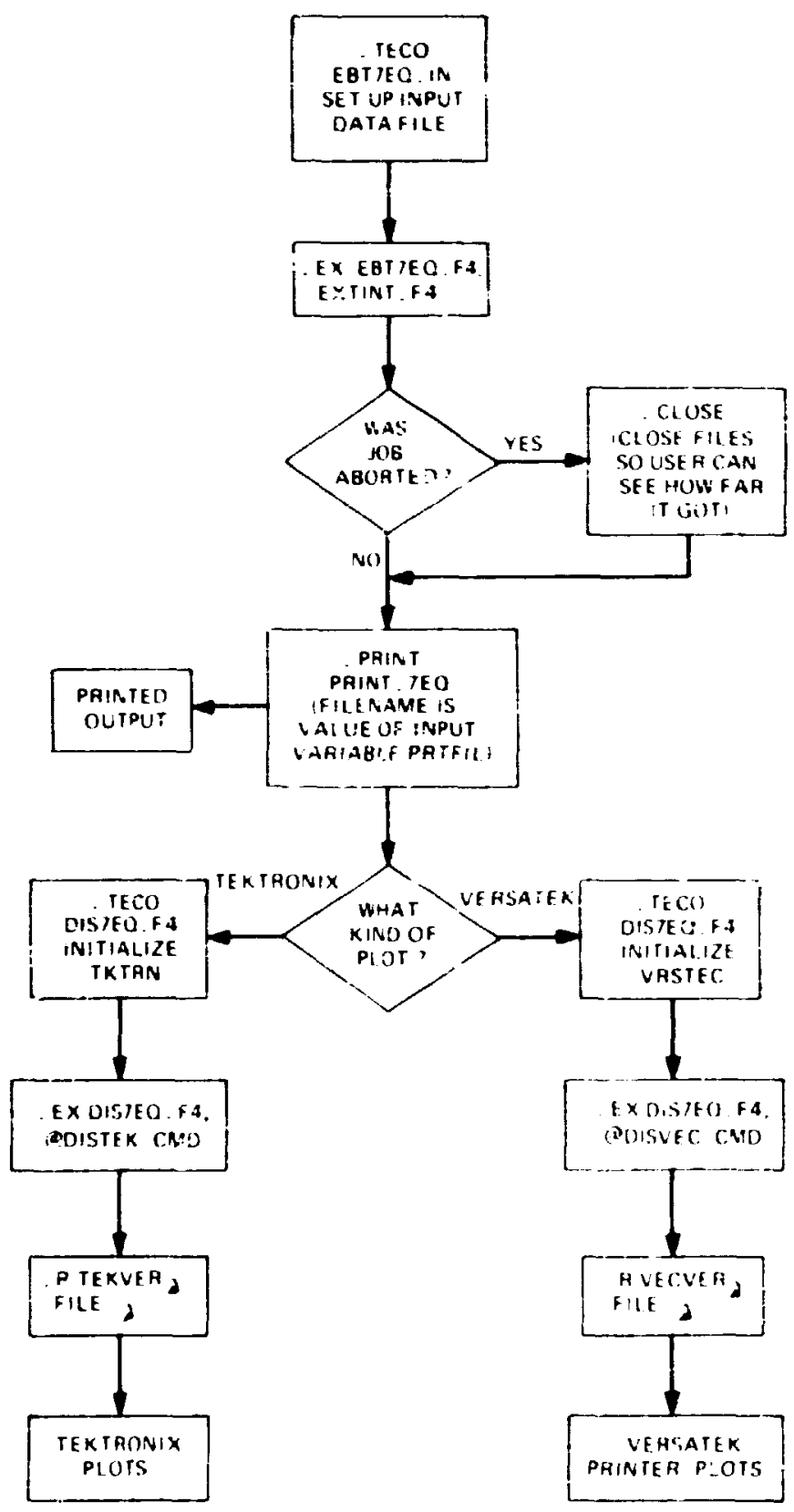

Fig. 3. Execution of seven-equation point model. 


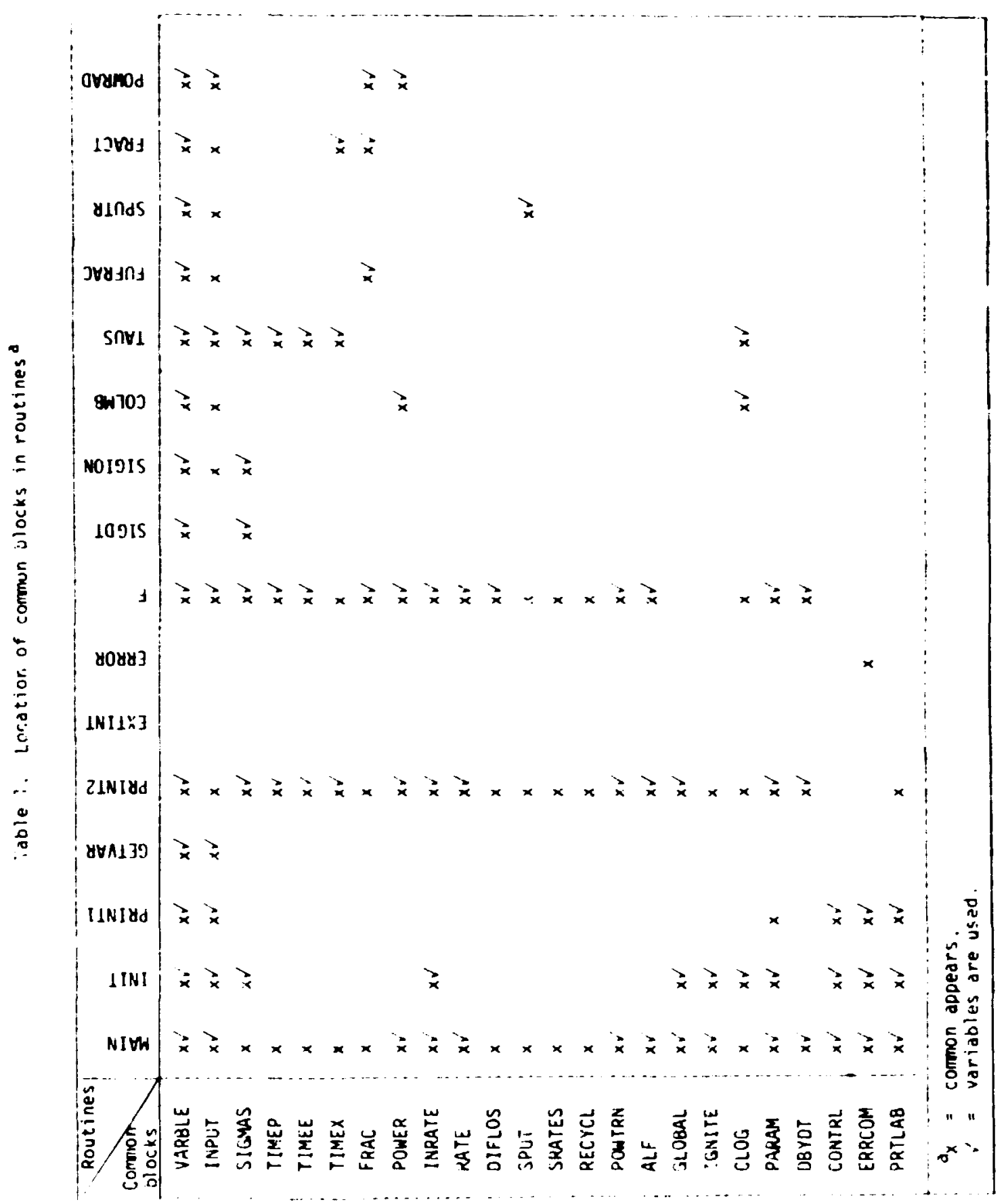


23

Appendix A

EQUATIONS IMPLEMENTED IN THE CODE

$$
\begin{aligned}
& \left.\frac{d n_{D}}{d t}=S_{D C O L D}-n_{D} n_{T}^{<\sigma V\rangle_{D T}}+n_{e} n_{O D}<\sigma V\right\rangle_{i O n i z}-\frac{n_{D}}{T_{p, D}} . \\
& \left.\left.\frac{d n_{T}}{d t}=s_{T C O L D}-n_{D} n_{T}^{\langle\sigma O V}\right\rangle_{D T}+n_{e} n_{O T}<\sigma V\right\rangle_{i o n i z}-\frac{n_{T}}{\tau_{P, T}} . \\
& \left.\frac{d n_{a}}{d t}=n_{D} n_{T}<\sigma v\right\rangle_{D T}-\frac{n_{a}}{\tau_{p, a}} . \\
& \frac{d n_{1}}{d t}=0 \text {. }
\end{aligned}
$$$$
\frac{d n_{H I}}{d t}=0 .
$$

$$
\begin{aligned}
& \frac{d n_{0 D}}{d t}=\left\{S_{D C O L D}-n_{e} n_{0 D}\langle\sigma v\rangle_{i o n i z} \text { if }\left|\frac{d n_{0 D}}{d t}\right|<\varepsilon_{0}\right. \text {, } \\
& \text { otherwise. } \\
& \frac{d n_{O T}}{d t}=\left\{S_{T C O L D}-n_{e} n_{O T}<O V\right\rangle_{i O n i z} \text { if }\left|\frac{d n_{0 T}}{d t}\right|<\varepsilon_{0} \text {, } \\
& \text { otherwise . } \\
& \left.\frac{d p_{e}}{d t}=p_{\mu}+n_{D} n_{T}<\sigma V\right\rangle_{D T}\left(U_{\alpha} f_{\alpha e}-e T_{e}\right)-\frac{p_{e}}{\tau_{E, e}}-p_{e i}-p_{R A D} . \\
& \frac{d p_{j}}{d t}=n_{D} n_{T}<\sigma V{ }_{D T}\left(u_{\alpha} f_{\alpha e}-3 T_{i}\right)+p_{e i}-\frac{p_{i}}{\tau_{E, i}},
\end{aligned}
$$


24

where

$$
\begin{aligned}
& n_{e}=n_{D}+n_{T}+2 n_{\alpha}, \\
& n_{i}=n_{0}+n_{T}, \\
& p_{e}=\frac{3}{2} n_{e} T_{e}, \\
& p_{i}=\frac{3}{2} n_{i} T_{i} .
\end{aligned}
$$


Appendix B

VARIABLES IN CODE

\begin{tabular}{|c|c|}
\hline $\begin{array}{c}\text { Code } \\
\text { variable } \\
\end{array}$ & $\begin{array}{c}\text { Analytical } \\
\text { expression } \\
\text { (if any) }\end{array}$ \\
\hline AHI & $A_{H I}$ \\
\hline AI & $A_{1}$ \\
\hline ALFAE & $\left.n_{D} n_{T}<\sigma V\right\rangle_{D T} U_{\alpha} f_{\alpha e}$ \\
\hline $\begin{array}{l}\text { ALFA! } \\
\text { ALPHA }\end{array}$ & $\begin{array}{l}{ }_{\left.D_{0} n_{T}<\sigma V\right\rangle_{D T} U_{\alpha} f_{\alpha i}} \\
10^{-3} Z_{j} \frac{E_{r} R_{C}}{T_{i}}\end{array}$ \\
\hline AREA & $S$ \\
\hline BDFUSN & $S_{\text {DBEAM }}{ }^{f} D$ \\
\hline BFIELD & B \\
\hline BFUSNE & $S_{D B E A M} f_{D} U_{\alpha}^{f}{ }_{\alpha i}$ \\
\hline BFUSNI & $S_{D B E A M} f_{D}{ }_{\alpha}{ }^{f} \alpha i$ \\
\hline C & \\
\hline C & $c_{j}$ \\
\hline
\end{tabular}

\section{Description}

Atomic number of high-2 impurity ions

Atomic number of low-2 impurity ion

Power delivered from a füticles to electrons

Power delivered from $\alpha$ particles to lons

The product of the charge of the particle $\times$ ERATIO

Surface area of bumpy torus

Rate of fusion of deuterium beam with plasma tritons

Magnetic field strength at center of midplane

Specific power delivered to electrons by $3.5 \mathrm{MeV}$ alphas from suprathermal fusion

Specific power delivered to ions by $3.5 \mathrm{MeV}$ alphas from suprathermal fuston

Power conversion factor from $\mathrm{keV} / \mathrm{sec} / \mathrm{m}^{3}$ to MW (in MAIN)

Coefficient for $\tau_{p, j}$ (in TAUS) 
Appendix B (continued)

Code variable

CIGNIT

$\begin{array}{ll}\text { COL.FRJ } & v_{j} \\ \text { COLON } & \frac{v_{j}}{\Omega_{j}}\end{array}$

COULOG $\quad$ \&n

PALP

CPLOSS

DBEAME $S_{\text {DREAM }} U_{\text {DREAM }}{ }^{f} D B, e$

DBEAMI $\quad S_{\text {DREAM }}$ DREAM $^{f} D B, i$

DELTAX $\Delta t$

TEND $n_{0}$

SEND $n_{0 D}$

DENDDF $n_{O D f}$

LEVITT ${ }^{0 T}$
Analytical

expression (if any)

Ignition criterion (ignition: CPALP - CPLOSS > CIGNIT), MW

Collision frequency for the $j^{\text {th }}$ particle $(j=0, T, x, I$, HI)

The ratio of the collision frequency to the precision for particle $\mathrm{J}$

Coulomb logarithm

Total alpha power produced (in whole device), MW

Total power losses (in whole device), MW

Specific power directly delivered to electrons from deuterium beam $\left(\mathrm{keV} / \mathrm{sec} / \mathrm{m}^{3}\right)$

Specific power directly delivered to ions from deuterium beam $\left(\mathrm{keV} / \mathrm{sec} / \mathrm{m}^{3}\right)$

Change in time between successive printouts

Total neutral density $\left(m^{-3}\right)=n_{O D}+n_{O T}$

Neutral deuterium density $\left(m^{-3}\right)$

Final neutral deuterium density desired $\left(\mathrm{m}^{-3}\right)$

Neutral tritium density $\left(m^{-3}\right)$

$\approx$ 
Appendix B (continued)

\begin{tabular}{|c|c|}
\hline $\begin{array}{c}\text { Code } \\
\text { variable }\end{array}$ & $\begin{array}{l}\text { Aralytical } \\
\text { expression } \\
\text { (if any) } \\
\end{array}$ \\
\hline DENDTF & $n_{\text {otf }}$ \\
\hline DENA & $n_{a}$ \\
\hline DEND & $n_{0}$ \\
\hline DENDTF & $n_{\text {DTf }}$ \\
\hline DENE & $n_{e}$ \\
\hline DENHIM & $n_{H I}$ \\
\hline DENI & $n_{i}$ \\
\hline DENIM & $n_{I}$ \\
\hline DENT & $n_{T}$ \\
\hline DERIV & $\frac{d}{d t}$ \\
\hline DIFA & $\frac{\alpha}{\tau_{p, \alpha}}$ \\
\hline DIFD & $\begin{array}{l}\frac{D}{\tau_{p, D}} \\
n_{H I}\end{array}$ \\
\hline DIFHIM & $\overline{\tau_{p, H I}}$ \\
\hline
\end{tabular}

Description

Final neutral tritium density $\left(\mathrm{m}^{-3}\right)$

Alpha particle density $\left(\mathrm{m}^{-3}\right)$

Deuterion density $\left(\mathrm{m}^{-3}\right)$

Final deuterion density = final triton density desired

Total electron density $\left(\mathrm{m}^{-3}\right)$

High- 2 impurity density $\left(\mathrm{m}^{-3}\right)$

Total ion density $\left(\mathrm{m}^{-3}\right)$

Low- 2 impurity density $\left(\mathrm{m}^{-3}\right)$

Triton density $\left(\mathrm{m}^{-3}\right)$

Array of right-hand sides of equations (for printout)

Alpha particle diffusion loss rate

Deuterium particle diffusion loss rate

High-2 impurity particle diffusion loss rate 
A?pendix B (continued)

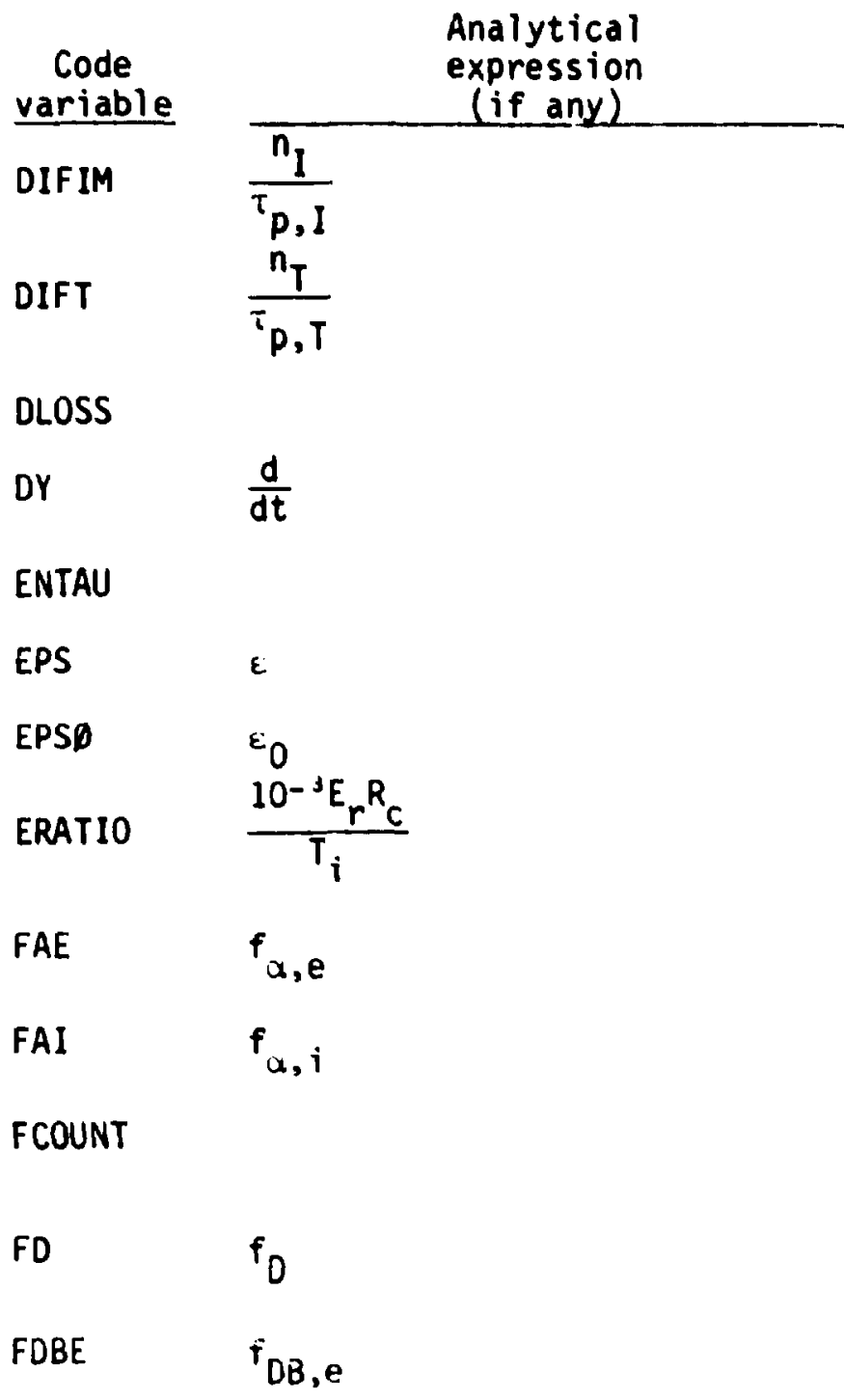

\section{Description}

Low- $Z$ impurity particle diffusion loss rate

Tritium particle difusion loss rate

Total lusses in $n_{D}$ equation

Array of right-hand sides

Global ni product

\section{Convergence criterion}

"ERROR condition" for neutral equations (steady state)

The ratio of the radial electric field $x$ the radius of curvature to the ion temperature

Fraction of $3.52 \mathrm{MeV}$ alpha energy given to electrons

Fraction of $3.52 \mathrm{MeV}$ alpha energy given to electrons

Number of times EXTINT calls $F$ during integration over one time-step

Fraction of deuterion beam which undergoes suprathermal fusion

Fraction of injected deuterium beam energy given directly to electrons 
Appendix B (continued)

\begin{tabular}{|c|c|c|}
\hline $\begin{array}{c}\text { Code } \\
\text { variable }\end{array}$ & $\begin{array}{l}\text { Analytical } \\
\text { expression } \\
\text { (if any) }\end{array}$ & Description \\
\hline FDBI & $f_{D B, i}$ & $\begin{array}{l}\text { Fraction of injected deuterion beam energy given cirectly } \\
\text { to ions }\end{array}$ \\
\hline $\mathrm{FH}$ & $f_{H}$ & $\begin{array}{l}\text { Fraction of hot-electron annuli syrichrotron radiation } \\
\text { energy transferred to background plasma }\end{array}$ \\
\hline FHSYNC & $f_{H} F_{H S Y N C}$ & $\begin{array}{l}\text { Power delivered to background electrons due to synchrctron } \\
\text { radiation from hot-electron annuli }\end{array}$ \\
\hline FRD & $f_{\mathrm{RD}}$ & Fraction of deuterions which are recycled \\
\hline FRT & $f_{R T}$ & Fraction of tritons which are recycled \\
\hline$H D$ & & The integration time-step (modified by EXTINT) \\
\hline LABEL & & An 80-character label for plots and printer output \\
\hline $\operatorname{MMAX}$ & & The minimum number of extrapolations before having $H D$. \\
\hline NMAX & & Number of equations $=9$ \\
\hline ONIEGAJ & $\Omega_{\mathrm{j}}$ & $\begin{array}{l}\text { Precession frequency for the } j^{\text {th }} \text { type particle } j=0, T, \alpha, \\
I, H I\end{array}$ \\
\hline PALPHA & & $\begin{array}{l}\text { ALFAE + ALFAI = total power delivered to electrons + toris } \\
\text { by a particles }\end{array}$ \\
\hline PBEAM & $P_{\text {BEAM }}$ & (Deuterium) beam power \\
\hline
\end{tabular}


Appendix B (continued)

\begin{tabular}{lll}
$\begin{array}{c}\text { Code } \\
\text { variab?e }\end{array}$ & & $\begin{array}{c}\text { Analytical } \\
\text { expression } \\
\text { (if any) }\end{array}$ \\
\hline PBREM & & $P_{\text {BREM }}$ \\
PCOLMB & $P_{e, i}$ \\
PE & $P_{e}$ \\
PHSYNC & $P_{\text {HSYNC }}$ \\
PI & $P_{i}$ \\
PLINE & $P_{L I N E}$ \\
PLOSS & \\
PLTFIL & \\
PMICRO & $P_{H}$ \\
PRAD & $P_{\text {RAD }}$ \\
PRTFIL & \\
PRTFRQ & \\
PSYNC & $P_{S Y N C}$
\end{tabular}

Description

Power loss due to Bremsstrahlung

Power transfer from electrons to ions by Coulomb collisions Electron "pressure" $=\frac{3}{2} n_{e}^{\top} e$

Power loss due to synchrotion radiation (from hot-electron annuli)

Ion "pressure" $=\frac{3}{2} n_{i} T_{i}$

Power loss due to line radiation

Total power losses (keV)

The plot file name

Specific power delivered to background electrons from microwaves $\left(\mathrm{keV} / \mathrm{sec} / \mathrm{m}^{3}\right)$

Total power losses due to various radiation processes

The print file name

Printer and plotting output frequency in seconds (integration time)

Power loss due to synchrotron radiation (from baskground electrons) 
Appendix B (continued)

\begin{tabular}{|c|c|}
\hline $\begin{array}{c}\text { Code } \\
\text { variable } \\
\end{array}$ & $\begin{array}{l}\text { Analytical } \\
\text { expression } \\
\text { (if any) }\end{array}$ \\
\hline PT & $P_{e}+p_{i}$ \\
\hline RATEDD & $n_{e} n_{O D}^{\langle\sigma V\rangle}$ ioniz \\
\hline RATEDT & $n_{e} n_{0 T}{ }^{\langle\sigma v\rangle}$ ioniz \\
\hline RATEDT & ${ }^{\left.n_{D} n_{T}<\sigma V\right\rangle_{D T}}$ \\
\hline RCURVA & ${ }^{R_{C}}$ \\
\hline $\begin{array}{l}\text { RE } \\
\text { RECYLD }\end{array}$ & $\begin{array}{l}\mathrm{R}_{\mathrm{e}} \\
\left(\frac{\mathrm{n}_{D}}{\tau_{\mathrm{n}, \mathrm{n}}}\right)_{\mathrm{RD}}\end{array}$ \\
\hline RECYIT & $\left(\frac{T}{T_{p, T}}\right) f_{i T T}$ \\
\hline RMAJOR & $R_{T}$ \\
\hline RMINOR & a \\
\hline$S$ & \\
\hline SÚBEAM & $S_{\text {DBEAM }}$ \\
\hline SDCOLD & $\mathrm{S}_{\text {OC.OLD }}$ \\
\hline
\end{tabular}

\section{Description}

Total "pressure" for electrons and fons

Deuterium - neutral ionization rate

Tritium - neutral ionization rate

Deuterium - tritium fusion rate

Radius of curvature of field $=\left\langle\frac{V B}{B}\right\rangle$

Reflection coefficient (used in calculating $P_{\text {SYNC }}$ )

Deuteron recycling rate

Triton recycling rate

Major radius (m)

Minor radius (m)

Array (in ERROR) of magnitudes of dependent variables for relative error check

Deuterium injection rate for fast atoms (beam) $\left(\mathrm{m}^{-s} \mathrm{sec}^{-1}\right)$

Deuterium injection rate for fast cold fue $1\left(\mathrm{~m}^{-3} \mathrm{sec}^{-1}\right)$ 
Appendix B (continued)

\begin{tabular}{|c|c|}
\hline $\begin{array}{c}\text { Code } \\
\text { variable }\end{array}$ & $\begin{array}{l}\text { Analytical } \\
\text { expression } \\
\text { (if any) }\end{array}$ \\
\hline SIGVCX & $\langle\sigma v\rangle c x$ \\
\hline SIGVDT & $\langle O V\rangle_{D T}$ \\
\hline SIGVIO & $\langle\sigma v\rangle_{\text {ioniz }}$ \\
\hline SIGVXX & $\langle\sigma v\rangle C X-D$ \\
\hline SIGVXT & $\langle O V\rangle_{C X} C X-T$ \\
\hline SPUTA & $I_{\alpha}$ \\
\hline SPUTD & $\mathrm{I}_{\mathrm{r}}$ \\
\hline SPUTHI & $\mathrm{I}_{\mathrm{HI}}$ \\
\hline SPUTI & $I_{1}$ \\
\hline SPUTN & $\mathrm{I}_{\mathrm{N}}$ \\
\hline SPUTT & ${ }^{1} T$ \\
\hline SRATEA & $\left(\frac{n_{\alpha}}{\tau_{0, \alpha}}\right) I_{\alpha}$ \\
\hline SRATED & $\left(\frac{I_{D}}{p, D}\right) I_{D}$ \\
\hline
\end{tabular}

\section{Description}

\section{Maxwellian-averaged charge-exchange crojs-section}

Maxwellian-averaged D-T fusion iross-section

Maxwellian-averaged ionization cross-section

Maxwellian-averaged charge-exchange cross-section for $D$

Maxwellian-dveraged charge-exchange cross-section for $T$

Sputtering coefficient for alpha particles

Sputtering coefficient for deuteroris

Sputtering coefficient for low-Z impuritie: (self-sputtering)

Sputtering coefficient for high-z impurities (self-sputtering)

Sputtering coefficient for neutrons

Sputtering coefficient for tritons

Sputtering rate for alpha particles

Sputtering rate for deuterons 
Appendix B (continued)

\begin{tabular}{|c|c|}
\hline $\begin{array}{c}\text { Code } \\
\text { variable }\end{array}$ & $\begin{array}{c}\text { Analytical } \\
\text { expression } \\
\text { (if any) } \\
\end{array}$ \\
\hline SRATEN & $\left(n_{D} n_{T}<\sigma V>D T+S_{D B E A M}{ }^{\dagger} D I_{n}\right.$ \\
\hline SRATET & $\left(\frac{T}{\tau_{p, T}}\right)^{1}{ }_{T}$ \\
\hline SSRHIM & $\left(\frac{h I}{\tau_{p, H I}}\right) I_{H I}$ \\
\hline SSRIM & $\left(\frac{1}{T_{0} I}\right)_{1}$ \\
\hline STCOLD & $\mathrm{S}_{\text {TCOLD }}$ \\
\hline TACOND & ${ }^{\tau} E$, COND \\
\hline TACX & ${ }^{\top} c x$ \\
\hline TAEE & ${ }^{\tau} E, t$ \\
\hline TAEI & ${ }^{r} E, i$ \\
\hline TAGLOB & $\frac{p_{e}+p_{i}}{P L O S S}$ \\
\hline TALFAE & $n_{D} n_{T}\langle\sigma V\rangle_{D T}\left(U_{\alpha} f_{\alpha e}-3 T_{e}\right)$ \\
\hline TALFAI & $\left.n_{D} n_{T}<u v\right\rangle_{O T}\left(U_{\alpha} f_{a i}-3 T_{i}\right)$ \\
\hline
\end{tabular}

\section{Description}

Sputtering rate foi neutrons

Sputtering rate for tritons

Self-sputtering rate for high-z impurities

Self-sputtering rate for low-z impurities

Tritium injection rate for cold fuel $\left(\mathrm{m}^{-1} \mathrm{sec}^{-1}\right)$

Energy confinement time for conduction

Charge-exchange time $=\frac{1}{n_{0}\langle 0 v\rangle c x}$

Energy confinement time for electron

Energy confinement time for fon

"Global" corfinement time

Net power delivered from $\alpha$-particles to electrons

Net power deltvered from a-particles t.o ions 
Appendix B (continued)

\begin{tabular}{ll}
$\begin{array}{c}\text { Code } \\
\text { variable }\end{array}$ & \multicolumn{1}{c}{$\begin{array}{c}\text { Analytical } \\
\text { expression } \\
\text { (if any) }\end{array}$} \\
TAPA & $\tau_{p, \alpha}$ \\
TAPD & $\tau_{p, D}$ \\
TAPHTM & $\tau_{p, H I}$ \\
TAPIM & $\tau_{p, I}$ \\
TAPION & $\tau_{p, i}$ \\
TAPT & $\tau_{p, i}$ \\
TAS & $\tau_{s}$ \\
TBEAME & $S_{D B E A M}\left(U_{D B E A M} f_{D B, e}+f_{D} U_{\alpha} f_{\alpha e}\right)$ \\
TBEAMI & $S_{D B E A M}\left(U_{D B E A M}{ }^{f} D B, i\right.$ \\
TDSTAR & $\tau_{D}^{\star}$ \\
TE & $T_{0}$ \\
TEF & $\left.T_{e f} f_{\alpha i}\right)$ \\
TI & $T_{i}$ \\
TIF & $T_{i f}$
\end{tabular}

\section{Description}

Particle confinement time for alpha particles

Particle confinement time for deuterons

Particle confinement time for high- $Z$ impurities

Particle confinement time for low- $z$ impurities

Particle confinement time for ions (weighted average for $D$ and $T$ )

Particle confinement time for tritons
Spitzer ion-electron momentum exchange time

Total power delivered to electrons from D-beam (including a's)

Total power delivered to ions frum D-beam (illcluding $\alpha^{\prime} s$ )

Time (seconds) that ${ }{ }_{O D}$ takes to reach steady state

Electron temperature (keV)

Final electron teniperature desired (keV)

Ion temperature (k:V)

Final ion temperature desired (kev) 
Appendix B (continued)

\begin{tabular}{|c|c|c|}
\hline $\begin{array}{c}\text { Code } \\
\text { variable } \\
\end{array}$ & $\begin{array}{l}\text { Analytical } \\
\text { expression } \\
\text { (if any) }\end{array}$ & Description \\
\hline $\begin{array}{l}\text { TLOSS } \\
\text { TRANE }\end{array}$ & $\frac{3}{2} \frac{{ }^{n} e T_{e}}{\tau_{E, e}}=\frac{P_{e}}{\tau_{E, e}}$ & $\begin{array}{l}\text { Total losses in } n_{T} \text { equation } \\
\text { Specific power loss from eiectrons due to transport } \\
\text { processes }\end{array}$ \\
\hline TRANI & $\frac{3}{2} \frac{n_{i} T_{i}}{\tau_{E, i}}=\frac{p_{i}}{\tau_{E, i}}$ & Specific power loss from ions due to transport processes \\
\hline TTSTAR & $t_{t}^{\star}$ & Time (seconds) that $n_{\text {OT }}$ takes to reach steady state \\
\hline UALPHA & $u_{\alpha}$ & Energ; of alpha particles $=3.52 \times 10^{3} \mathrm{keV}$ from $D-T$ fusion \\
\hline UCR & $U_{i R}$ & $\begin{array}{l}\text { Critical entigy during the slowing down process, at which } \\
\text { energy is being iransferred equally to plasma ions and } \\
\text { electrons }\end{array}$ \\
\hline UDBEAM & U UBEAM & Energv of injected deuterons (kev) \\
\hline VOLUME & v & Volume of "torus" $=2 \pi^{2} R_{T} a^{2}$ \\
\hline$x$ & $t$ & Integration time (seconds) \\
\hline XFINAL & $t_{\text {final }}$ & Final integration time (seconds) \\
\hline Xol.D & & Previous printout time; do printout if $X-X O L D \geq P R T F R Q$ \\
\hline $\begin{array}{l}\text { XSTART } \\
\text { Y }\end{array}$ & $t_{\text {start }}$ & $\begin{array}{l}\text { Initial integration time (seconds) } \\
\text { Arrdy of dependent variables for EXTINT }\end{array}$ \\
\hline
\end{tabular}


Appendix B (continued)

$\begin{array}{lll}\begin{array}{c}\text { Code } \\ \text { Variable }\end{array} & & \begin{array}{c}\text { Analytical } \\ \text { expression } \\ \text { (if any) }\end{array} \\ \text { ZEFF } & Z_{\text {eff }} & \\ Z H I & Z_{H i} \\ Z I & Z_{I}\end{array}$

Description

Effective charge $=\Sigma Z_{j}{ }^{2} n_{j} / \Sigma Z_{j} n_{j} \quad j=D, T, \alpha, I$, HI

Charge number of high-Z impurity

Charge number of low- $Z$ impurity 
Appendix C

LISTINGS OF FILES

\author{
EBT7EQ. IN \\ EBT7EQ.F4 \\ EXTINT .F4 \\ SIGVDT .DA? \\ DISTEQ.F4 \\ DISVEC.CMD \\ DISTEK.CMD
}

7EQ.CMD 
ETB7EQ. IN - Sample Input File

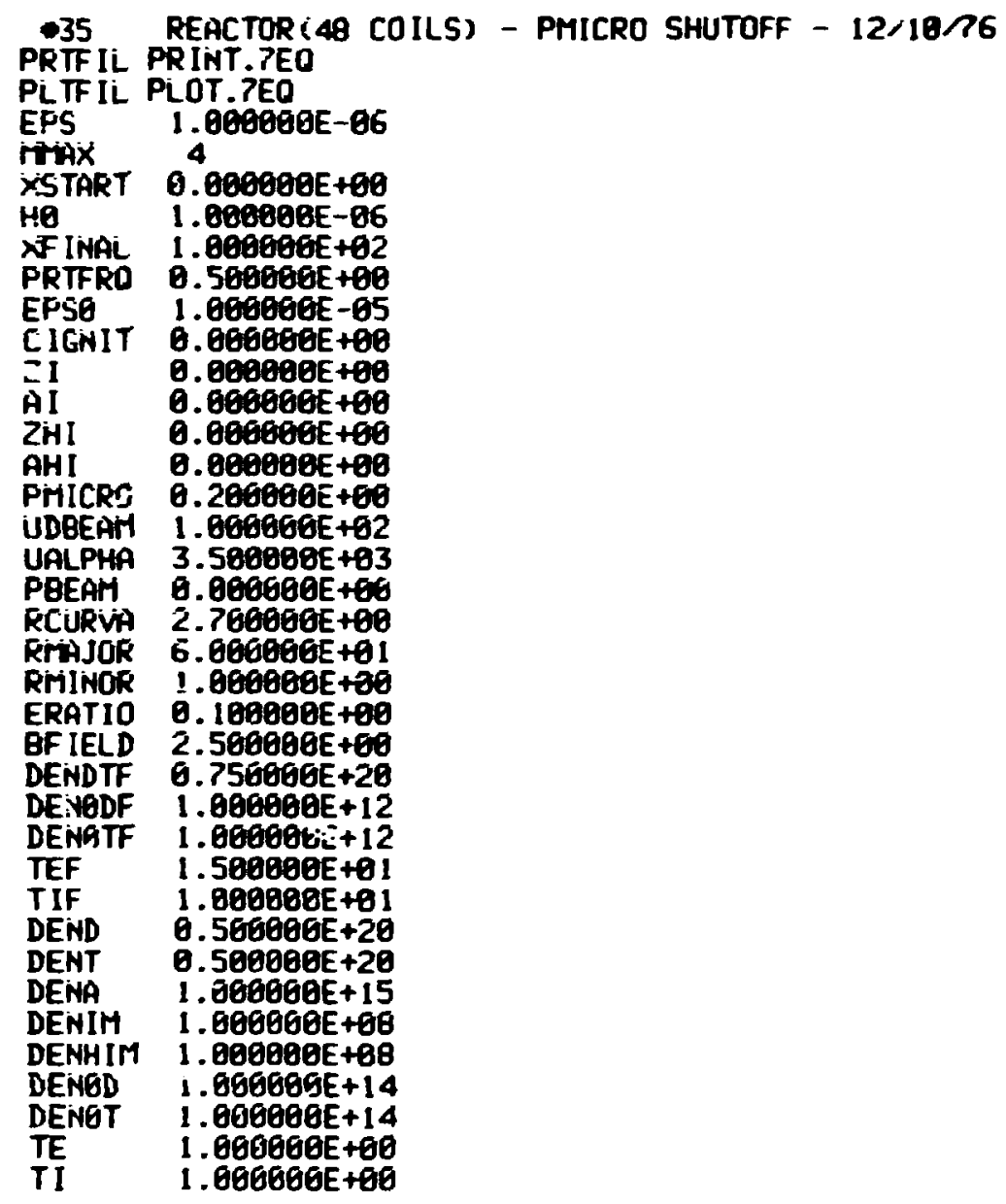


EBT7EQ.F4 - Point Model Code Source Listing

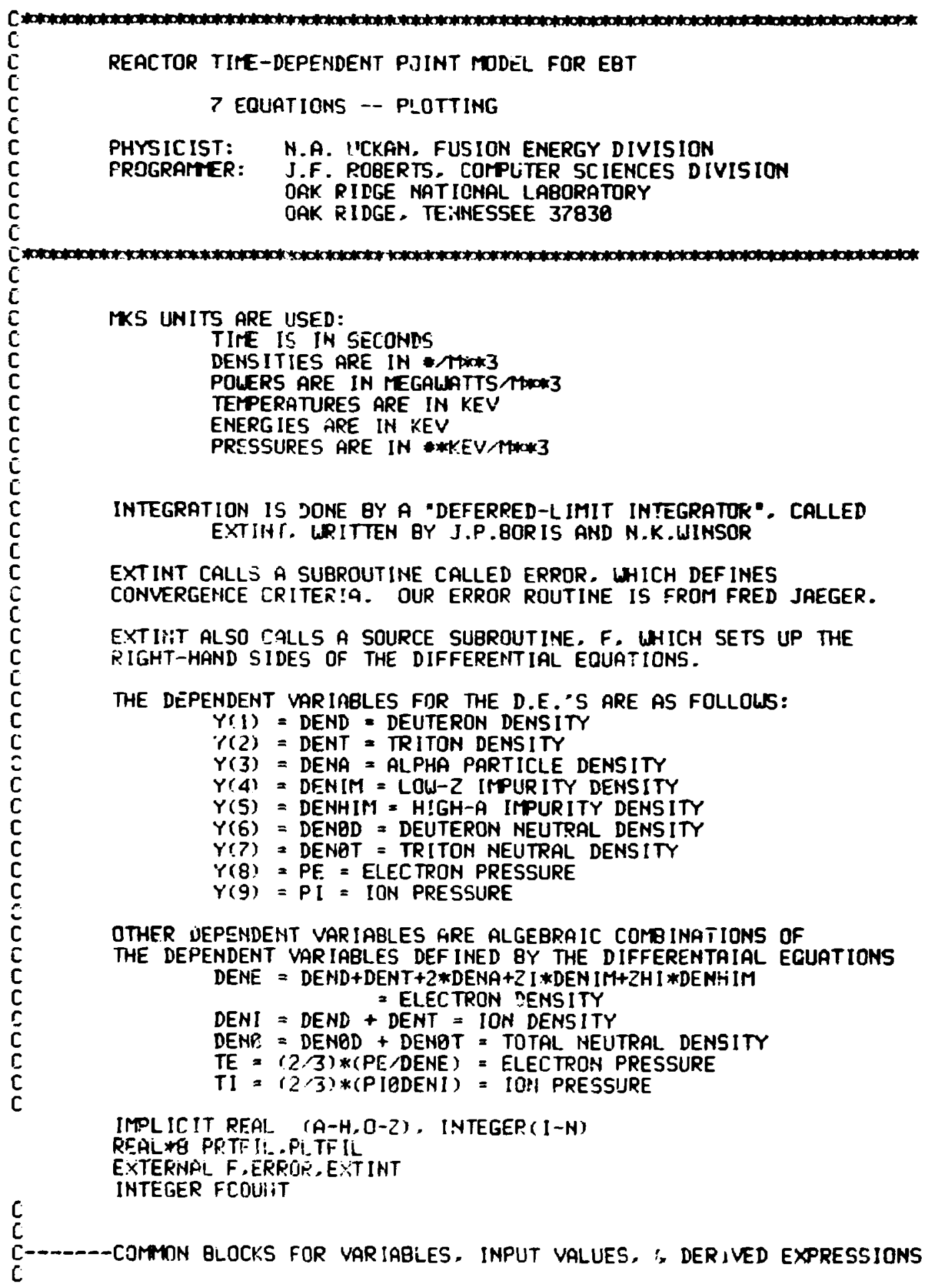


C

?

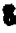
COMON/SIGMAS/SIGVDT, SIGVIO, SIGVX, SIGVX, S IGVXI
COMON/TIMEP TAPD. TAPT, TAPA. TAPIM. TAPHIM, TAP ION

COHHON/TITEE/TAEE, TAE I, TACOND COMTON, TIMEX TAS. TACX

COMDN/FRAC FDBE, FLEI , FAE, FAI, FRD,FRT, FH,FD

COMON/POLER, PSYNC, PHSWC, FHSYNC, PL INE, PBREM. PRAD, PCOL HB

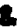
COTMN /INRATE/SDEEAM, SDCOLD.STCOLD. DENDTF. DENOPF, DENOTF. TEF,

COMTONARATE RATEDT, RATEQD, RATEET, BDFUSN

COMON/DIFLOS $\mathcal{A}$ !FD. DIFT. DIFA. DIF IM. DIFHIM

COMTIN/SPUT/SPUTN, SPUTD,SPUTT, SPUTA,SPUTI , SPUTHI

COMON/SRATES/SRATEN, SRATED.SRATET,SRATEP,SSR IM.SSRHIM

COITLNARECYCL.REC YLD.RECYT COMTON/POLIRN/DBEATE, DBEAMI , BFUSNE, BFLSSH I TBEAME, TBEAMI , TRAME. TRANI

COMOH ALF ALFAE, ALFAI, TALFAE, TALFAI

COMMN GLOPAL PALPHA, PLOSS, CPALP, CPLOSS, TAGLOB, ENTAU, C

COHWH/IGNITE/CIGNIT.TIF

COMTON/CLOG COULOG

COINON/PARAMLFCQUNT.EPSO

COHTON/DEYDT/DERIV(9)

COMON,CONTRL XSTART.HQ, XF INAL,PRTFRO

COMON/ERRCOMEPS, S(160), Y(180), NMAX, MAAX

$\mathrm{c}$ COMONARTABAABEL (20),PRTF IL,PLTF IL

CALL INIT

$\ddot{c}$

c

CALL PRINTI

C-D--COMVERT PMICRO TO KEV/SEC THOK3 FOR CALCULATIONS

$\mathrm{C}$

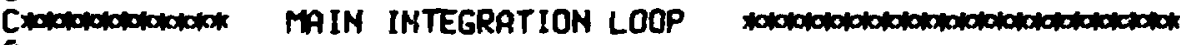

C

c

150

$\ddot{X}=X$ XSTART

XULL $=$ XSTART

FCUUNT $=0$

CALL EXTINT (NMAX,X,Y,F,HO,MAX,ERROR)

$\mathrm{C}$

C

CALL GETVAR(Y)

CNIF (TE.LT. 1.Q) $H \theta=1 . \theta E-5$

Conton IF (TI.LT.1.8) HO=1.0E-5 


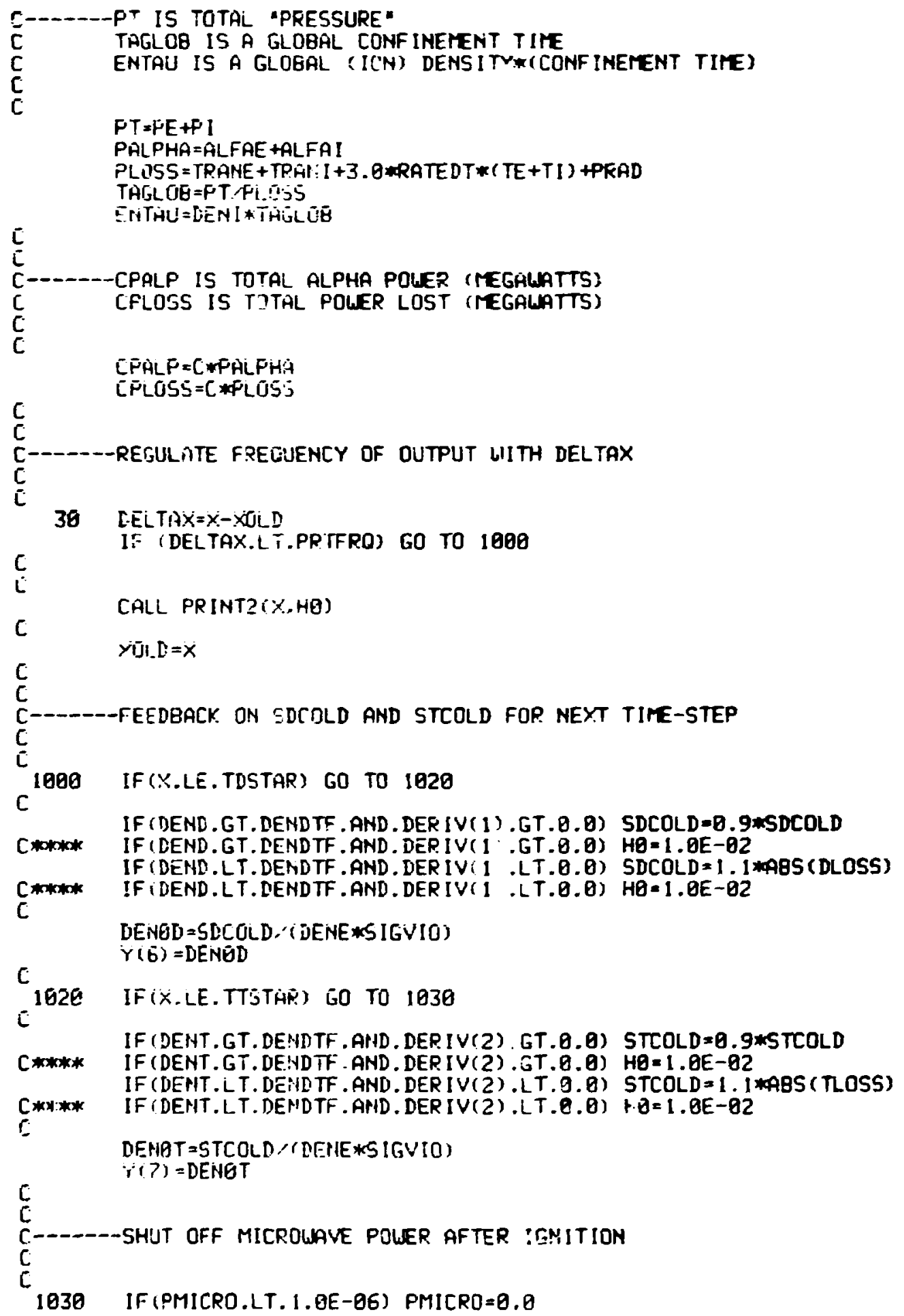




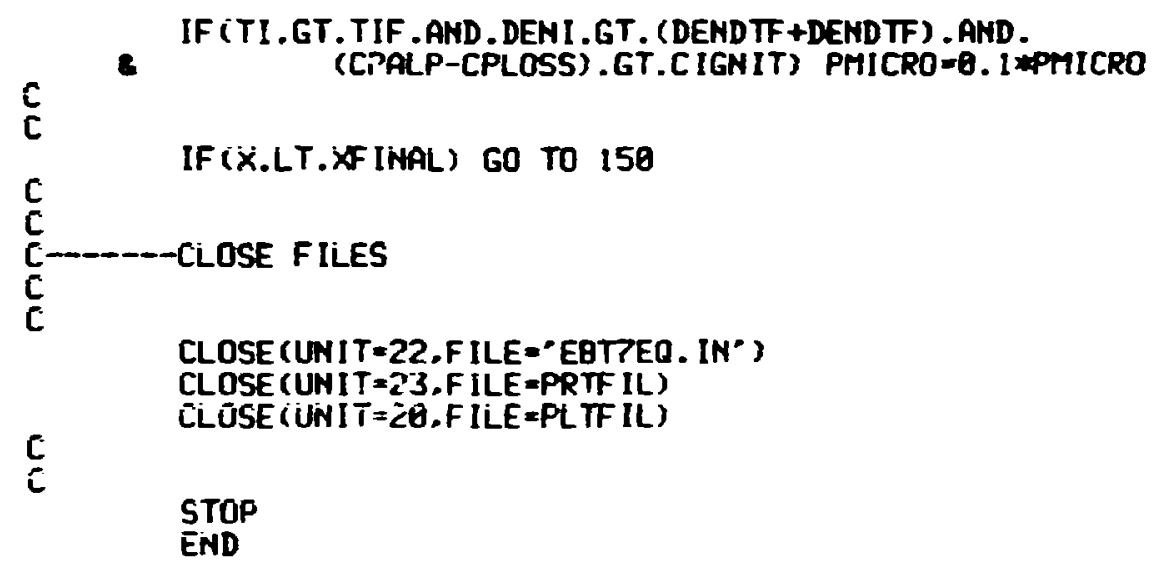




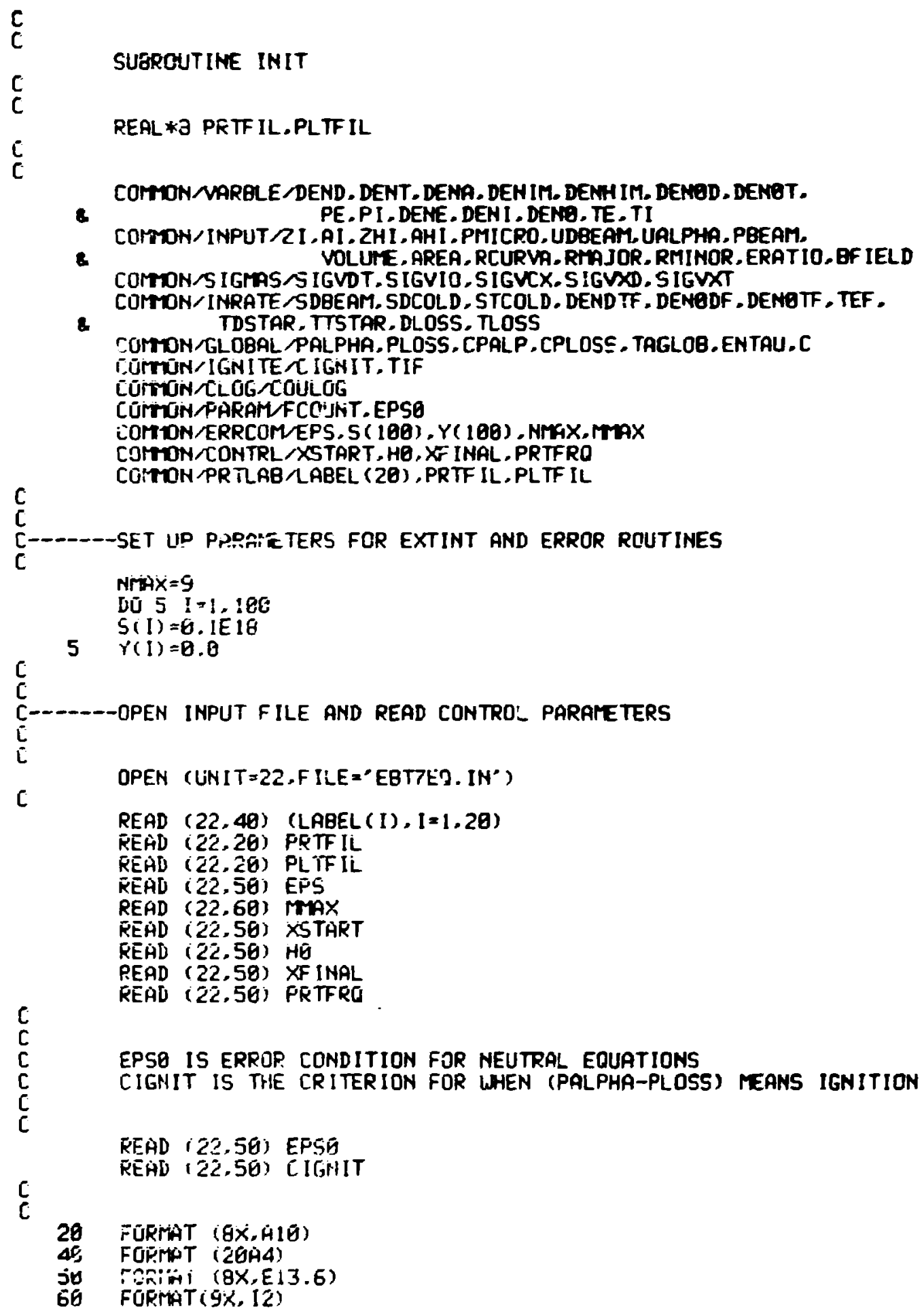




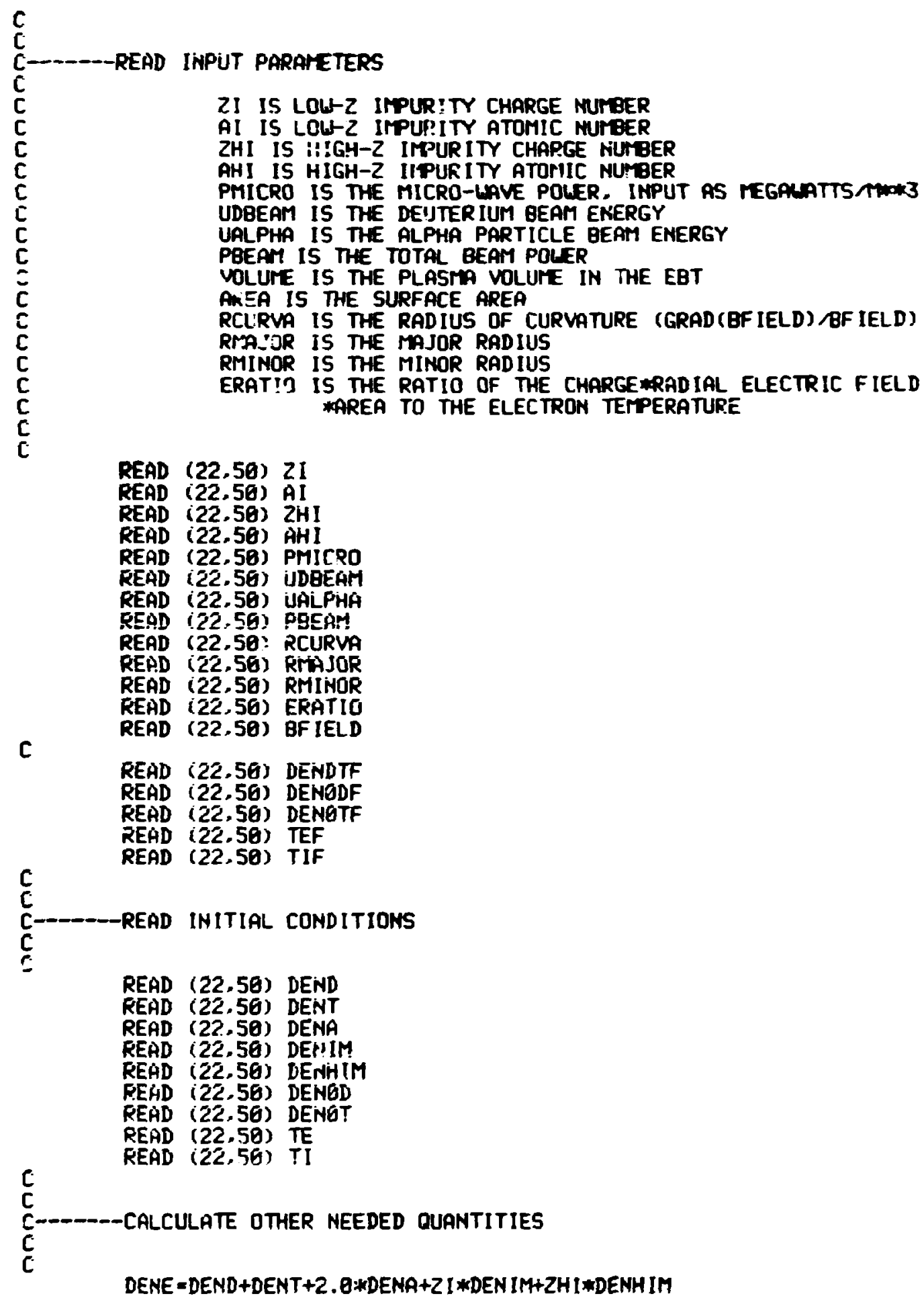




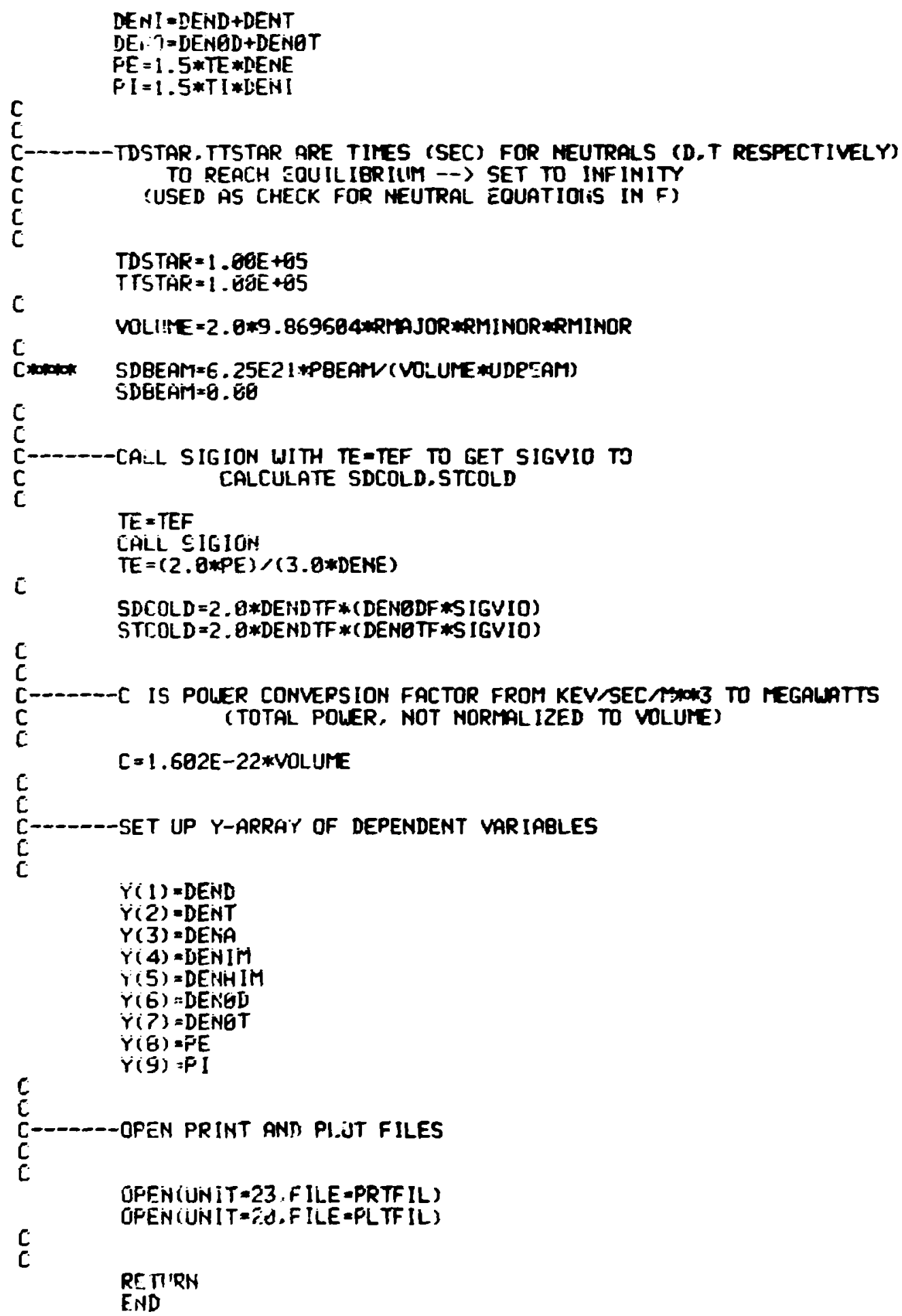




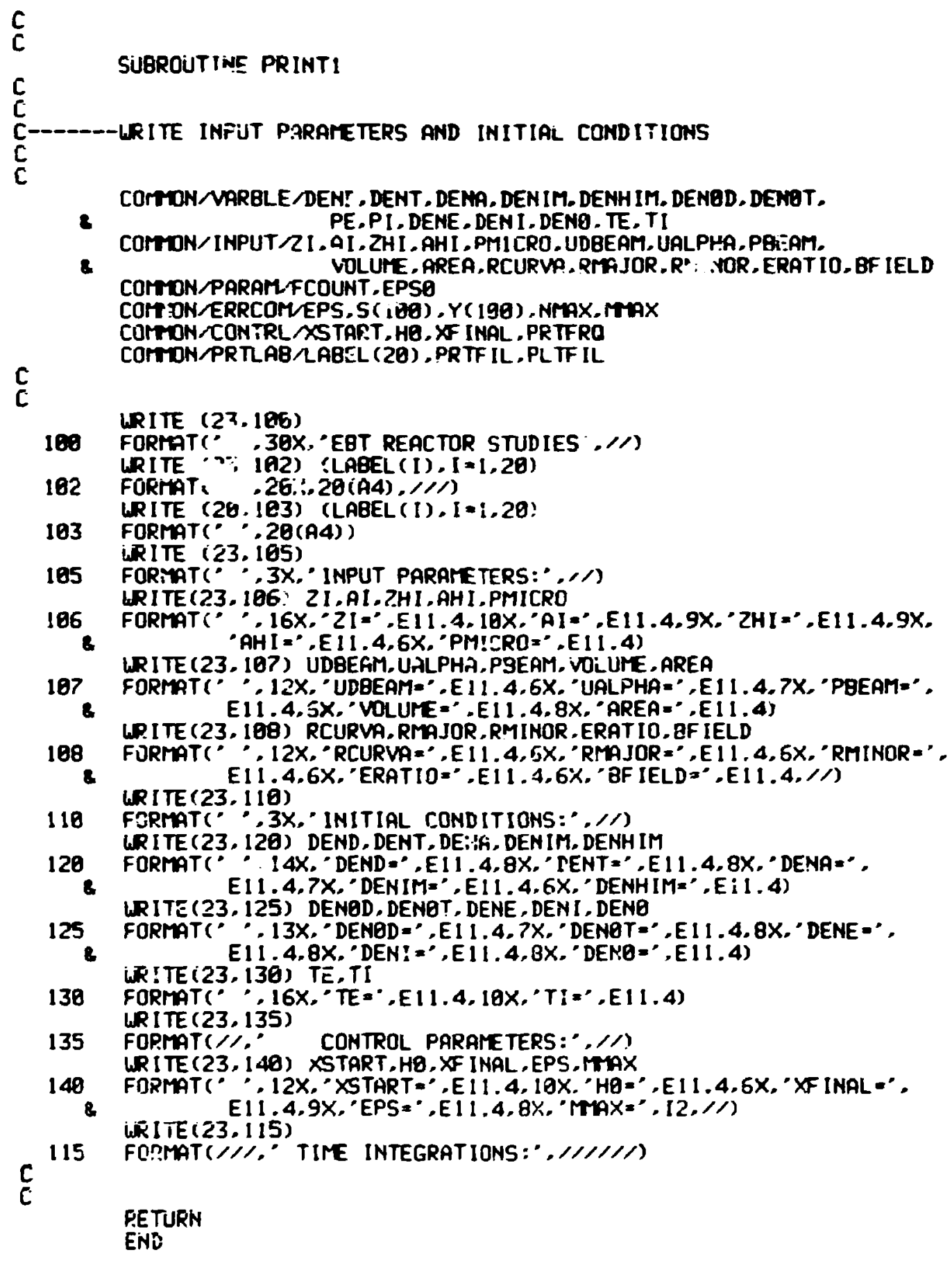




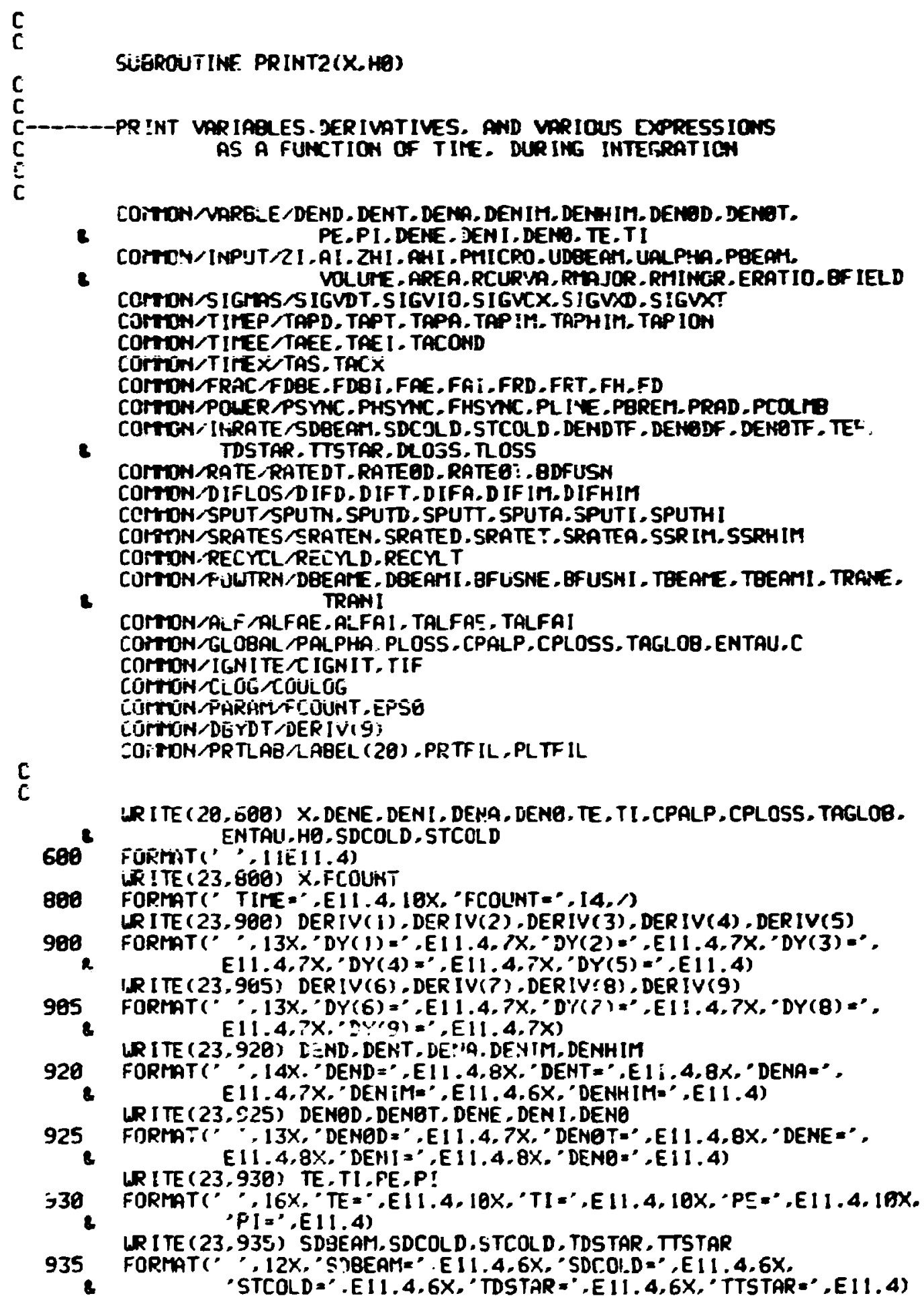




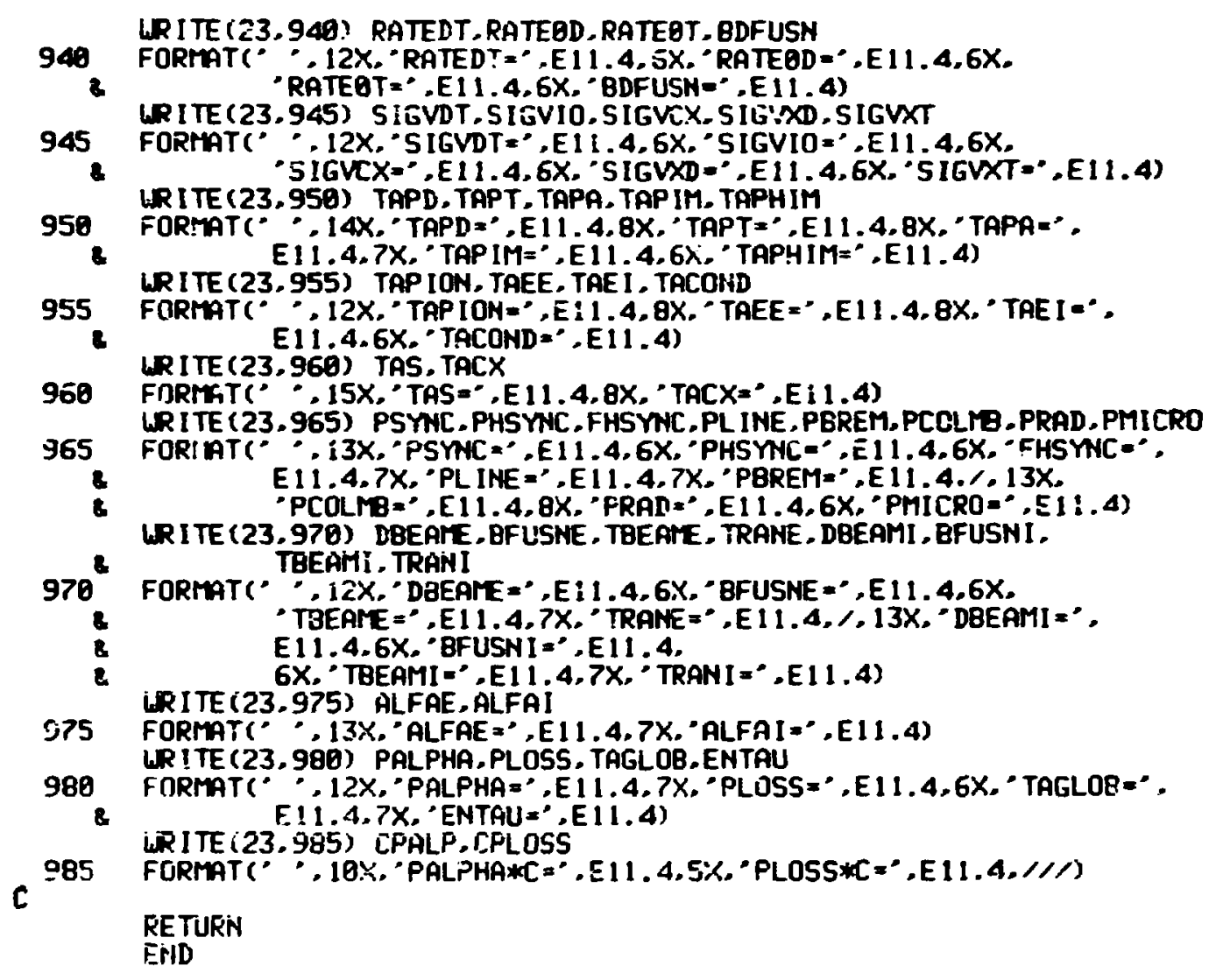




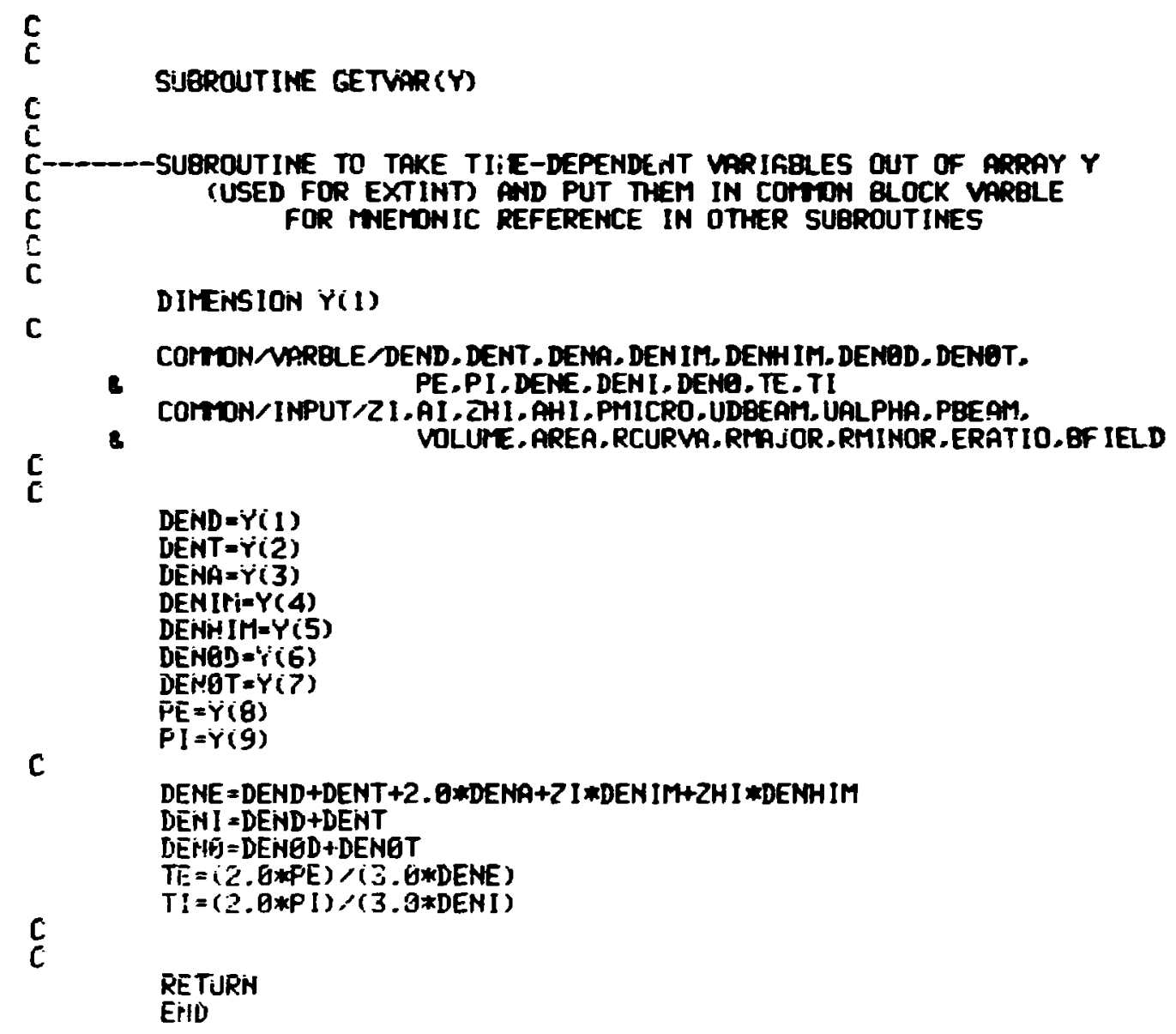




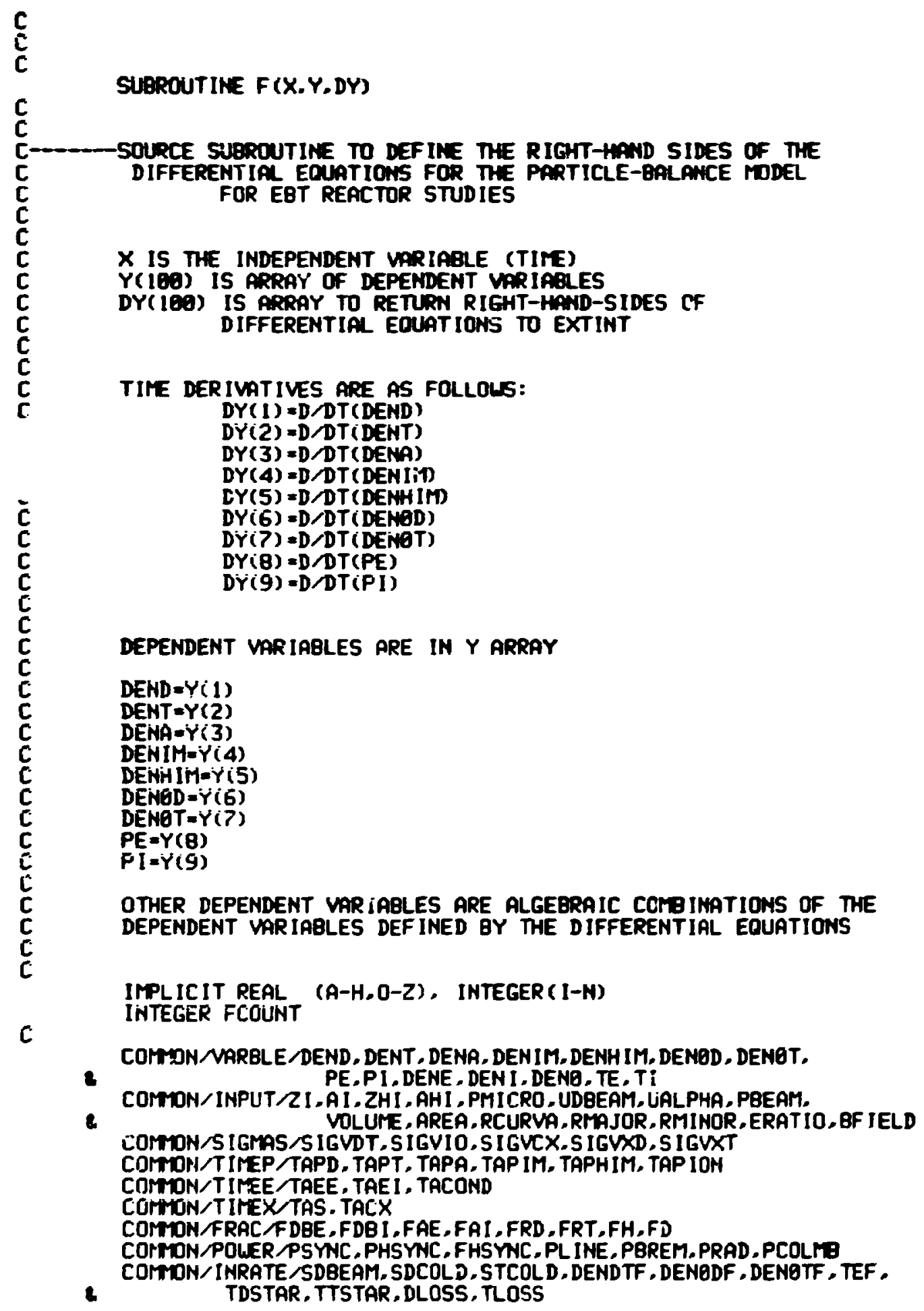




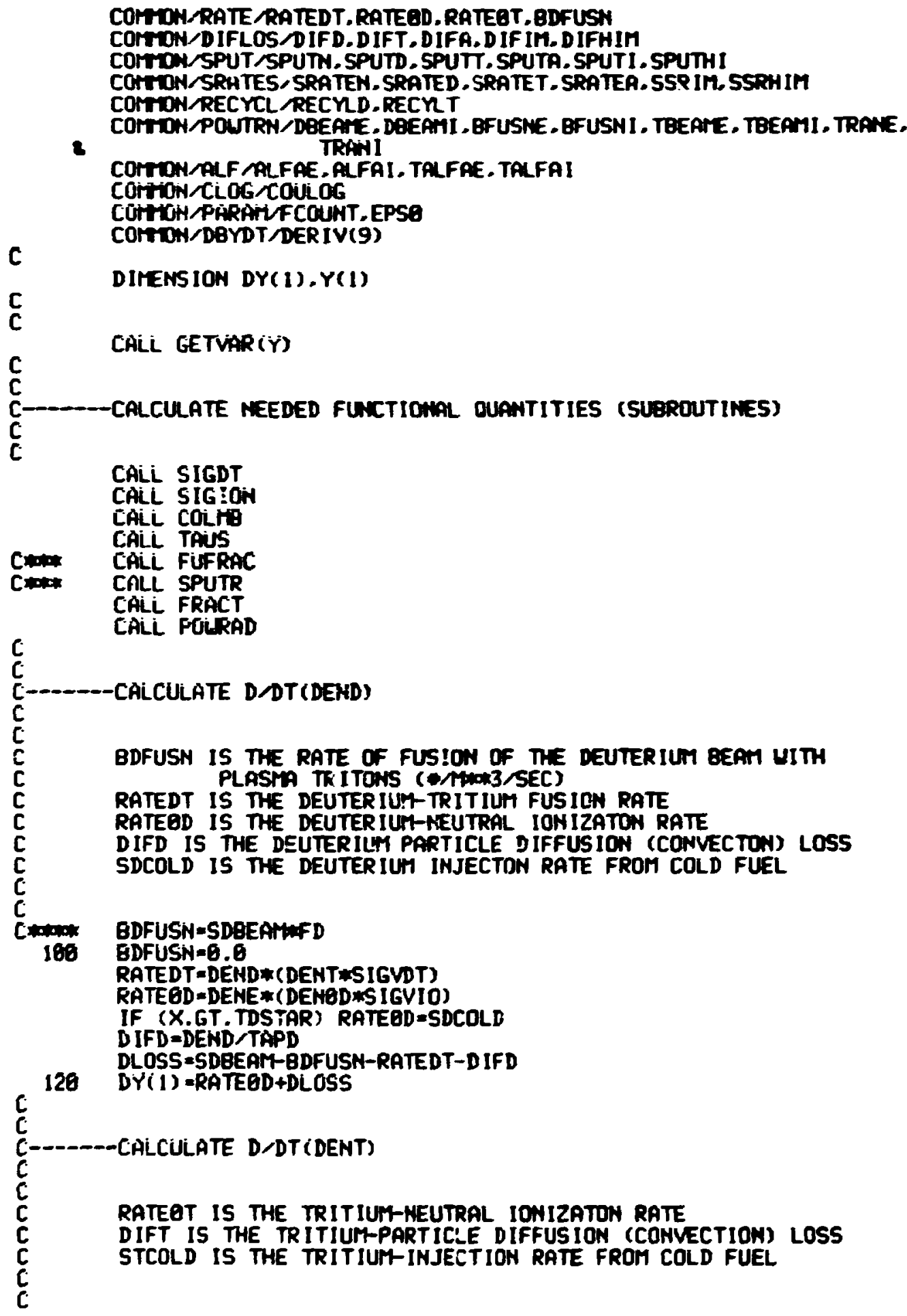




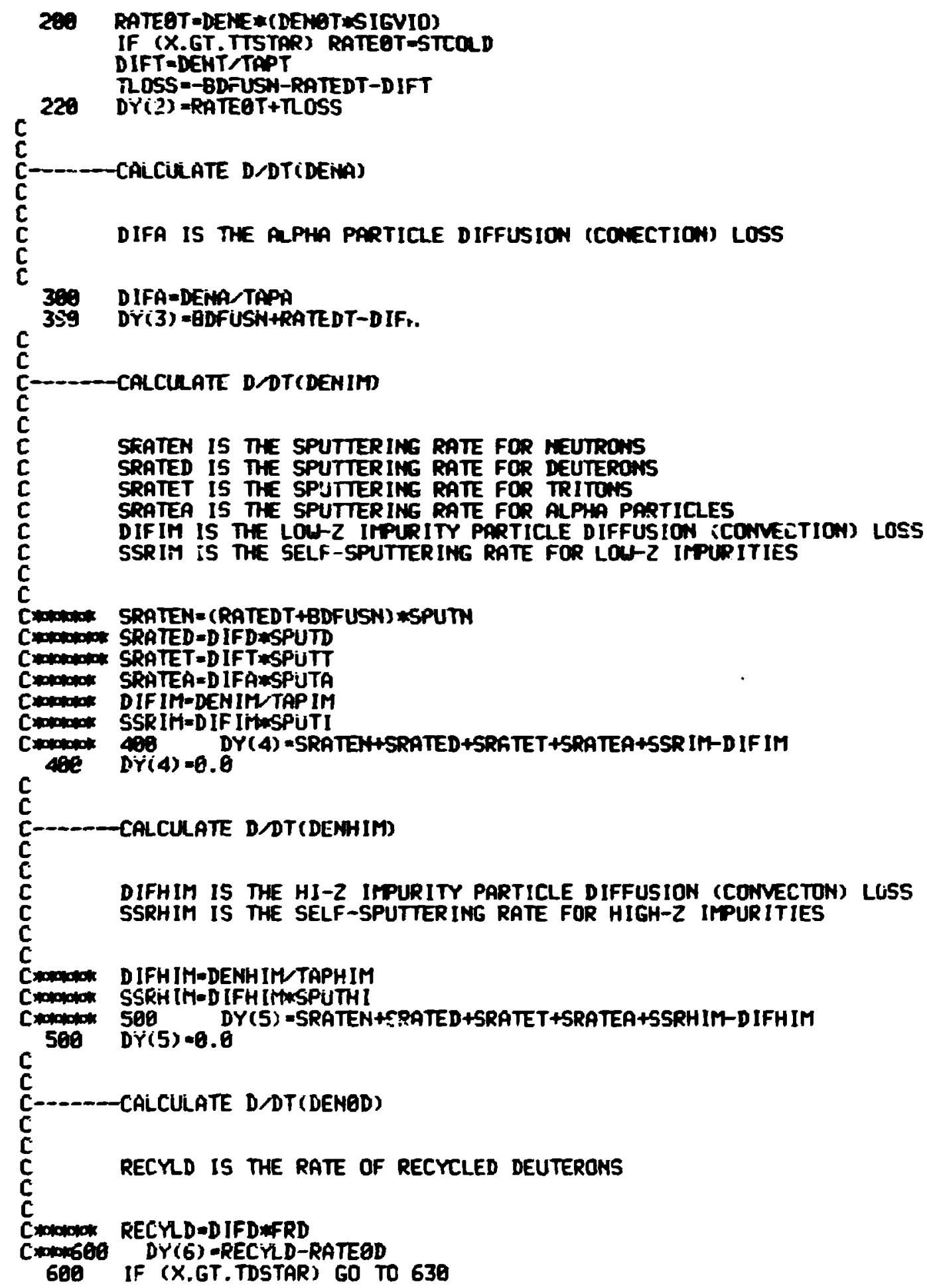




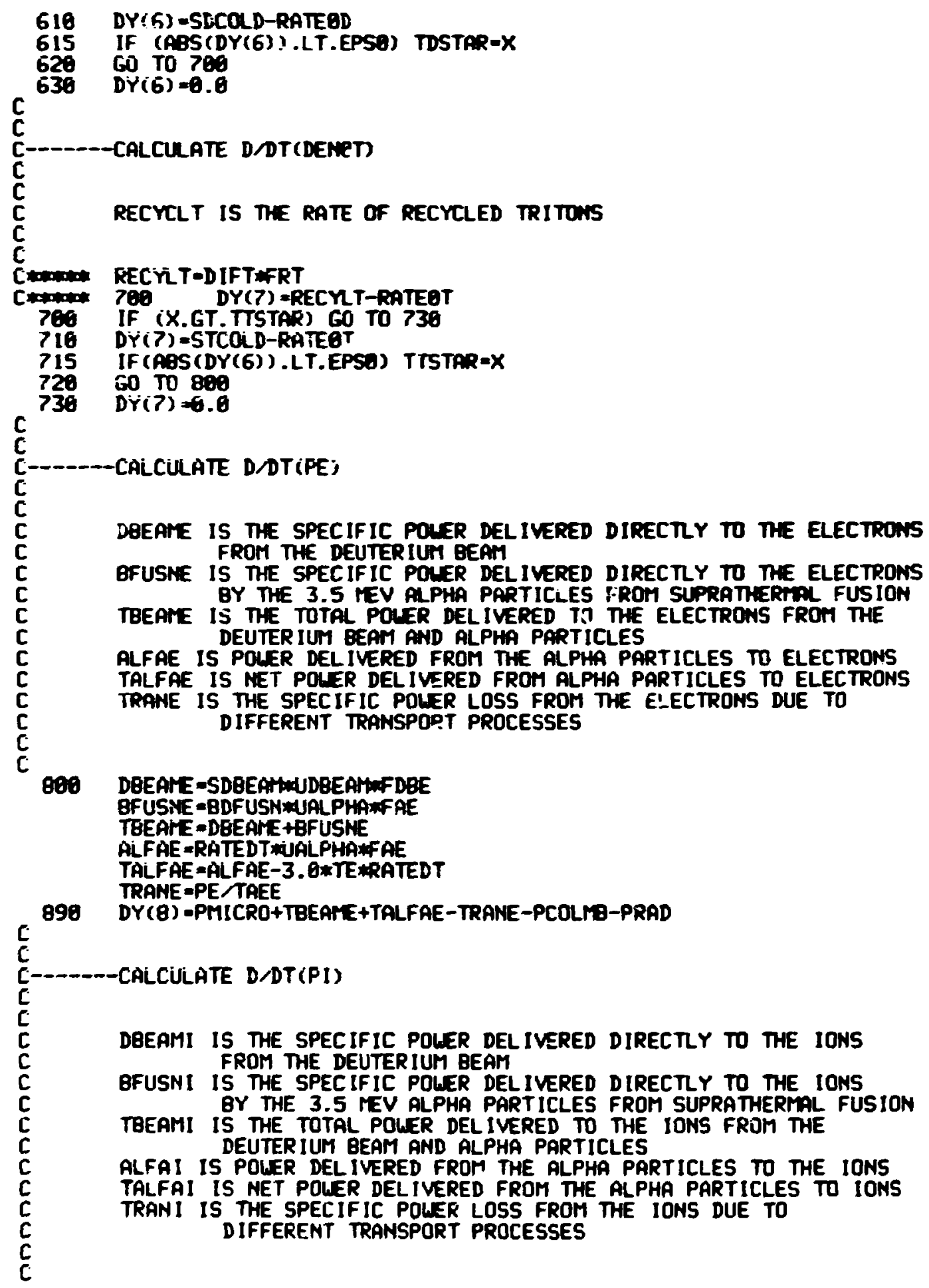




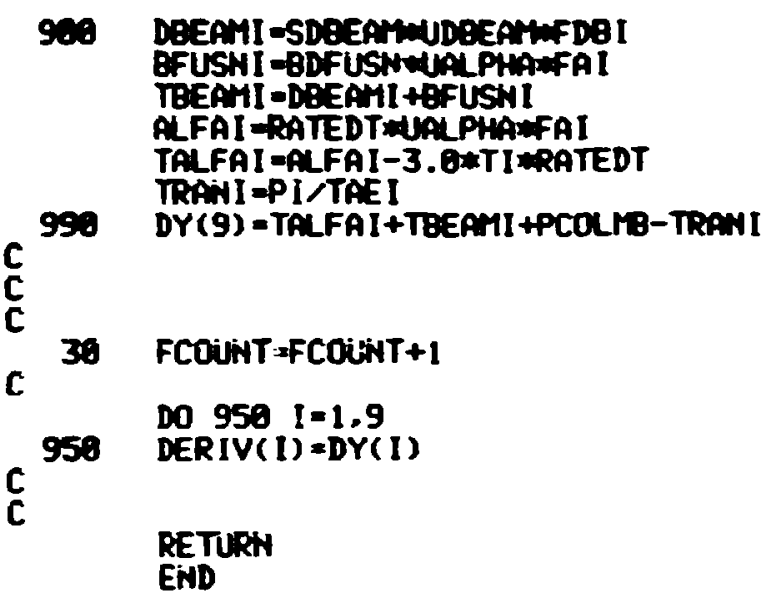




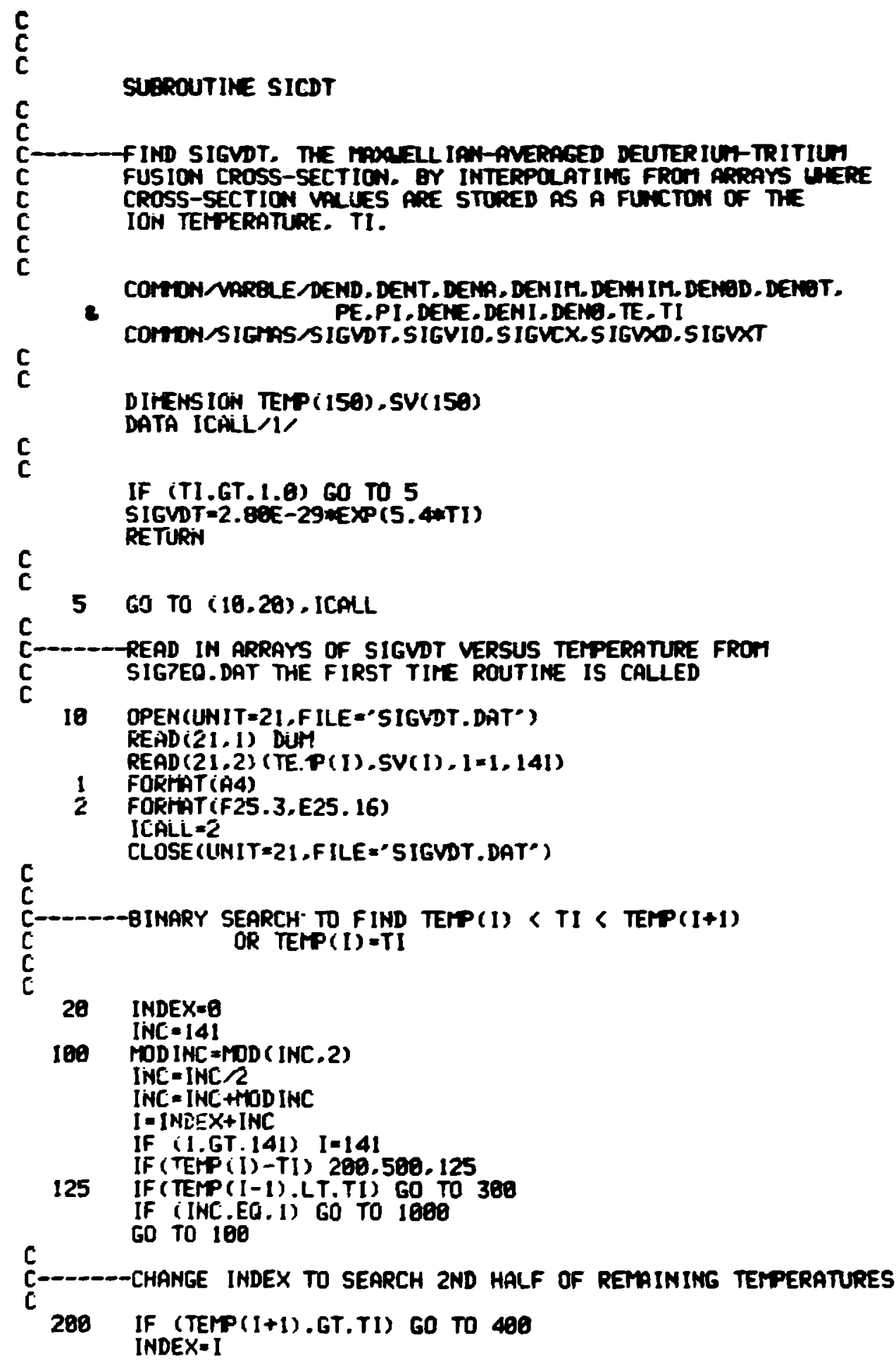




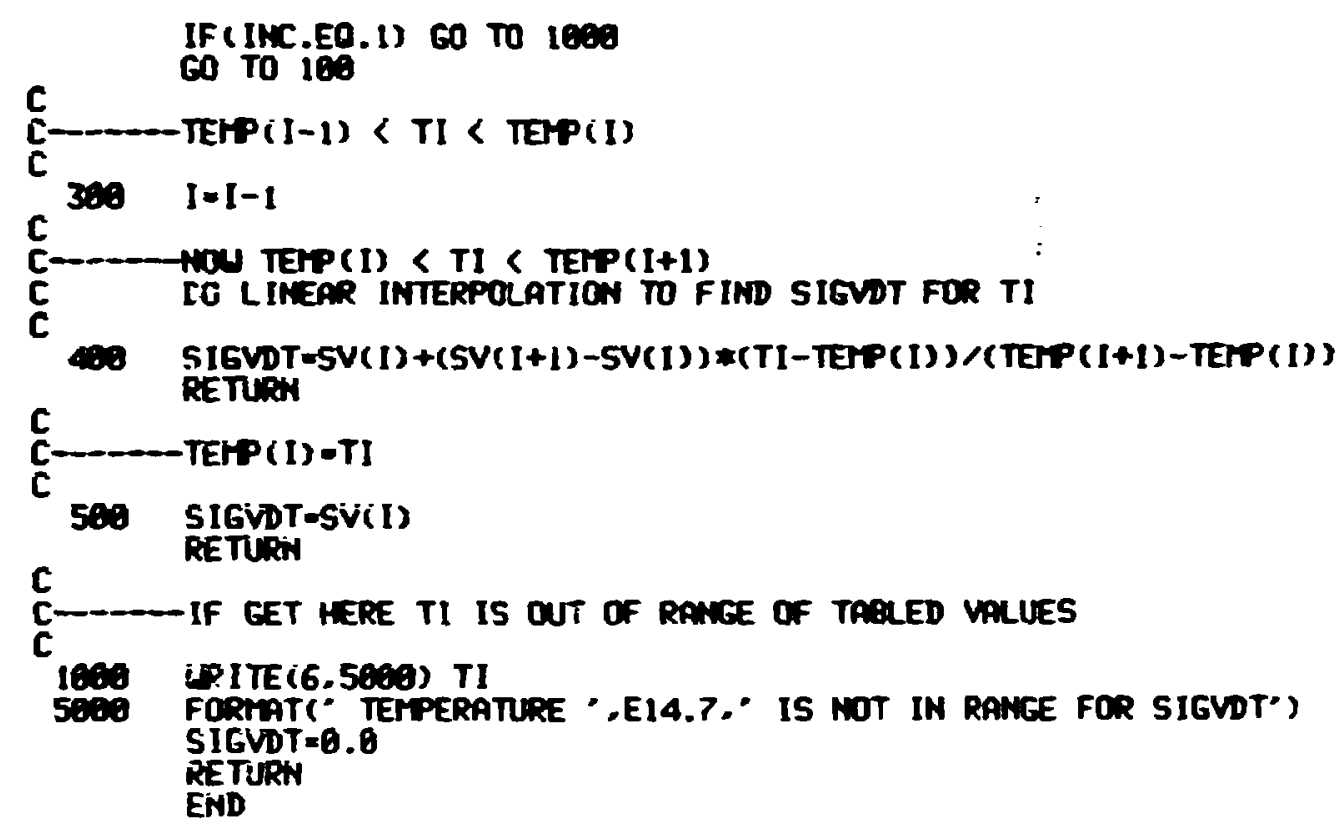




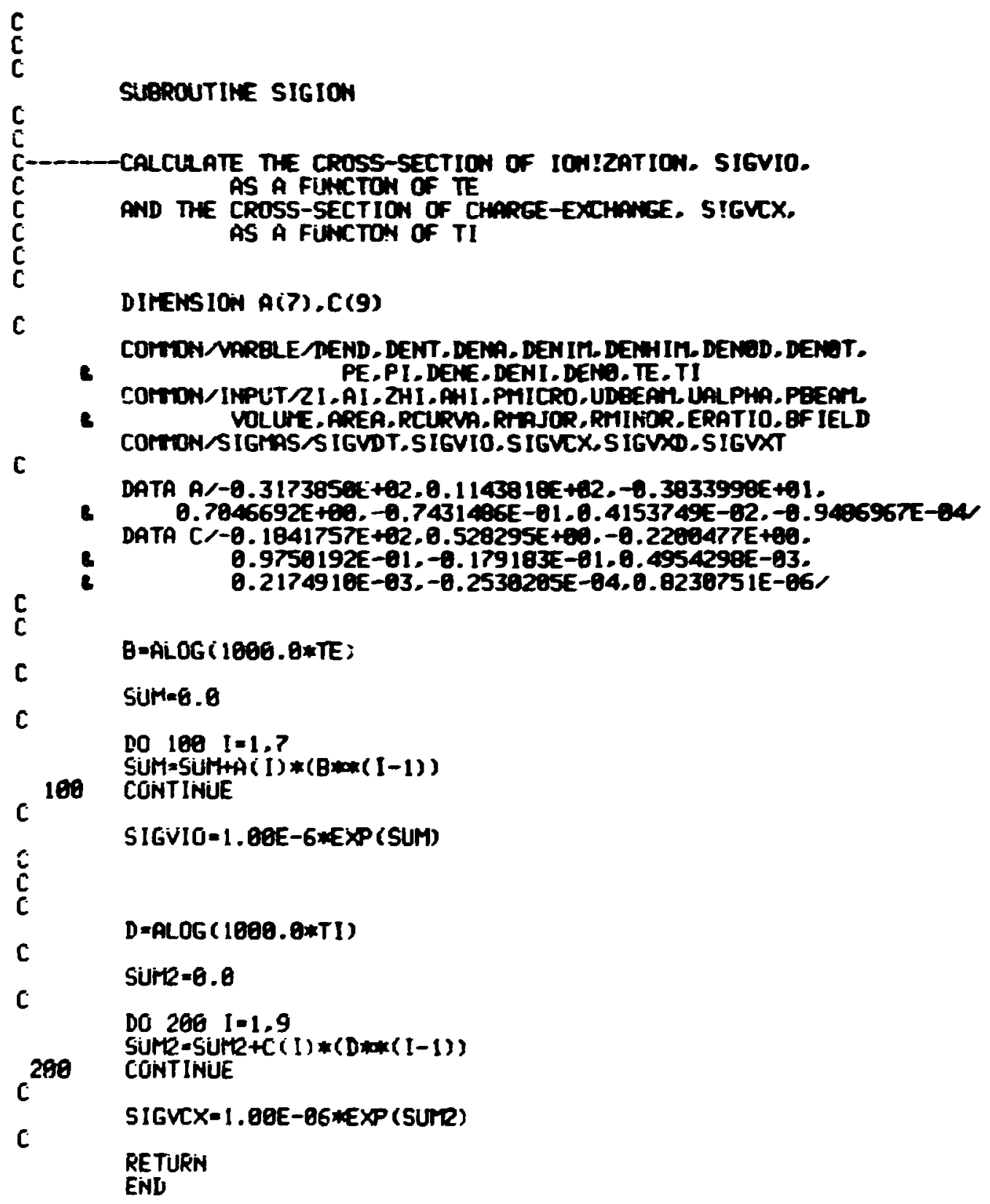




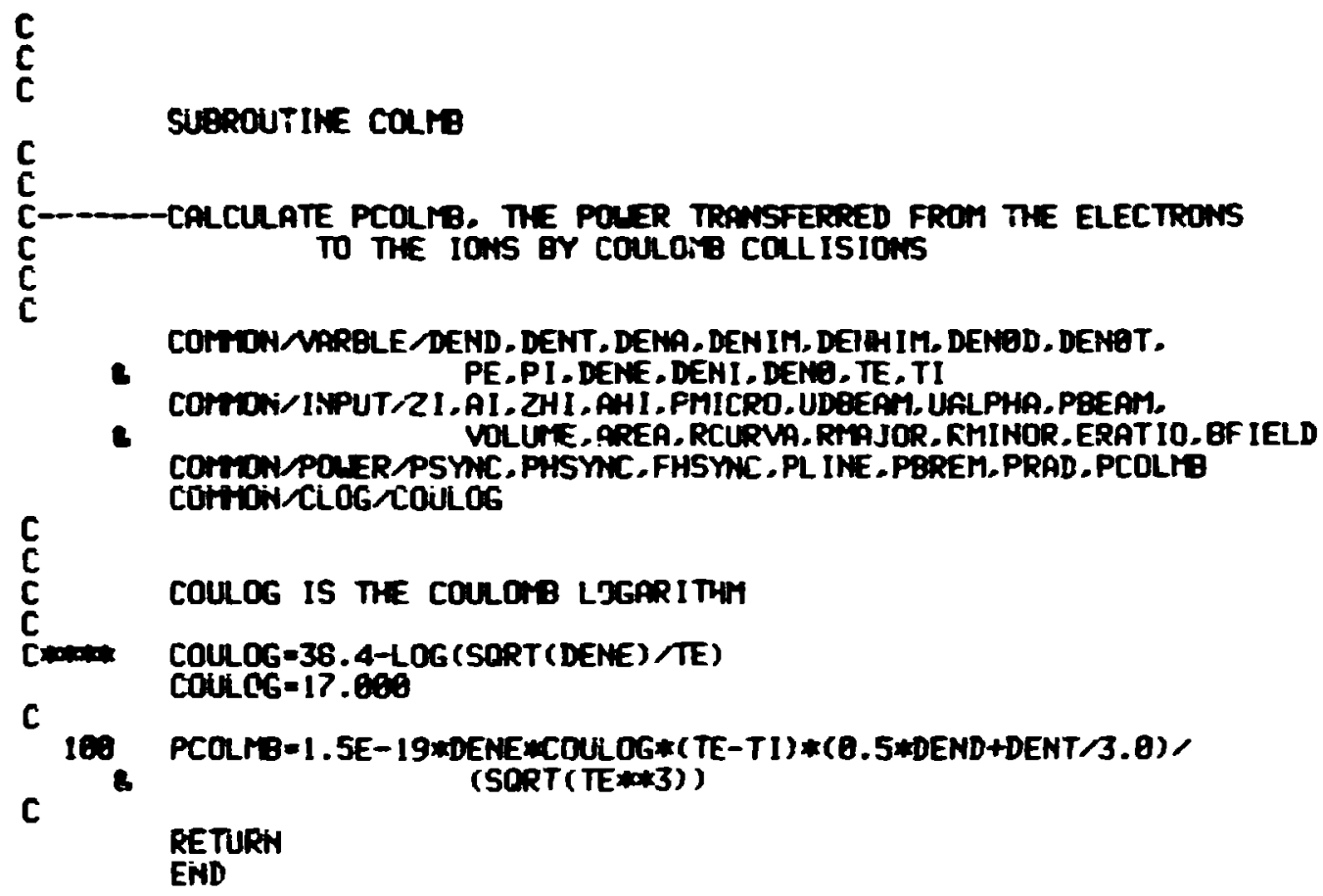




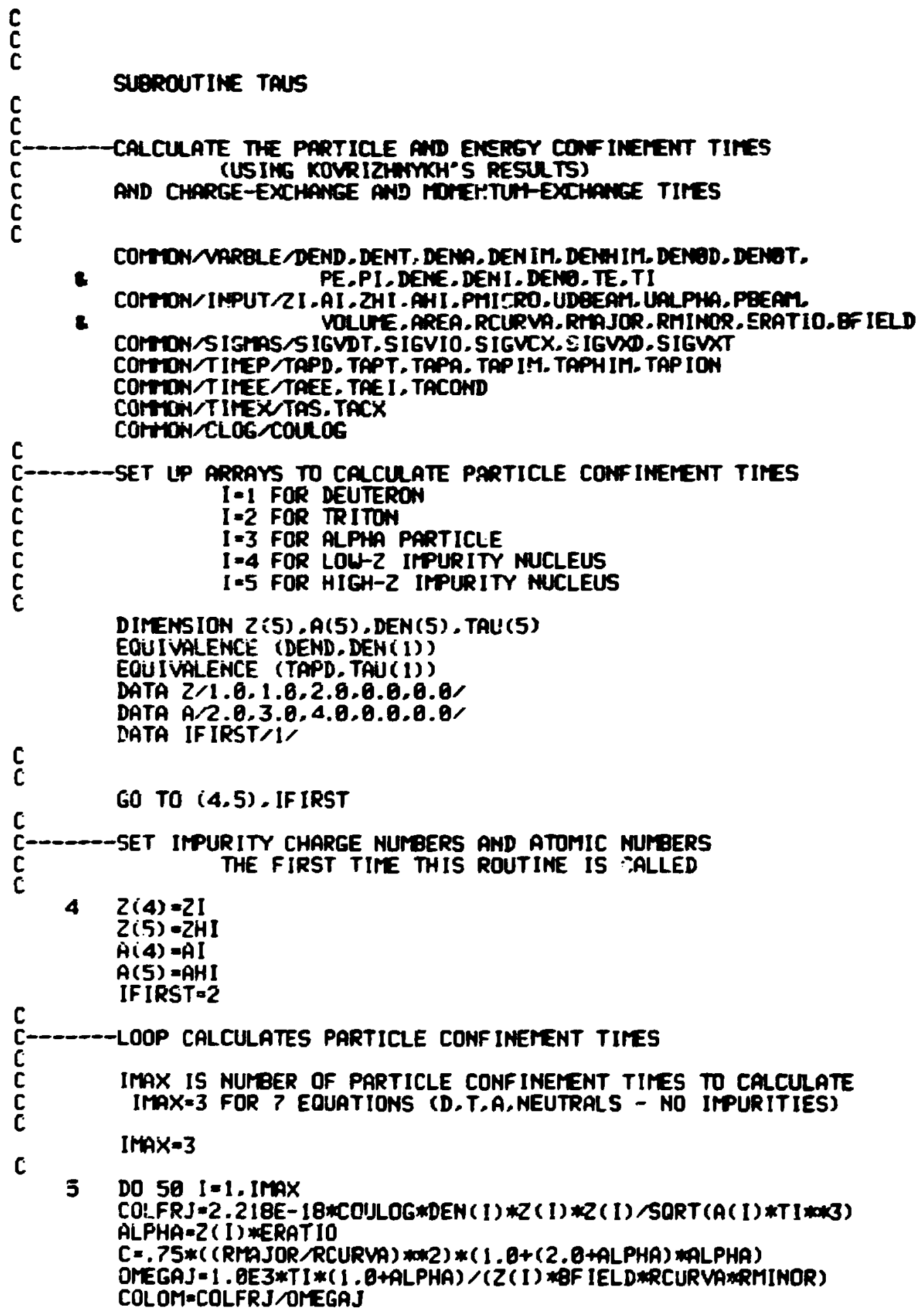




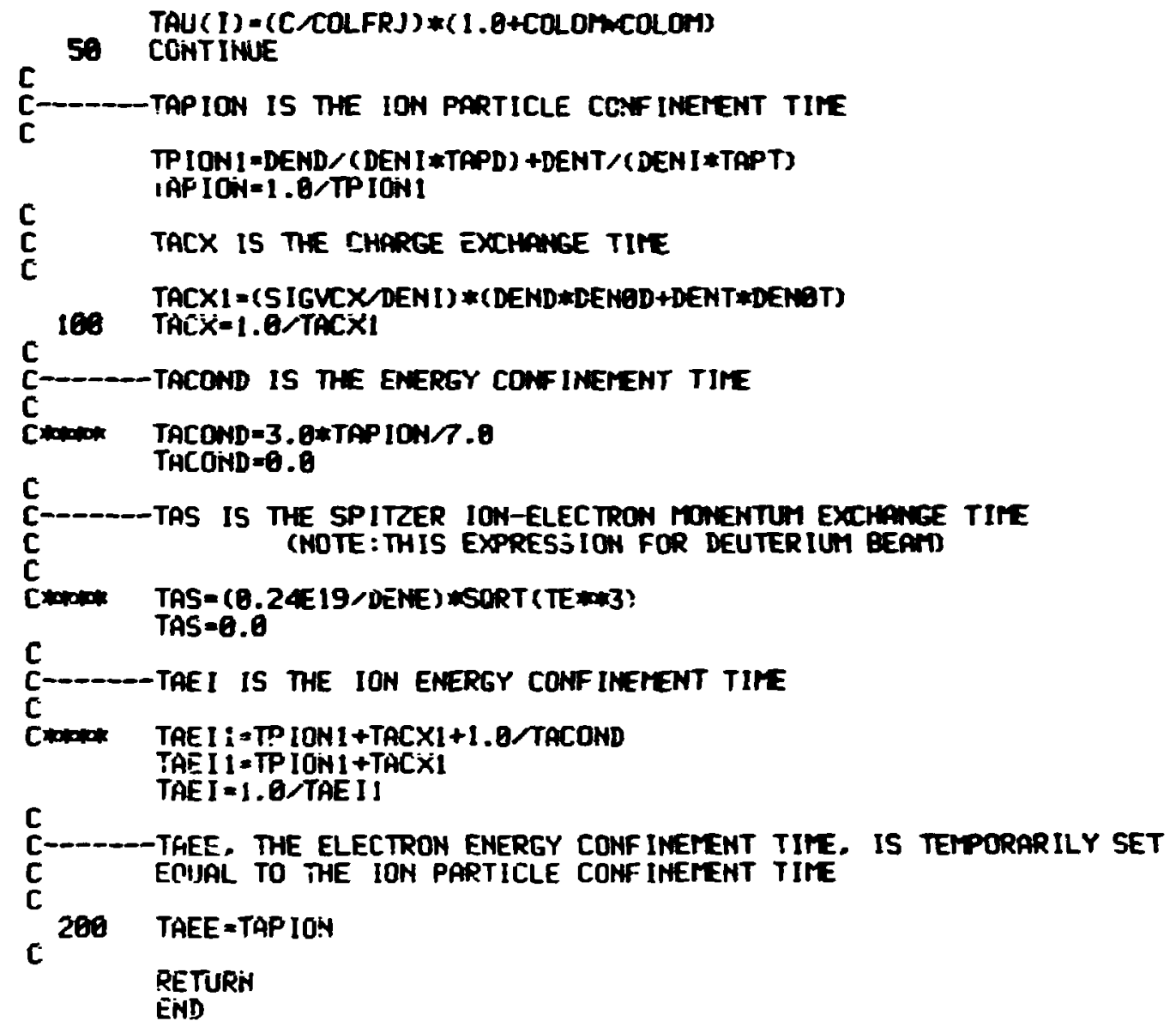




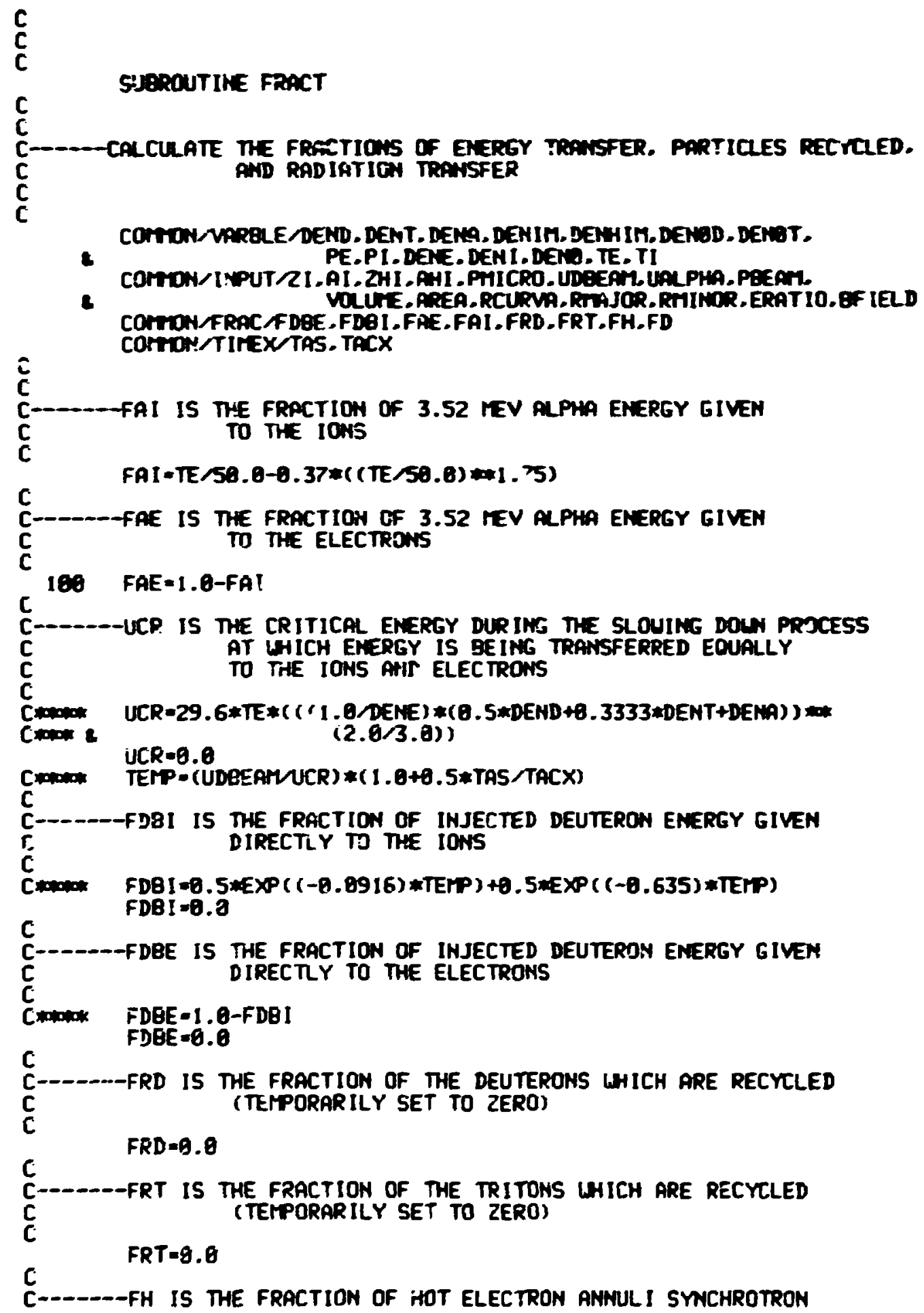


RADIATION TRANSFERRED TO BACKGF:OUNL ELECTRONS (TEMFORARILY SET TO ZFRO)

$F H=0.0$

RETURN

END 


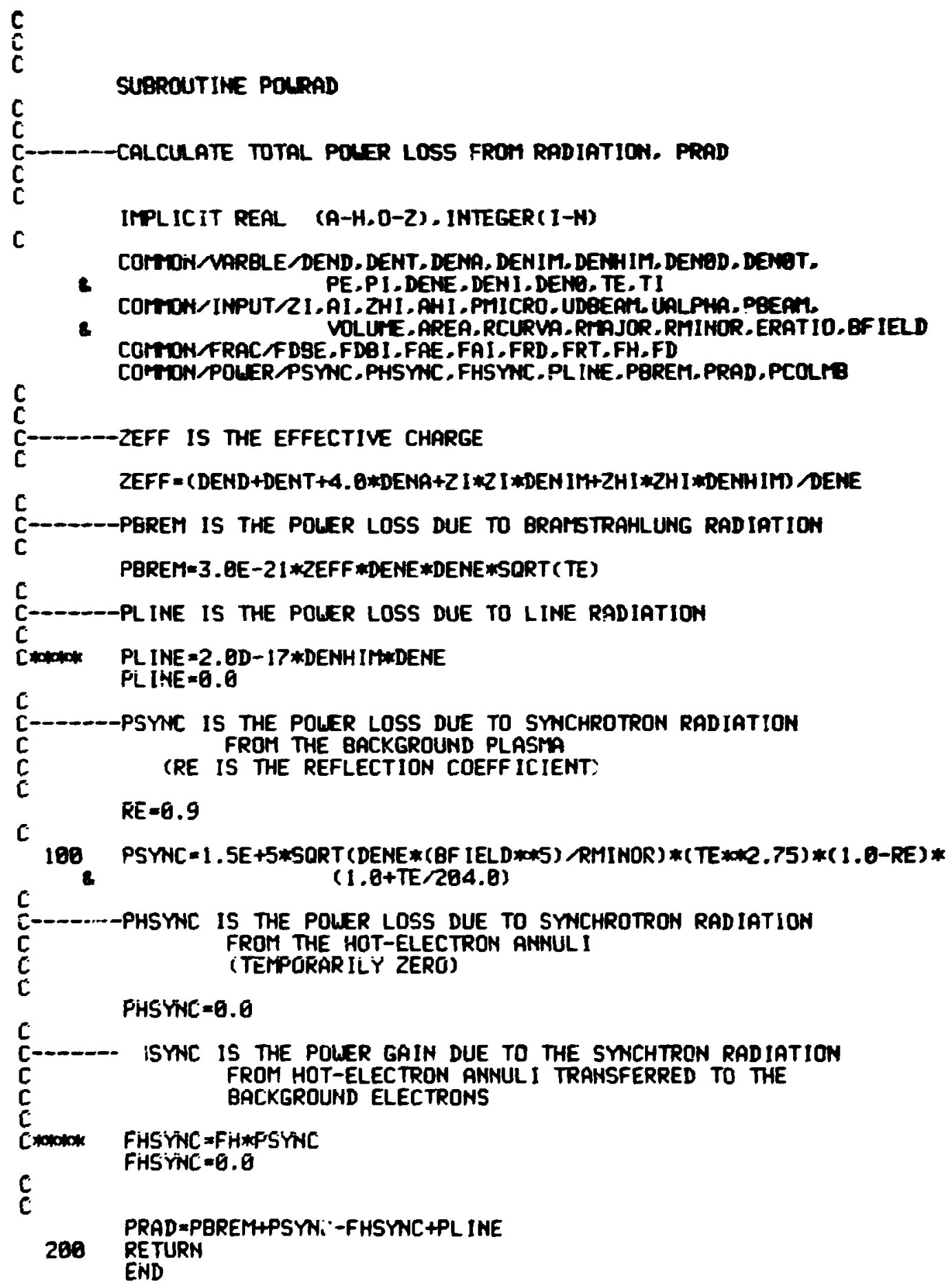




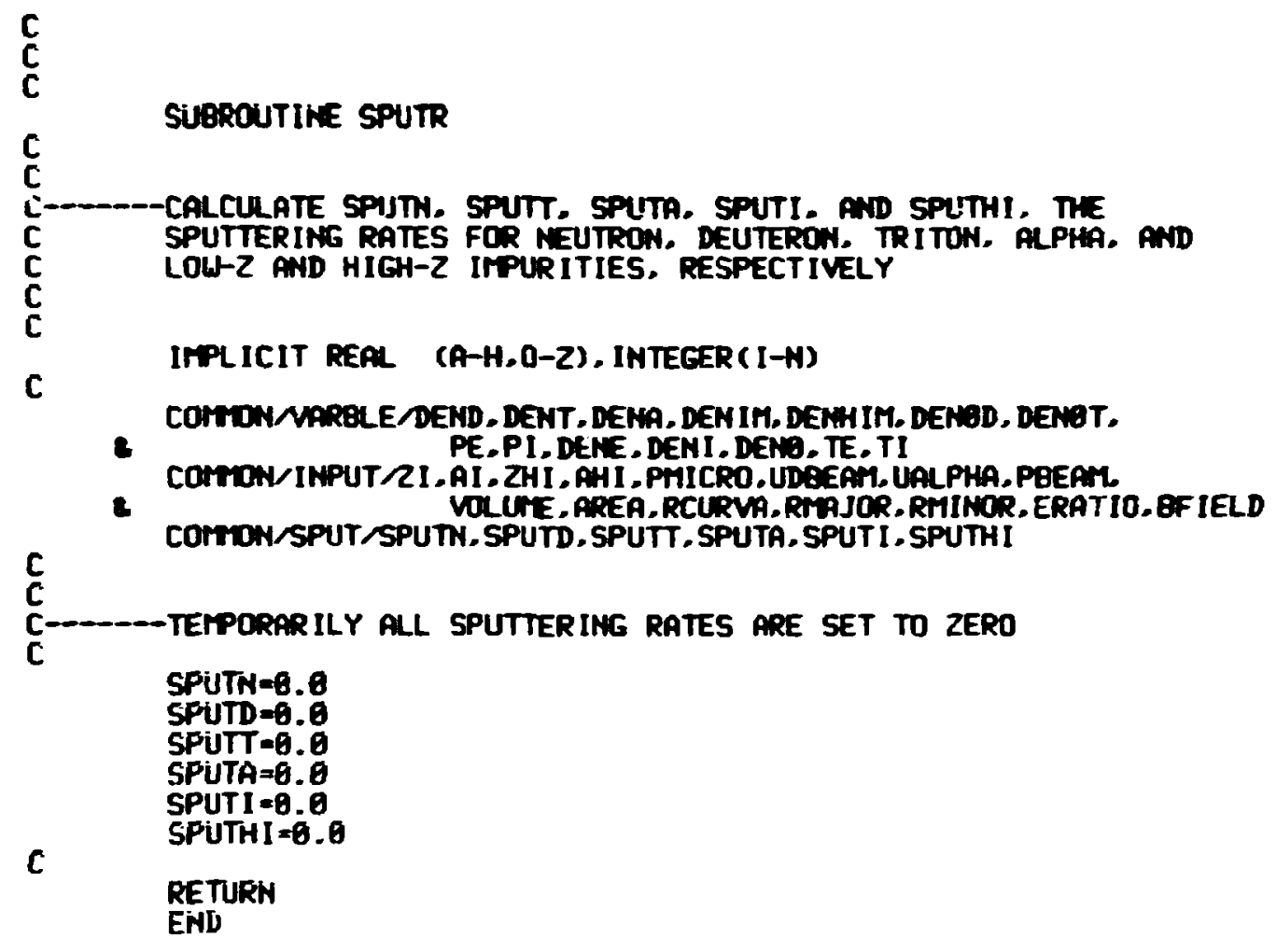




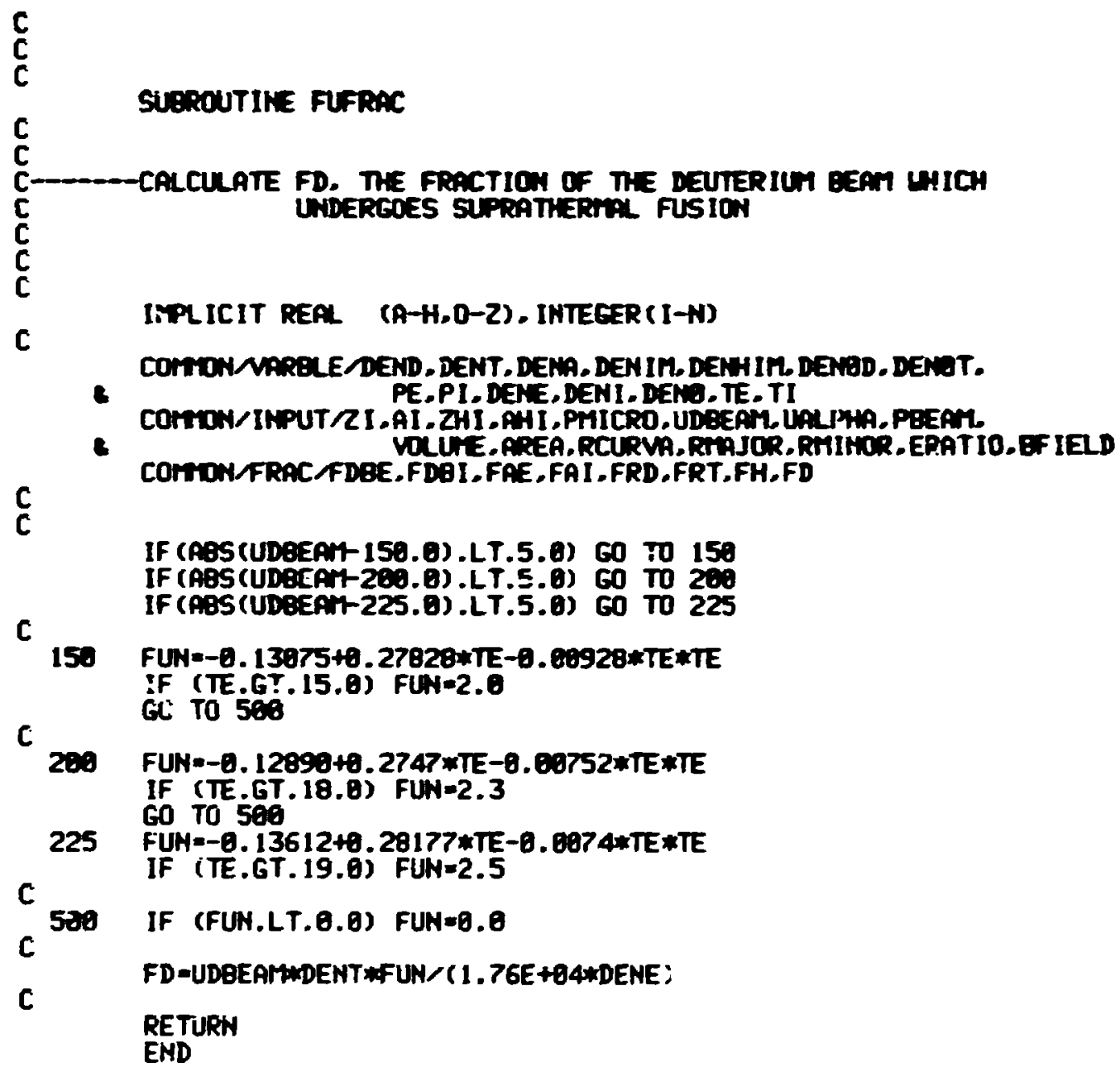


EXTINT.F4 - Source Listing for EXTINT, ERROR

C

$\boldsymbol{c}$

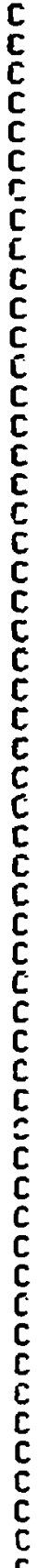

SUBROUTIME EXTINT (MMAX, X, Y, F. H. M MAX, ERROR)

ITPLICIT REPR (A-H,O-Z), IMTEEER $(1-N)$

INTEGER N MAX. M $\operatorname{MaX}$

REAi $\dot{X}_{0}$ ita. Y(intax)

A DEFERRED-LIMIT INTEGRATOR (J.P. BORIS AND N.K. UINSOR)

THIS SUBROUTIME INTEGRATES UP TO 160 SIMULTAMEOUS FIRST ORDER ORD INARY DIFFERENTIAL EQUATIIOHS FROM $x$ TO $x+$ WO BY REPEATED EXTRAPOLATIONS ON A MIDPOINT RULE. UP TO IO EXTRAPOLATIONS MAY BE REOUESTED BEFORE REDUCTION OF THE INITIAL STEPSIZE IS CARRIED OUT. (REF. R. BULIRSCH AND J. STOER - MUERISCHE MATHEMTIK 8.1 (1966)

$\max$

THE TOTAL MUMBER OF DEPENDENT VARIABLES BEIMG INTEGRATED. THERE WILL BE ONE FIRST ORDER EOUATION FOR EACH DEPENDENT VARIABLE.

$x$

THE INDEPENDENT VARIABLE, $X$ IS TREATED AS REAL AND MONOTON IC DUR ING THE INTEGRaTION STEP. THE VALUE OF $X$ ON RETURN FROM "-EXT INT" CONTAINS THE VALUE WHICH IS APPROPRIATE TO THE LENGTH OF THE INTEGRATION ACTUALLY PERFORTED. IF CONVERGENCE HAS BEEN OESERVED IM $M$ MAX OF FELLER EXTRAPOLATIONS. $X$ (AT EXIT) $=X$ (AT ENTRY) + HO. OH ENTRY $X$ MUST BE SET TO THE INITIAL VALUE OF THE INLEPENDENT VARIABLE FOR THE INTEGRATION STEP BEING CONTERPLATED.

THE DEPENDENT YARIABLES. EACH DEPENDENT YARIABLE Y(N) (FOR $N=1,2, \ldots$ MIAX) IS INTEGRATED FROM $X$ TO $X+H$ IF ADEDUATE CONVERGENCE. AS DEF INED BY THE - ERROR"SUBROUTINE, OCCURS IN M MAX OR FELER EXTRAPOLFTIONS.

THE DERIVATIVE SUBROUTINE SUPPL IED BY THE USER FOR HIS PARTICULAR PROBLEM. IT MUST BE OF THE FORM $F(X, Y$, DY) WHERE THE ARRAY DY(N) (FOR $N=1.2, \ldots$ MMAX) IS RETURNED CONTAINING THE NMAX DERIVATIVES (DY (N) DX) $(X, Y)$.

HO

IS THE BASIC STEPSIZE OF THE INTEGRATION. IN CONVERGENCE OCCURS WITHIN MTAX EXTRAPOLATIONS, X RETURNS FROM EXT INT WITH THE VALUE $X+$ HO. THE VALUES IN THE ARRAY Y ARE THE VALUES OF THE DEPENDENT VARIABLES AT THIS VALUE OF $X$. IF CONVERGENCE DOES NOT OCCUR. HO IS HALVED AND THE ENTIRE EXTRAPOLATION PRDCEDURE IS

REPEATED AND REPEATED AGAIN UNTIL CONVERGENCE DCCURS. AN ATTEMPT HAS BEEN MADE TO UTILIZE AS MUCH PREVIOUSLY COMPUTED INFORMATION AS POSEIBLE GHEN HO MUST BE HAL VED FOR CDNVERGENCE.

$M$ MAX

CONTAINS THE MUMBER OF TIMES EXTRAPOLATION IS ATTEMPTED BEFORE HO IS HALVED. THIS VALUE WILL VARY WITH COIPUTER RDLIND-OFF ERROR AND WITH THE TMPE AND MUMBER OF EQUATIONS BE ING INTEGRATED. IN ALL CASES. HOLEVER, DNE SHOULD SPECIFY AN M MAX ' $G O$ ' 2 . THE STEPSIZE FOR FUTURE ITERATIONS IS SELECTED AND RETURMED IN HO. THIS NEW VALUE IS CHOSEN SO THAT CONVERGENCE WILL BE OBSERVED AT ABOUT THE 0.65*THAX-TH EXTRAPOLATION. AS LRITTEN, MAX.LE.10. 


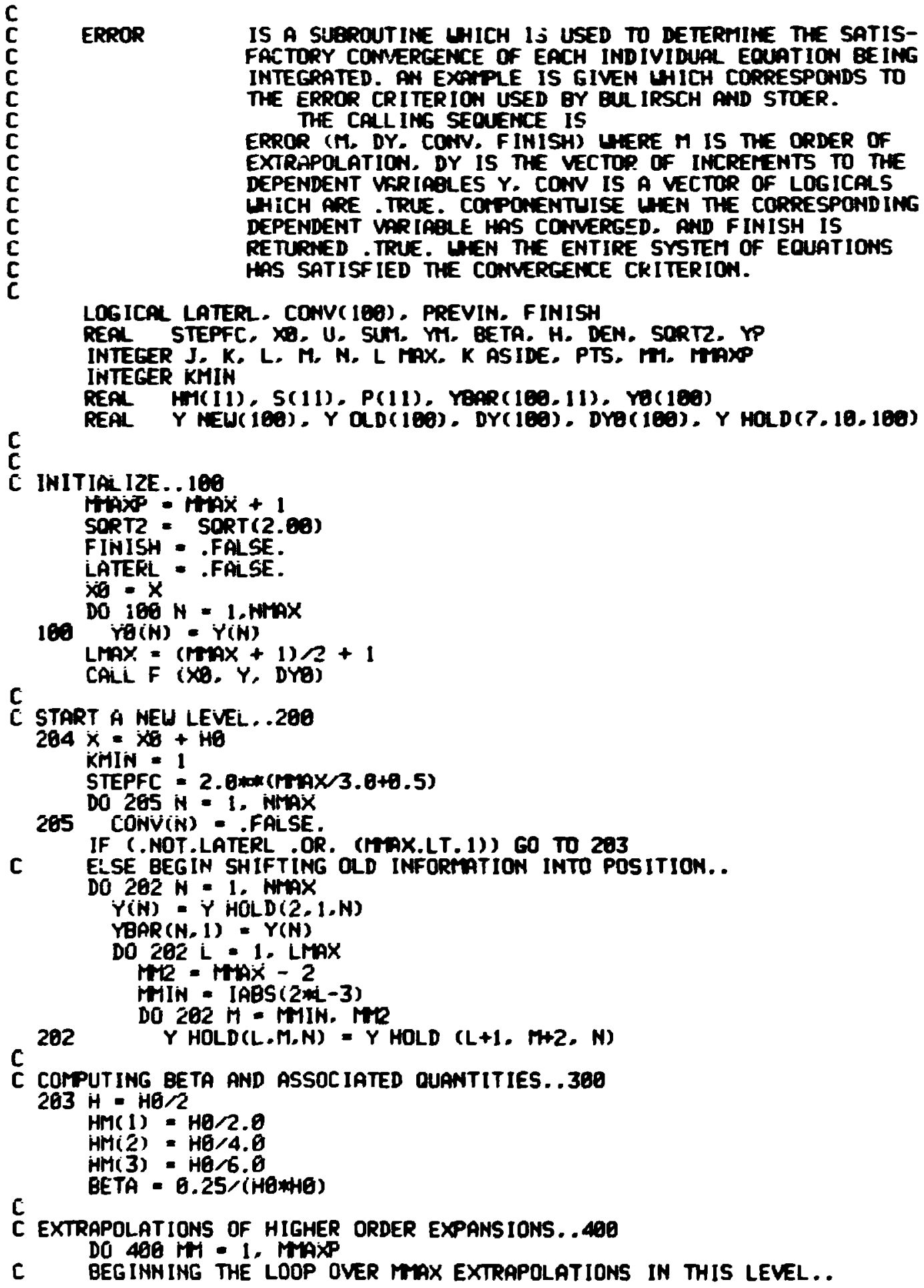




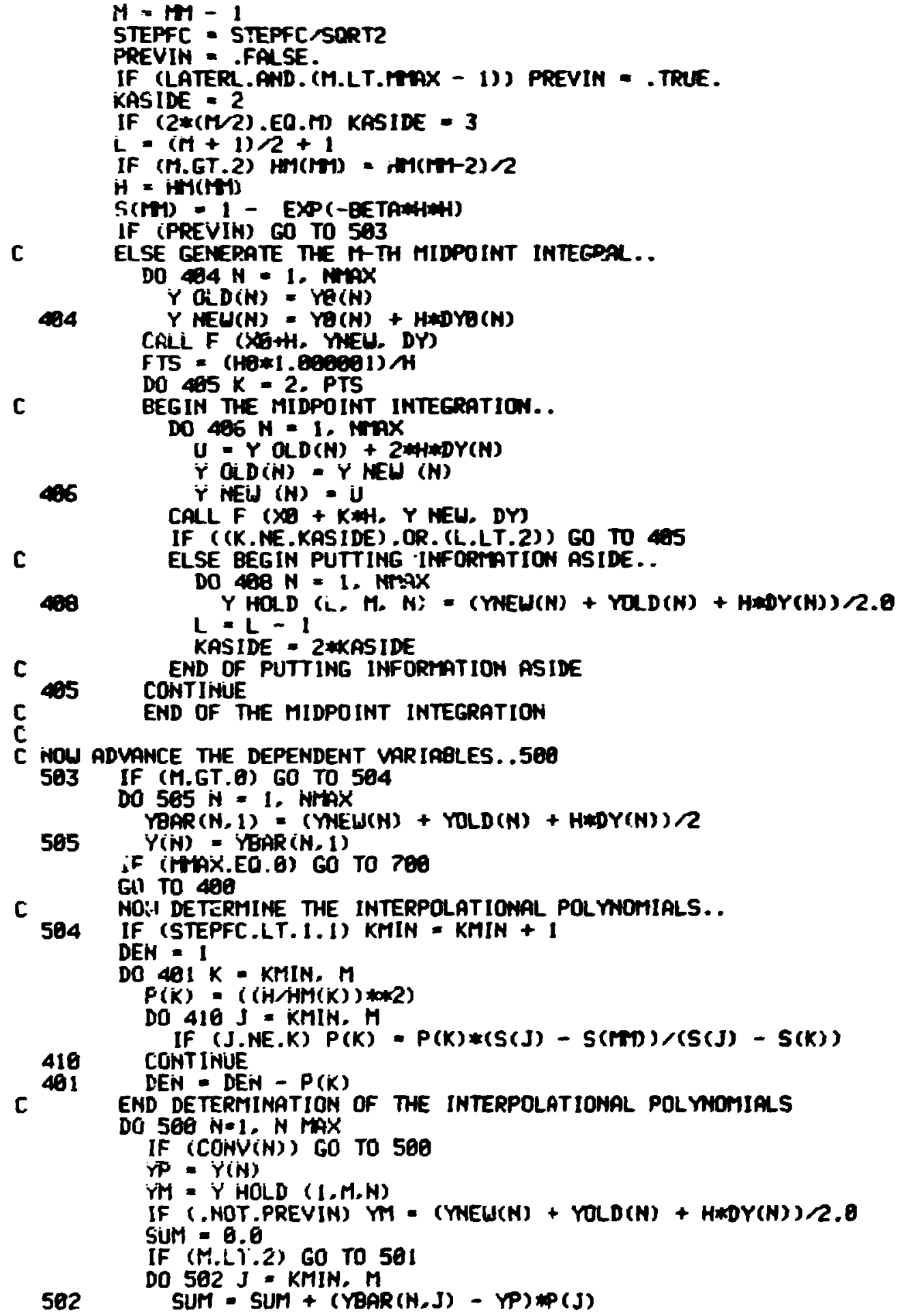




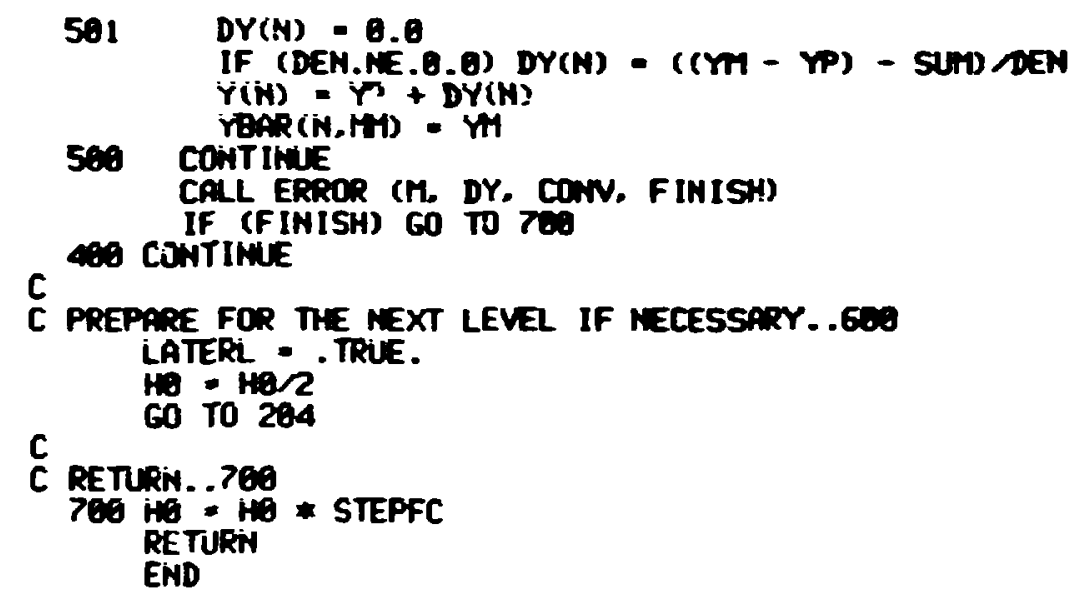




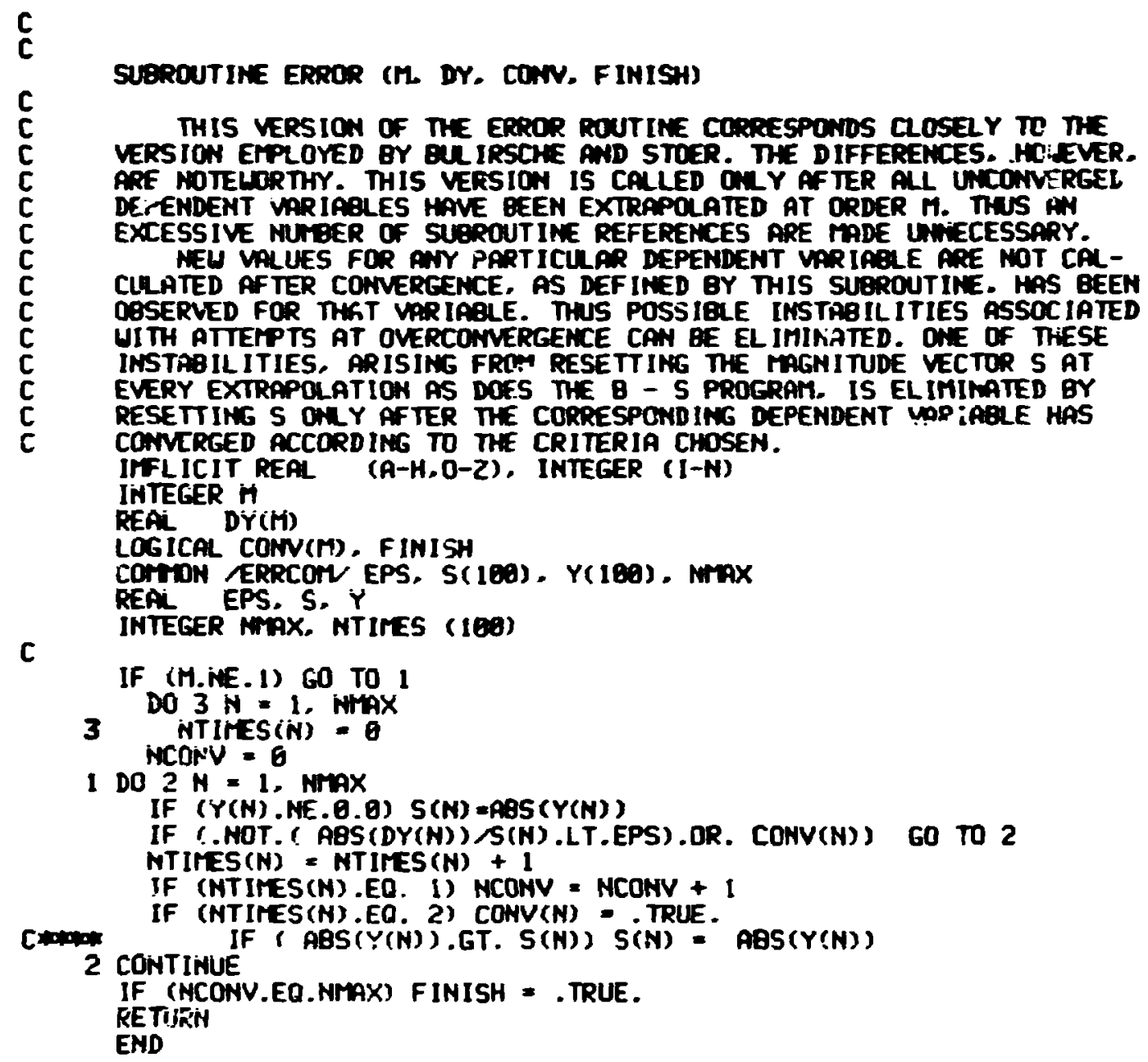


TERPERATURE, KEV 1.000

1.280

1.400

1.660

1.800

2.000

2.200

2.400

2.680

2.800

3.600

3.260

3.400

3.600

3.800

4.600

4.200

4.480

4.680

4.800

5.600

5.260

5.490

5.600

5.800

6.800

6.200

6.400

6.600

6.800

7.909

7.200

7.400

7.698

7.800

8.080

8.200

8.400

8.689

8.800

9.000

9.200

9.400

9.600

9.800

10.000

12.090

14.000

16.000

18.000

28.000

22.090

24.000

26.000

28.000

30.000

32.000

34.000
SIGMaV FCR DT. The3/SEC (MAR. 24.75)

0.6269999990200000E-26

0. 18660001100000 aE-25

$0.4439999990000000 \mathrm{E}-25$

0.3110000000000000 E-25

$0.1670020009000000 E-24$

$0.2830000010000000 \varepsilon-24$

$0.4470000020000000 E-24$

$0.67200000000000005-24$

$0.9669999960000000 E-24$

O. $13399999900000005-23$

0. $1818000018000000 E-23$

$0.2380000016000000 E-23$

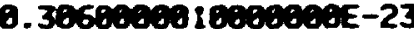

$0.3860000000000000 E-23$

$0.4790000000000000 E-23$

$0.59599999900000005-23$

$0.7070000016000000 E-23$

0.842999995000000.2-23

$0.9950000020000000 E-23$

0. $1168000000000000 E-22$

Q. $1349999990002000 E-22$

$0.1550000000000000 \mathrm{E}-22$

B. $1769999990009000 E-22$

$0.2000000000000000 E-22$

$0.2260000000000000 \mathrm{E}-22$

0.25380009 1G000000E-22

$0.2810000010000000 \mathrm{E}-22$

0.31 199999a98agaage-22

$0.3439999990000000 E-22$

0.3779999990000000E-22

$0.4148000918000000 E-22$

$0.4519999990000000 E-22$

$0.4910000000000000 E-22$

0.5310900018000080E-22

$0.5739999968000000 E-22$

0.6170000900009000E-22

$0.6630000020000000 E-22$

0.7090000040000000E-22

0.7569999970909090E-22

$0.8069999970009000 E-22$

0.8569999978009000E-22

0.9090000040000009E-22

$0.9620000020000000 \mathrm{E}-22$

0. 102909a9ag9a9agaE-21

0.1070000000000000E-21

6.1130000000000000E-21

อ.17498ดดดดดดอดดดอE-21

$0.2389999990000000 E-21$

$0.3860000000900009 E-2$

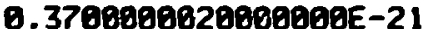

$0.4309999990000000 E-21$

0. 4880000020000000E-2I

$0.5389999990000000 E-21$

$0.5859999970000000 E-21$

0.6279999998080008E-21

$0.6649999990000000 \mathrm{C}-21$

B.6980000010000000E-21

$0.7269999980000000 \mathrm{E}-21$ 
$12-3008080866666651 \varepsilon^{\circ} \theta$

$808 \cdot 809$

$12-30000000666666 \mathrm{i} 2 \varepsilon^{\circ} \cdot$

$000^{\circ} 829$

$12-3000000066,0666 \angle 2 \varepsilon^{\circ}$

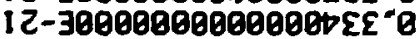

$000 \cdot 009$

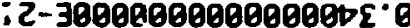

$800^{\circ} 085$

I $2-30008060180800 \angle \nabla \varepsilon^{\circ} B$

$600^{\circ} 095$

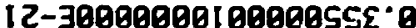

$800^{\circ} B 05$

$000^{\circ} 025$

IZ-30000080000000ع9\&.0

$060^{\circ} 005$

1 $\mathrm{c}-300000000000081<\varepsilon^{\circ}$

B80.

I 2-380080801 808001 BE 0

I 2 -300000080000001 $6 \varepsilon^{\circ} 0$

$000^{\circ} 095$

$000 \cdot 000$

$880^{\circ} 826$

1 $12-380000006666662$ it.

$12-30090808 \angle 66566520 \cdot 0$

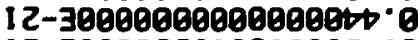

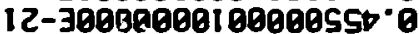

$12-38908080 \angle 666661 \angle t^{\circ} \theta$

1 $2-3808008086666668 b^{\circ} \cdot 8$

I 2-398080902808060 Is.

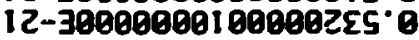

$12-38808088888980 \angle 55^{\circ} \mathrm{O}$

$12-30008008666666885^{\circ} 0$

$12-38880808666666519^{\circ} 0$

$12-300000008666666 \nabla 9^{\circ} 0$

I 2 -38в08808880888689.0

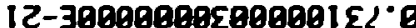

$12-38000000 \varepsilon 00000 \angle \angle 2 \cdot 0$

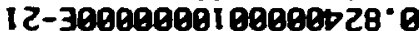

$12-30000000 \angle 66666828^{\circ} \mathrm{B}$

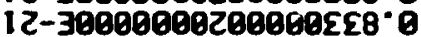

I $2-30900909088908 \angle \mathbf{2 8}{ }^{\circ} \mathrm{O}$

$12-30080000260800208^{\circ} 0$

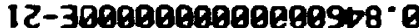

:?-300000008666666\$8 $\cdot \mathrm{B}$

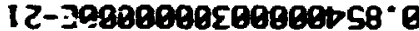

IZ-30380000 $666666958^{\circ} \mathrm{O}$

I $12-30000000100000198^{\circ} \mathrm{C}$

$12-30000000566666598^{\circ} \mathrm{O}$

$12-360090001$ 1 8P000 $298^{\circ} \mathrm{O}$

$12-30900009566666698^{\circ} \mathrm{C}$

$12-300000000000002 \angle 8^{\circ} \mathrm{B}$

$12-30000000000000 \mathrm{~b} \angle 8^{\circ} \mathrm{O}$

$12-300000009666665 \angle 8^{\circ} \mathrm{O}$

$12-30000000900000 \angle \angle 8^{\circ} \mathrm{B}$

$12-300090000000098 \angle 8^{\circ} \mathrm{a}$

$12-300000000000008 \angle 8^{\circ} 0$

$12-30900009909090 \angle \angle 8^{\circ} 0$

$12-30000809966666518^{\circ} \mathrm{O}$

$12-30000000000800128^{\circ} \mathrm{B}$

I2-30080809566666699. $\mathrm{B}$

$12-30000000 \varepsilon 00000998^{\circ} \mathrm{O}$

12-309808091 Bopegl $98^{\circ} \mathrm{E}$

$12-30600000200000658^{\circ} \mathrm{O}$

$12-38080600200000508^{\circ} \mathrm{C}$

$12-32080009866666 b \varepsilon 8^{\circ} \theta$

12-30000000 $66666228^{\circ} \mathrm{B}$

$12-38000000008009608^{\circ} \mathrm{O}$

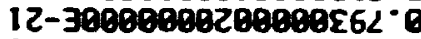

12-38000009580000\$ $\angle L^{\circ} 0$

I $2-308 B 068 B \angle 66666 I^{\circ} L^{\circ} \theta$

$800^{\circ} 00 \mathrm{P}$

$800^{\circ} .882$

$B 80^{\circ} \cdot 69 \varepsilon$

$000 \cdot 602$

$680^{\circ} 825$

$B 80 \cdot 8 B 2$

Boe. 082

880.092

$880^{\circ} 8 b^{\circ}$

$000^{\circ} 022$

$880^{\circ} 802$

$090 \cdot 081$

B08. 091

$B 00^{\circ} \mathrm{BP}$

$B Q 0 \cdot B Z I$

B80. 881

$B B B^{-86}$

$B 80.96$

$000 \cdot 66$

$800^{\circ} 26$

$800^{\circ} 06$

$000 \cdot 88$

808. 98

$000^{\circ}-8$

$600 \cdot 28$

608. 88

$600^{\circ} \mathrm{B}$

$000 \cdot 92$

$800^{\circ} \checkmark 2$

$000 \cdot 22$

$000^{\circ} \mathrm{CL}$

$800 \cdot 89$

$800^{\circ} 99$

$000^{\circ}-9$

$000^{\circ} 29$

600.09

809-85

$000^{-95}$

$000-05$

$000^{\circ} \mathrm{ZS}$

000.05

$080^{\circ} 8$

800.98

$000^{\circ}$.

$800^{\circ} 2$

$000^{\circ} \mathrm{O}$

$080^{\circ} 8 E$

$000 \cdot 9 \varepsilon$ 
660.880

680.800

780.080

728.080

740.008

760.000

780.880

800.080

820.000

$\forall 40.888$

860.000

880.008

980.008

920.000

940.808

960.000

980.000

1080.000

1820.000

1040.000

1860.808

1080.800

.100 .800

0.31160800808009080E-21

0.30700000 18000000E-र̂́

0.3019999990000000E-21

$0.2980000018000008 \mathrm{E}-21$

0.2940000000000000E-21

$0.2900000020000000 E-21$

$0.28600000000008000 \mathrm{E}-21$

B. ?830000006000000E-21

B. $2789999390000000 E-21$

0.2759999990090080E-21

$0.2729999990000000 \mathrm{E}-21$

$0.2780000028009000 E-21$

$0.2679999990000000 \mathrm{E}-21$

$0.2649999990000000 E-21$

$0.2619999990000000 \mathrm{E}-21$

9.2600000000000000E-21

$0.2580000010080000 \mathrm{E}-2$ !

0. $2550006010000000 \mathrm{E}-21$

$0.2549996284006031 \mathrm{D}-21$

$0.2549996284026031 \mathrm{D}-21$

0.254999628408603 ID-21

0.254999628400603 ID-21

0.254999628400683ID-2: 
DIS7EQ.F4 - DISSPLA Plotting Program Source Listilig

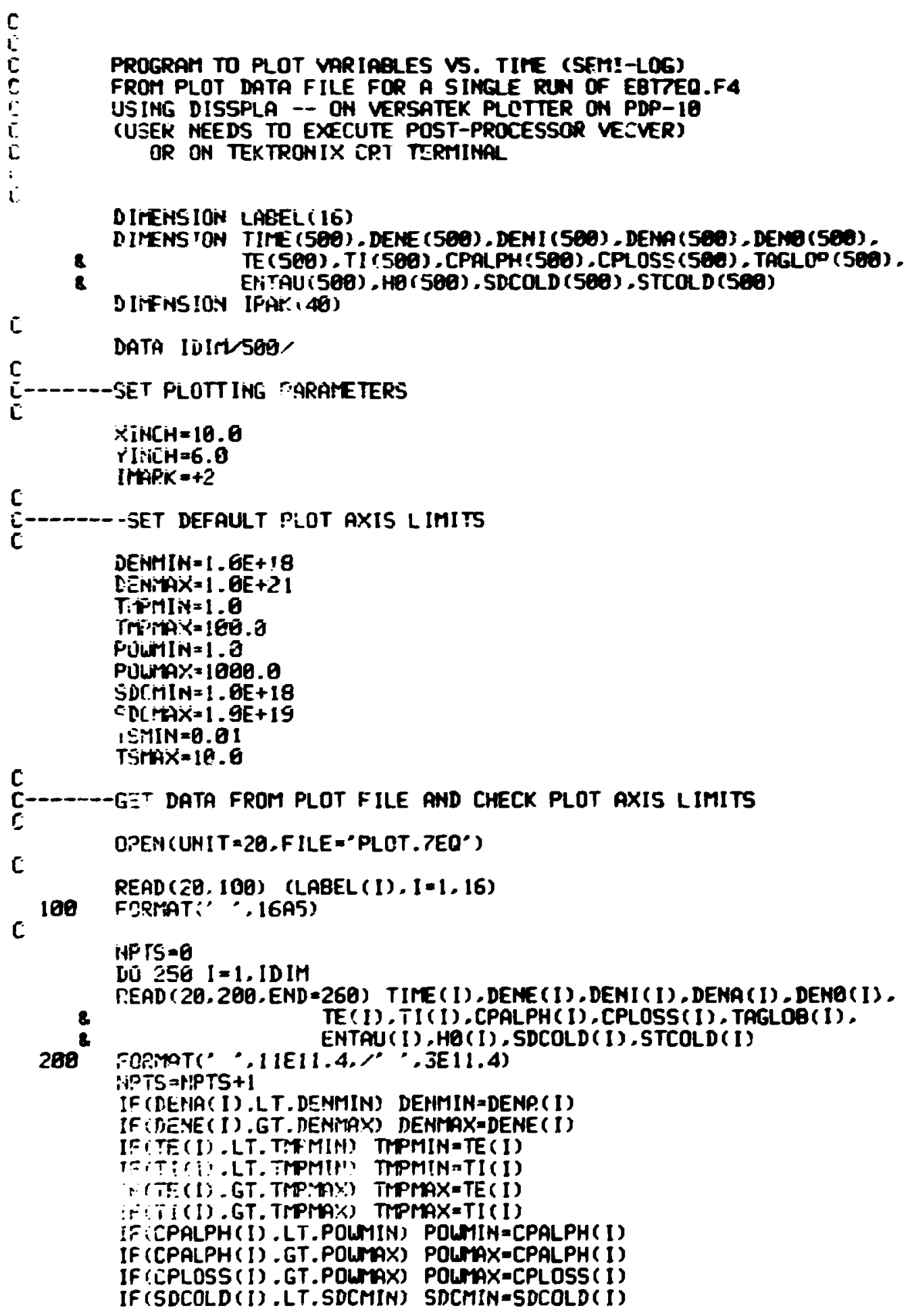




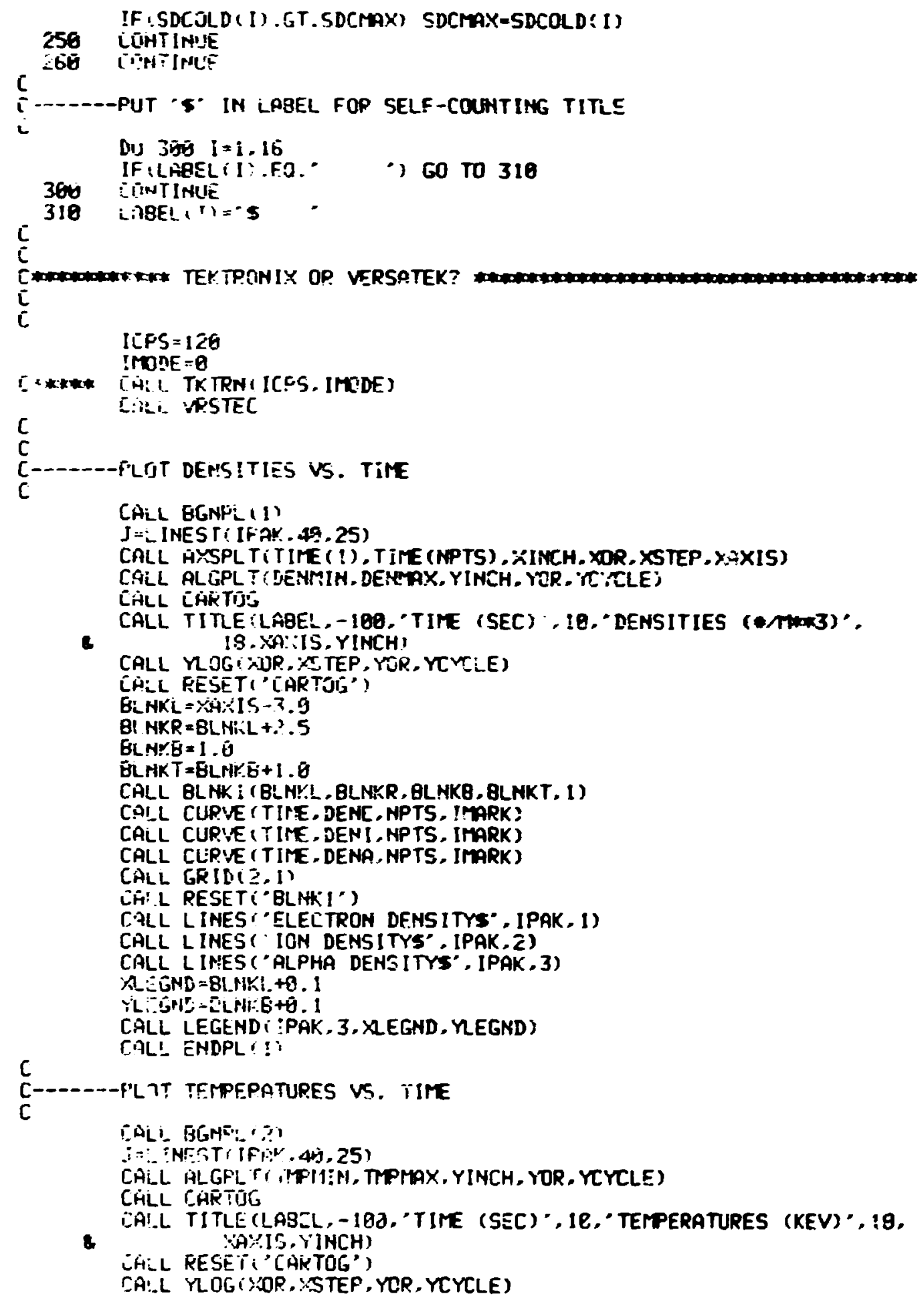




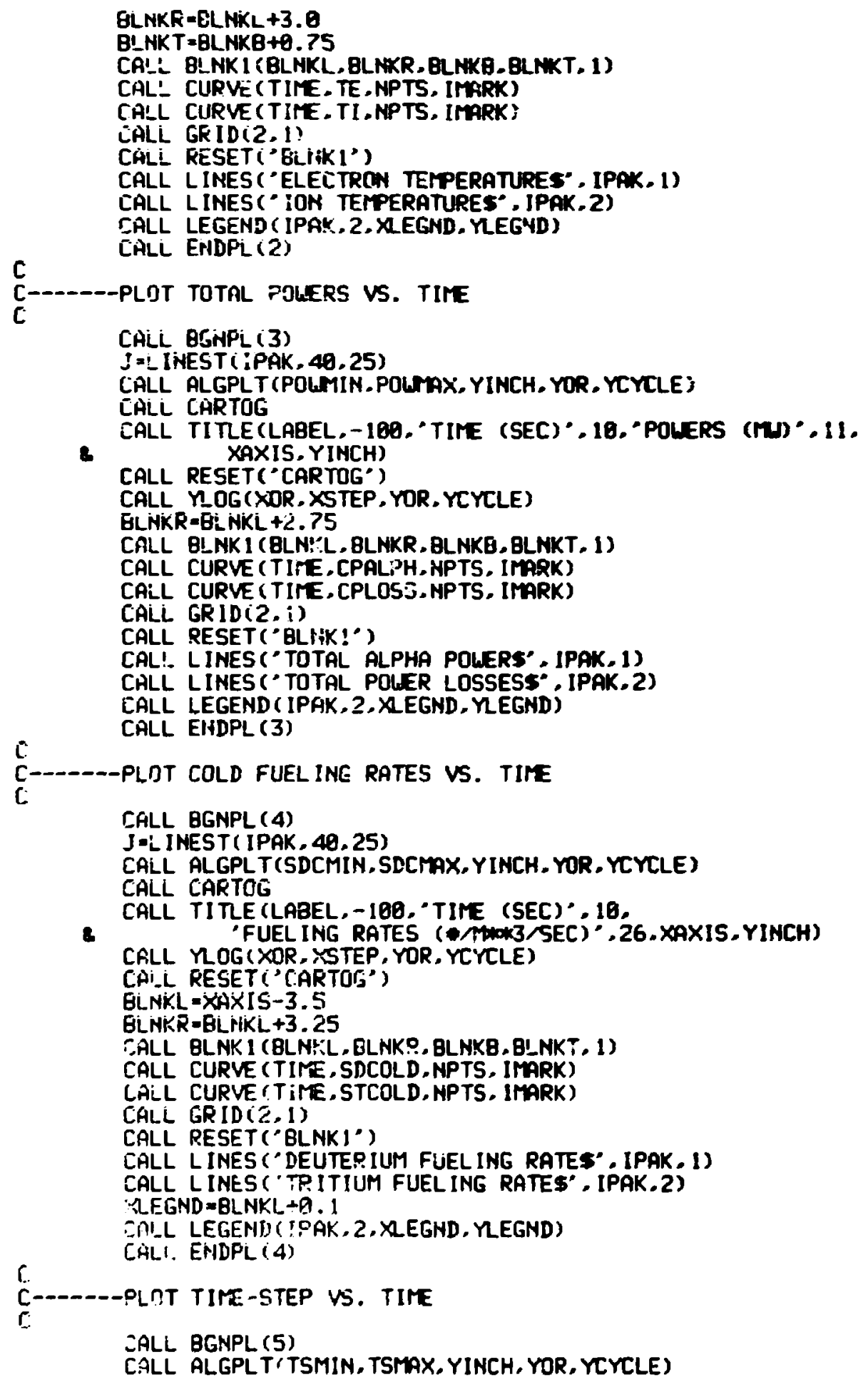




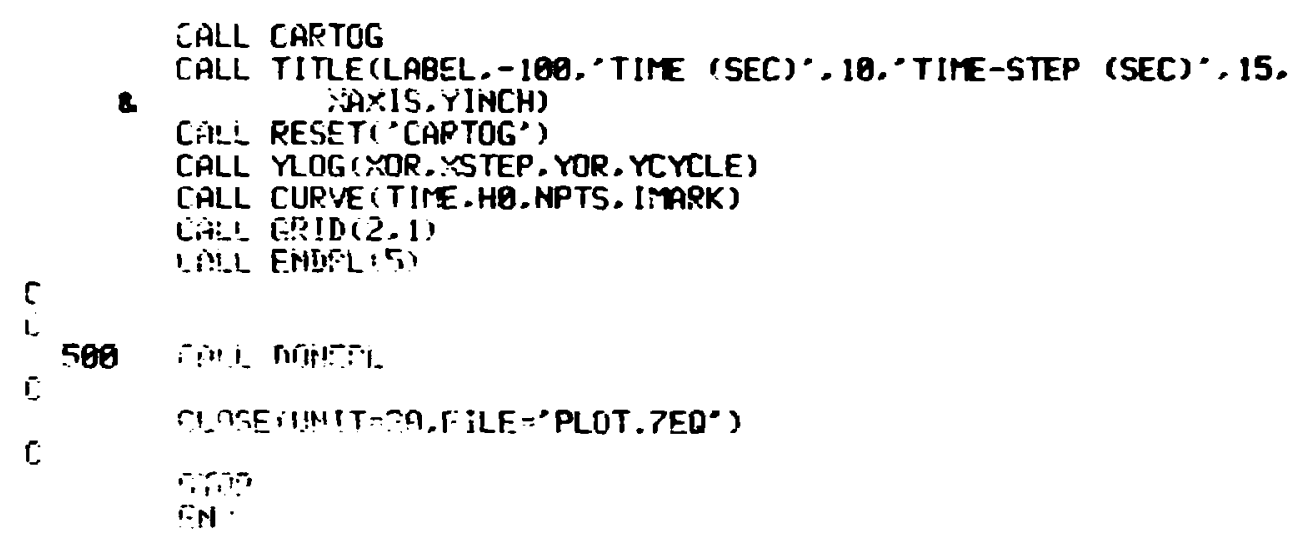


DISVEC.CHD - Linkage Command File for Versatek Plots

DSKC: PLOTS. REL $[10,100]$, DSKC \& PLOT. REL $[10,100]$, DSKCIVECW. REL $[10,100]$, DSKC: FFEED. REL $[10,100]$, DSKCIQQVTEC. REL 10,100$]$, DSKCILIB. REL $[10,100]$, SEA, DSKC:

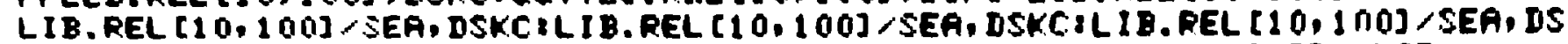
KC:LIB.REL $[10,100]$ SEA, DSKCILIB.REL 1100100$]$ SEAIPUB I CALVEC.REL LL IB

DISTEK.CMD - Linkage Command File for Tektronix Plots

DSKC: TSEND. REL [10,100], DSKC BL1B. REL 110,100$] /$ SEA, DSKCILIB. REL $[10,100] /$ SEA

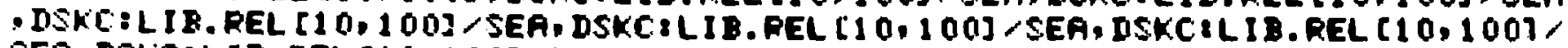
SEA. DSKC:LIB. REL $[10,100]$ SEA.PUR, AG 4010 . REL L I B 
7EQ.CWO - Batch Comand File

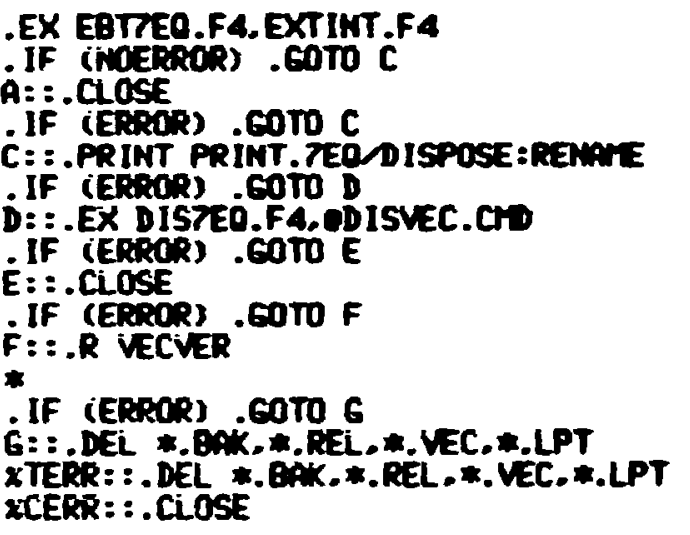


Appendix D

SAMPLE OUTPUT

PRINT .7EQ

PLOT.7EQ

SEGINT. EPL

i 


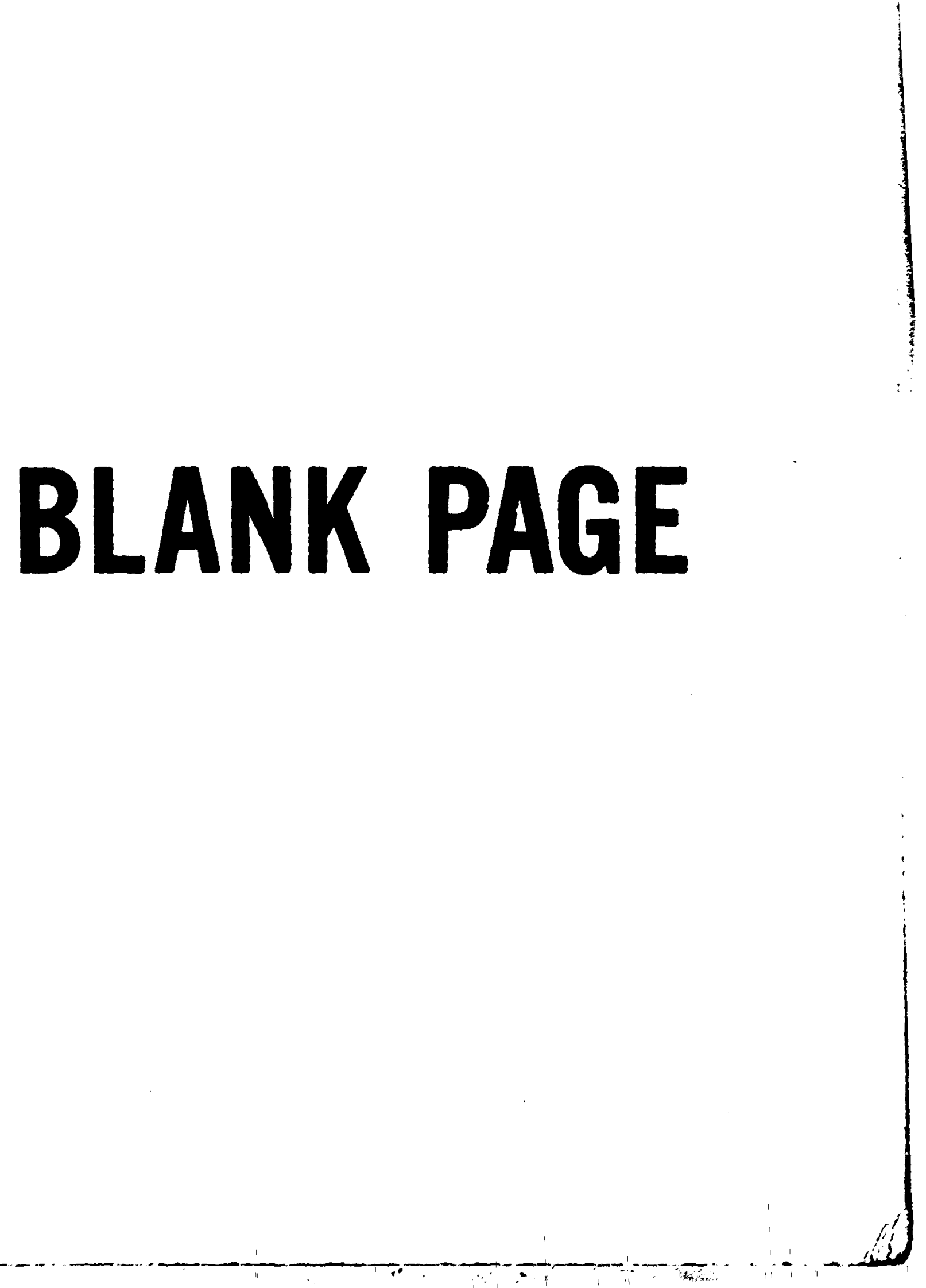


PRINT.7EQ - Partial Listing of Printer Output from Sample Run

\author{
arime shas

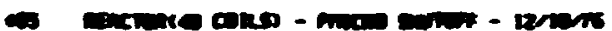

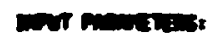
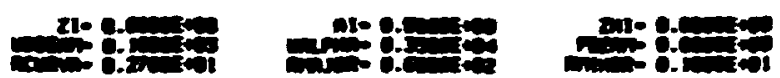

antiting

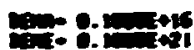

Ti: $8=0$

$\operatorname{arn}-3$

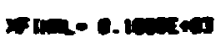

as - 0. 1ences

\section{0.}

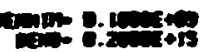

का. 8.

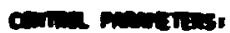

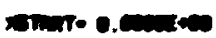

nom a

Tor moromist

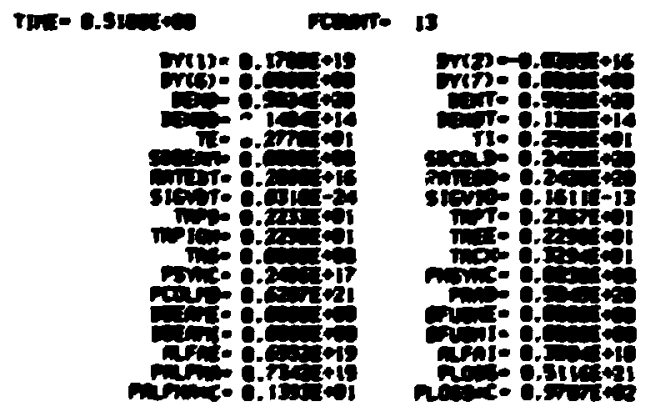

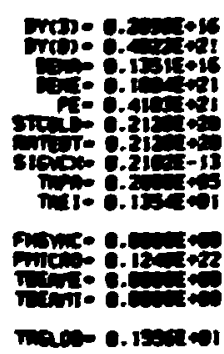

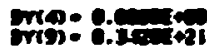

ming

an: 8. 1.02

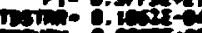

SID

The

nime 0.000

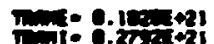

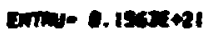

or(s) - 0.6m

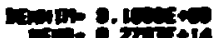

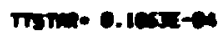
steme 8.tences

mon $0.500 x+20$ 
Ex-10.9 0-251 - onsul tovis:

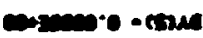

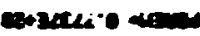

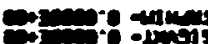
10-20 pezix:nesmene ctsua

aricice

1203020 and $1203000.9-14$

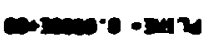
180

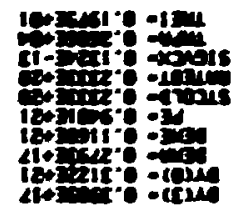

16rase' arith C+cis

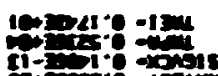
con - int tin: 7 Totwe - I ind 1 tortis. ecem

torsesto trom

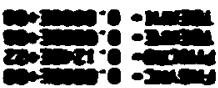

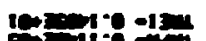
1-7.91.9 cold - 대 tol. ion- $=$ $1+-10$ soc.to - an

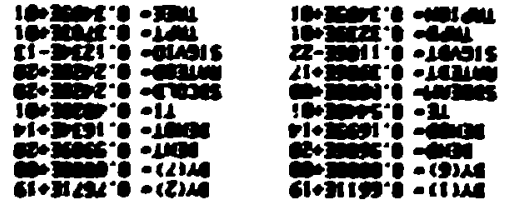

Is -117ns

Ier I-
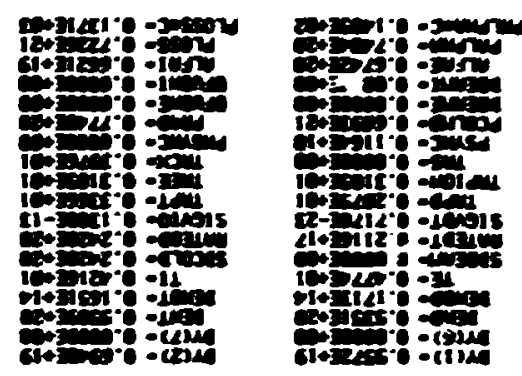

is armas

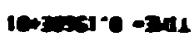
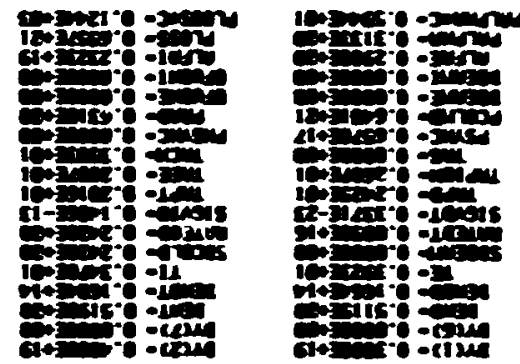

I) erimes

Iexin - an 

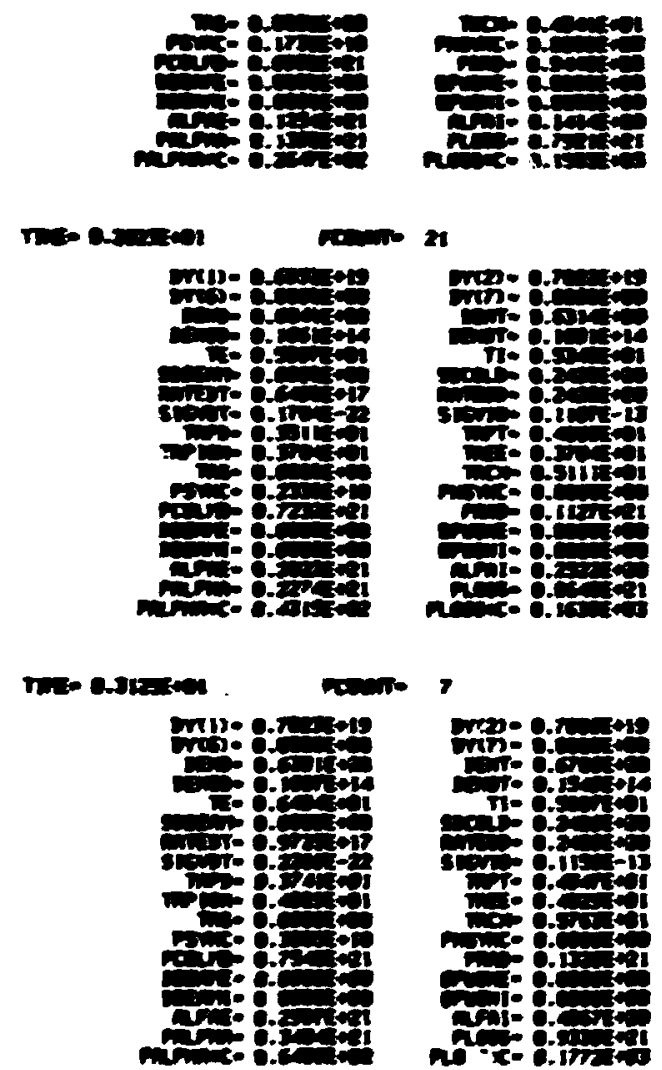

roce aremest

nanow

mal 0.7 reters

p.to

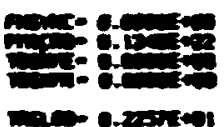

nes: 0.entem

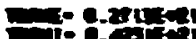

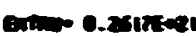

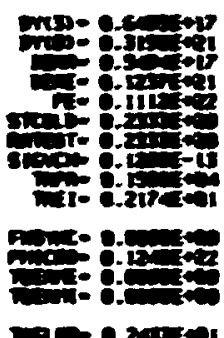

mane 0.20100

mp: 8.9u다.

1.

a o.t.

1.t. 8.

ont 8

mi- 8 ant

مum- 8.

Lب:

man $0.200 \times 1$

mbe $0.10 x+10$

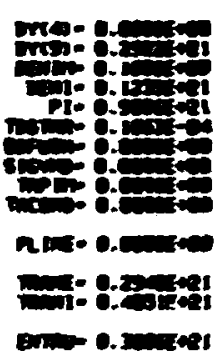

ma:8.m5 an 11. 6.4 pi- .14 ה \$ren Muse Hute e.jurveg| onno 0.5Fecel

mo- 0.000
0.96

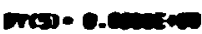
Dis min- e. $10 x-4$ son.

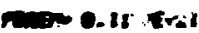

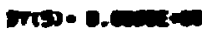
10 rsmon- 0. Lenten sucwer a of nom $0.131 \mathrm{neat}$ mose 0. 0mans 

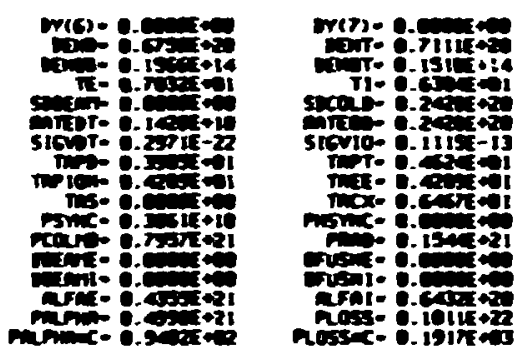

Tato-0.0iset rount- 2:

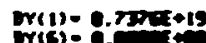
r(s)- 8.rates

- $0.15 x+14$

프 - e.m-1

ant- e.20tit

stovr- 0.25-2

no o otre

10. exper

once - $10 x+10$

mon- 8.erart?

14- 8.

artic- Q.05

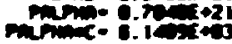

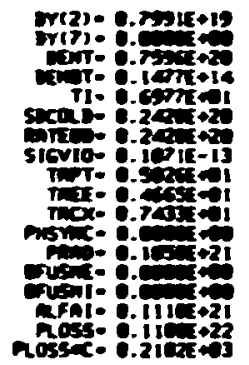

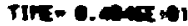

FCon- 13

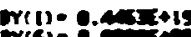

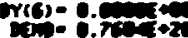

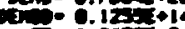

N- $0.915=$

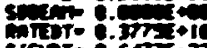

sicnt- c.con-2

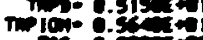

nic. actol

car. elas of

wine-
$0 \times(2)=-2.200 .10$ pin: 0 ant: 0.75

$T 1=0.013 x+1$

scas: :1 1

sicuto: :

T)

nit- -

mine: 8. $216 \times 2$

conte

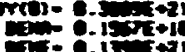

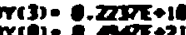

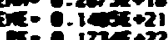

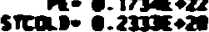

sical- :21018

sisvex-e.ter-is

the - $-2 x+1$

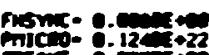

niche $.12=22$

ran-0.200ete

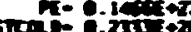

stoce

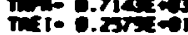

niceo: 120

1)

nan- e.meret

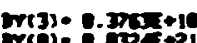
mist

210. $15 x+2$

1. 0.211L +2

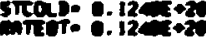

stox $0.83-1$

The :-3.

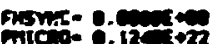

Thin:

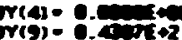

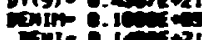

InI- $.1-2$

nsti- :.teres

Th- 8-

nim

ming - e.tent

The:- 0.5ient?

EMry- 0.4nex+2

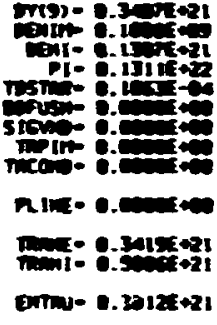

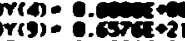
nin

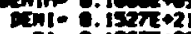

1. .

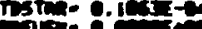

JiswTin

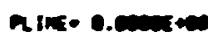

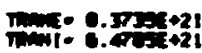

ran 1

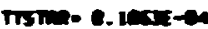
s1907.

Moun t. ISNIE+21

m(s) - 0.cus

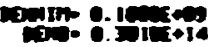
monm- 0. 165i-a SISNA- Q.

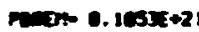

w(s) - 0.centen moll Trnin- e. 105:-4

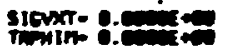
1) 0.215:-2 
PLOT.7EQ - Partial Listing of Intermediate Plot File from Sample Run

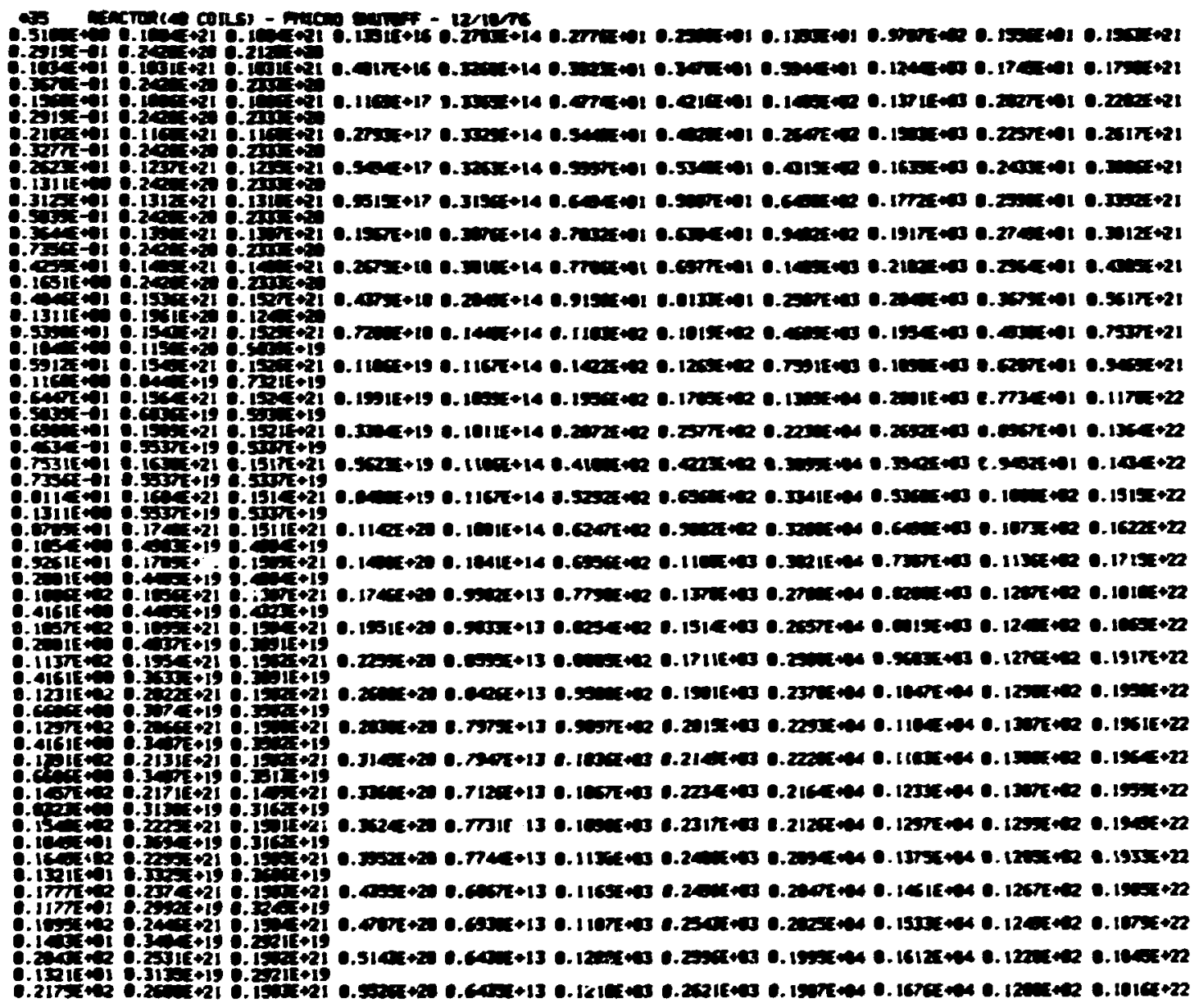


SEGMNT.EPL - Versatek Printer Plots from DIS7EQ.F4 from Sample Run

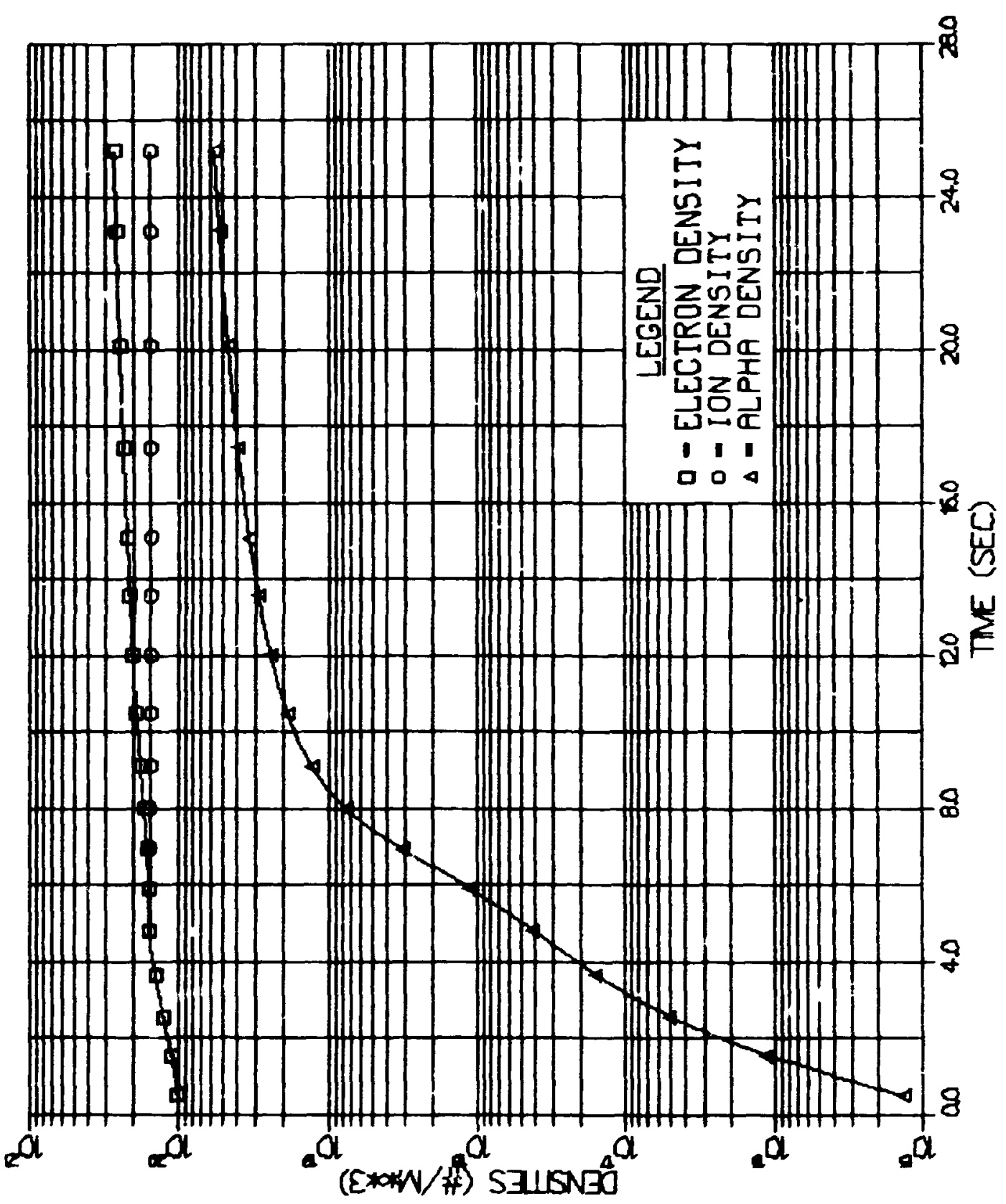




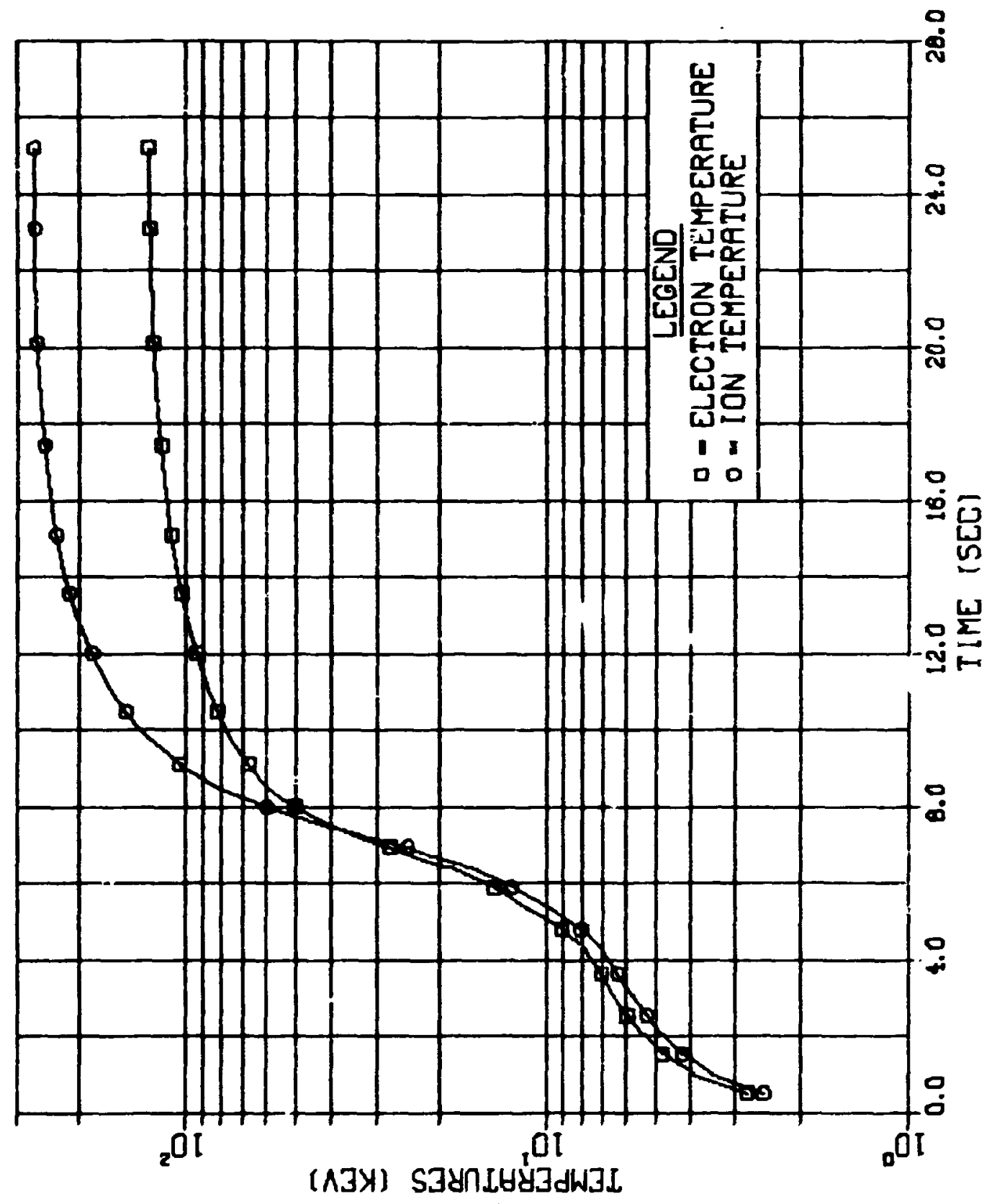




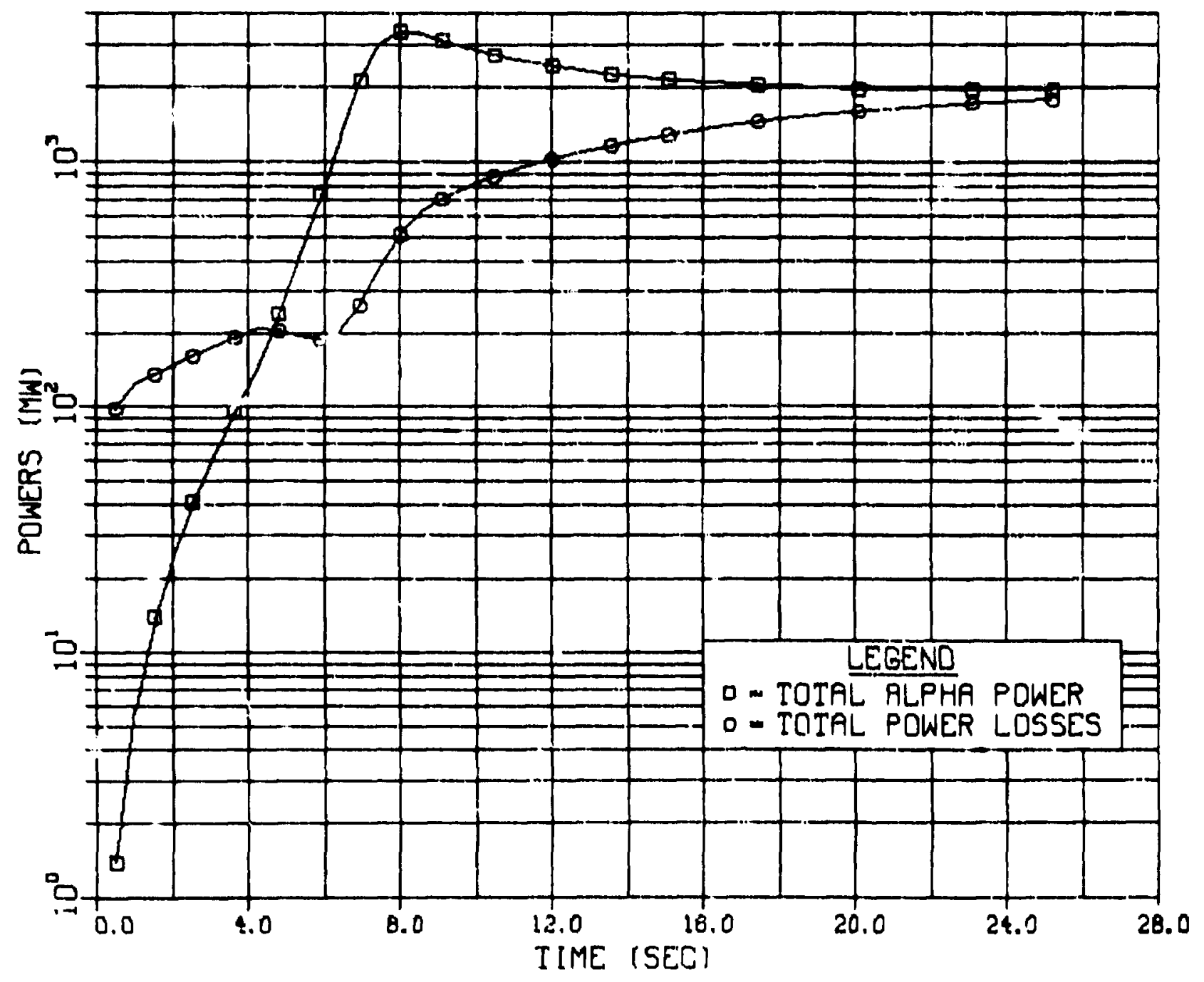




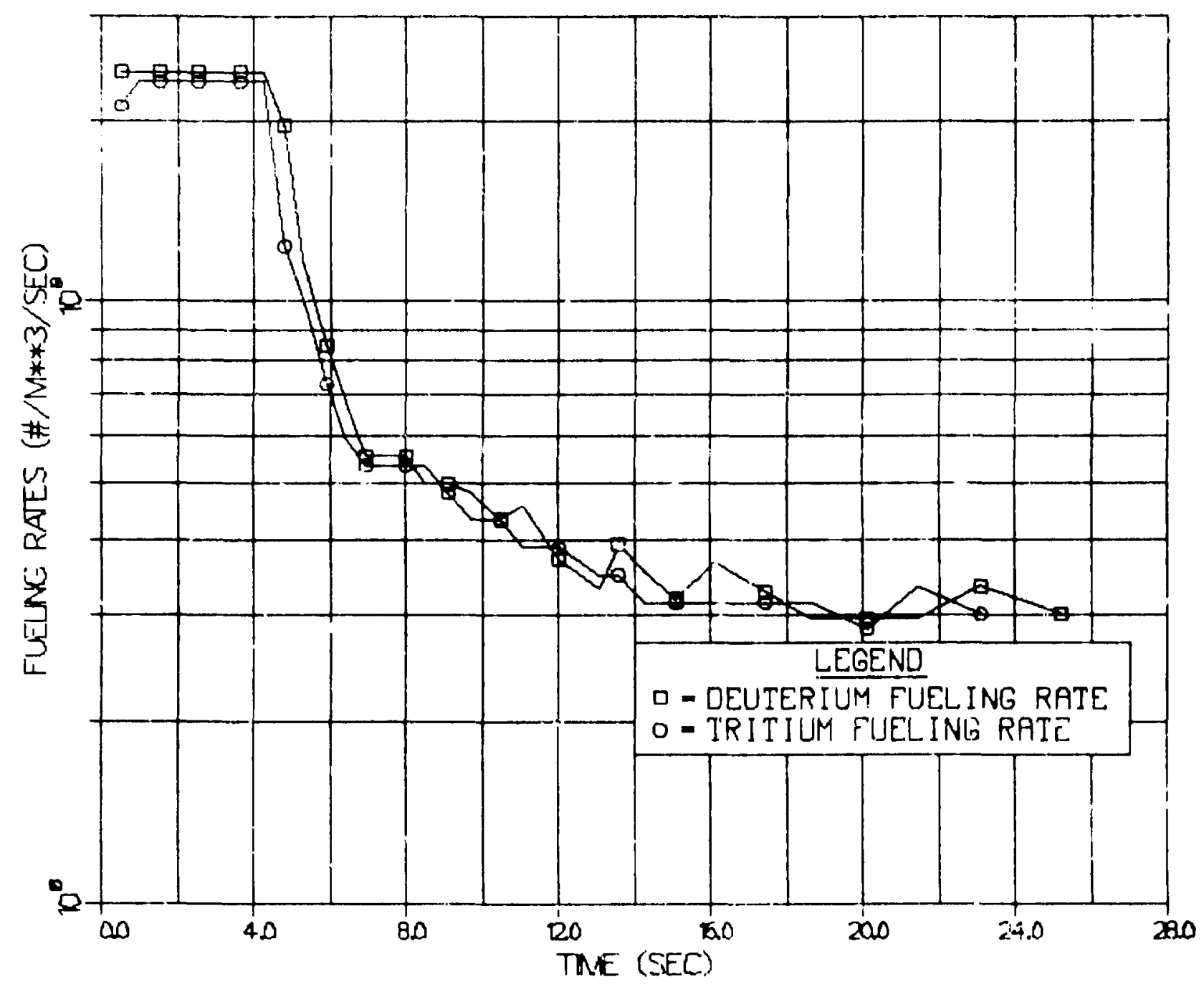




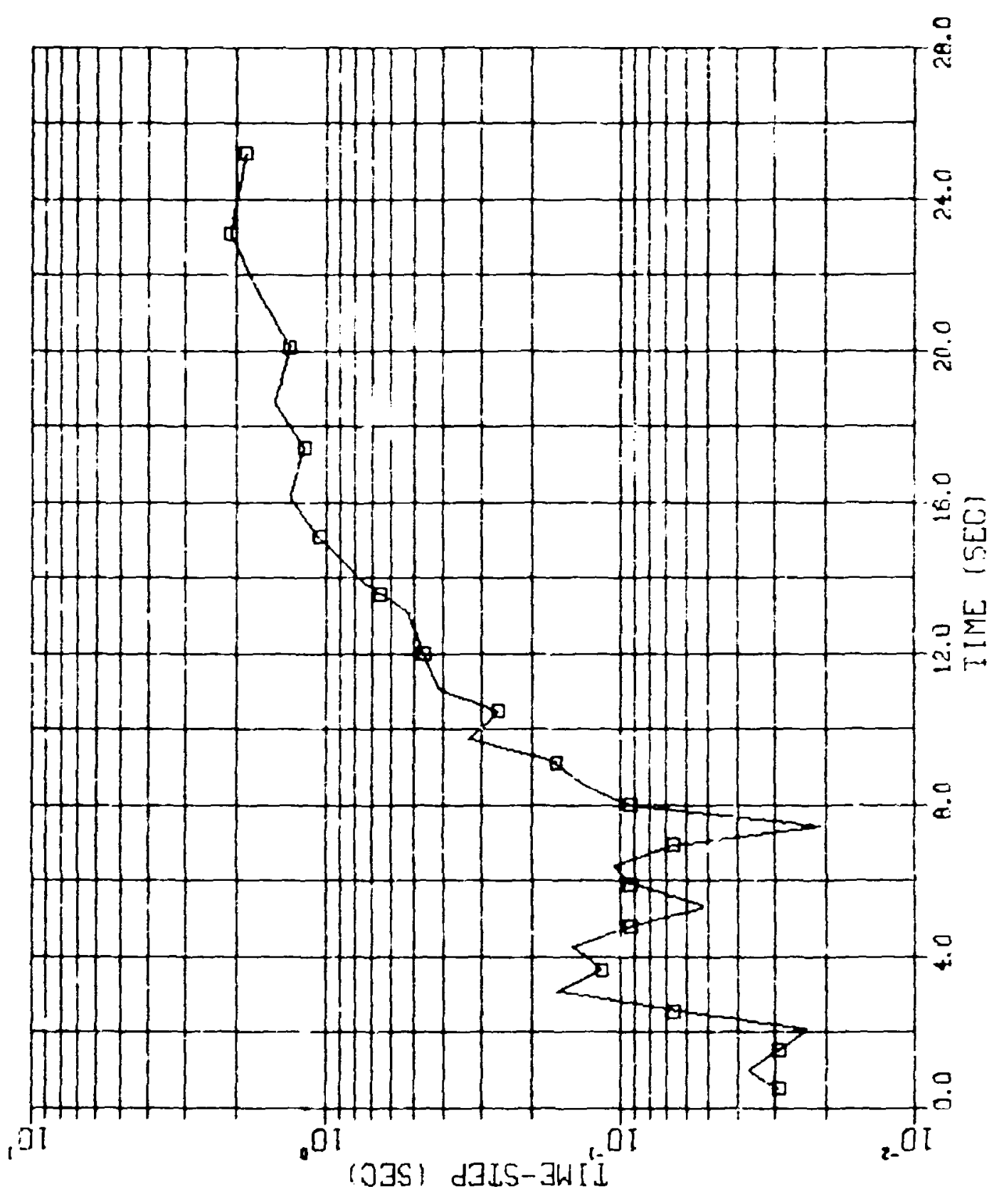

